Illinois State University

ISU ReD: Research and eData

Theses and Dissertations

$1-2-2016$

\title{
High School General Education Teachers' Perception of IEP Accommodations for Students with Asperger Syndrome
}

Mary Patricia Krones

Illinois State University, marypatk@comcast.net

Follow this and additional works at: https://ir.library.illinoisstate.edu/etd

Part of the Elementary and Middle and Secondary Education Administration Commons, Secondary Education and Teaching Commons, Special Education Administration Commons, and the Special Education and Teaching Commons

\section{Recommended Citation}

Krones, Mary Patricia, "High School General Education Teachers' Perception of IEP Accommodations for Students with Asperger Syndrome" (2016). Theses and Dissertations. 514.

https://ir.library.illinoisstate.edu/etd/514

This Dissertation is brought to you for free and open access by ISU ReD: Research and eData. It has been accepted for inclusion in Theses and Dissertations by an authorized administrator of ISU ReD: Research and eData. For more information, please contact ISUReD@ilstu.edu. 


\title{
HIGH SCHOOL GENERAL EDUCATION ENGLISH TEACHERS’ PERCEPTION OF IEP ACCOMMODATIONS FOR STUDENTS WITH ASPERGER SYNDROME
}

\author{
Mary Patricia Krones
}

\section{Pages}

The purpose of this qualitative design study was to better understand the experiences of high school general education English teachers who have students with Asperger Syndrome in their classes. More specifically, this researcher wanted to better understand the teacher's perception of the IEP-denoted accommodations the general education teachers are responsible for implementing. Data collection consisted of semistructured interviews, classroom observations, journal entries and collection of artifacts. Findings of this study include: the IEP document and IEP process from the lens of the general education teacher do not provide adequate information when considering the unique needs of students with Asperger Syndrome; general education English teachers are committed not only to forming relationships with students with Asperger Syndrome, but often take it a step further, taking on the role of advocating for the student as well as encouraging the student to advocate for himself or herself; and general education English teachers are committed to doing what works for the student, regardless of what information can be found in the IEP document. 
KEYWORDS: Asperger Syndrome, Autism, General Education Teacher, High School, Individualized Education Plan, Special Education 
HIGH SCHOOL GENERAL EDUCATION ENGLISH TEACHERS'

PERCEPTION OF IEP ACCOMMODATIONS FOR

STUDENTS WITH ASPERGER SYNDROME

MARY PATRICIA KRONES

A Dissertation Submitted in Partial

Fulfillment of the Requirements

for the Degree of

DOCTOR OF EDUCATION

School of Teaching and Learning

ILLINOIS STATE UNIVERSITY

2016 
(C) 2016 Mary Patricia Krones 
HIGH SCHOOL GENERAL EDUCATION ENGLISH TEACHERS'

PERCEPTION OF IEP ACCOMMODATIONS FOR

STUDENTS WITH ASPERGER SYNDROME

MARY PATRICIA KRONES

COMMITTEE MEMBERS:

Gary Weilbacher, Chair

Douglas Hatch

Ryan Brown

Stacey Jones Bock 


\section{ACKNOWLEDGMENTS}

It is hard to believe this doctoral journey is coming to completion. When I began the process a few years ago I had recently lost my dad, and my mom was receiving treatment for ovarian cancer. My parents, Jim and Judy Krones, have truly been the biggest influence on my education throughout my life. Their work ethic, people skills and encouragement have provided lessons in all aspects of my life. My mom passed away while I was completing the coursework for this degree-I made her promise me that she would be my doctoral angel and give me the strength to finish this dissertation. I have no doubt that both of my parents are proud of me, and I have them to thank for helping me to believe in myself even when the obstacle seems quite large.

I also want to thank my sisters, Laurie Kellen and Jacquelyn Krones, and my brother, Richard Krones. From assisting with proofing and editing to checking in with me, to understanding why my free time was often spent writing papers and working on my dissertation over the past few years, I thank you. Your love and encouragement have meant more than I could ever express. I also thank my friends who have heard "no" many more times than "yes" over the past few years, but continued to keep me sane by forcing me out on occasion. I look forward to saying "yes" and catching back up on life.

I would also like to thank the administrators in my school district, both current and retired, who agreed to invest in those of us who were part of this doctoral cohort. Without their support and innovative thinking, I highly doubt I would be where I am 
today. Along with the administrators in the district, I am indebted to the teachers who agreed to participate in this study. Their insight, honesty, and more importantly, dedication to their students are what made this study interesting and meaningful.

I would like to thank my dissertation committee members, Dr. Douglas Hatch, Dr. Ryan Brown, and Dr. Stacey Jones Bock for offering insight and guidance through this dissertation process. Finally, I would like to thank my Dissertation Chair, Dr. Gary Weilbacher. Dr. Weilbacher's encouraging words, quick turn-around time, guidance and perspective have made this process motivating, fun, and rewarding. I am honored to be the one of the first of many of your students to complete a dissertation under your guidance as a Chair.

M.P.K. 


\section{CONTENTS}

\section{Page}

ACKNOWLEDGMENTS

CONTENTS

TABLES vi

CHAPTER

I. INTRODUCTION 1

Background, Context, and Theoretical Framework 3

Background $\quad 3$

Context 4

Theoretical Framework $\quad 5$

Statement of the Problem $\quad 9$

Purpose and Scope of the Study 10

Research Questions 10

Significance of the Study 11

Definitions 11

Assumptions 13

Limitations 14

$\begin{array}{ll}\text { Summary } & 14\end{array}$

$\begin{array}{ll}\text { II. } & \text { REVIEW OF LITERATURE }\end{array}$

Historical Context of Special Education $\quad 16$

Understanding Asperger Syndrome 23

Conceptualizing Asperger Syndrome $\quad 27$

Asperger Syndrome in the Schools 31

General Educator Attitudes and Beliefs about Inclusion $\quad 34$

General Educator Attitudes and Beliefs towards Students with Autism 39

$\begin{array}{ll}\text { Summary } & 47\end{array}$ 
Statement of the Problem 49

Rationale for Qualitative Research $\quad 50$

The Role of Qualitative Research in Education 51

The Phenomenological Design 53

Research Sites and Participant Selection Process 56

Research Site $\quad 56$

Research Participant Selection Process $\quad 57$

Data Collection $\quad 60$

Data Collection Process $\quad 62$

Data Analysis $\quad 66$

$\begin{array}{ll}\text { Trustworthiness and Authenticity } & 70\end{array}$

$\begin{array}{ll}\text { Ethical Issues } & 72\end{array}$

$\begin{array}{ll}\text { Summary } & 74\end{array}$

IV. RESULTS, ANALYSIS AND DISCUSSION 75

Participant Profiles $\quad 75$

$\begin{array}{ll}\text { Research Issue and Findings } & 79\end{array}$

Uniqueness/Individuality of Students with Asperger Syndrome $\quad 80$

The Importance of Relationships $\quad 81$

Involvement in the IEP Process 85

Role of Advocacy $\quad 88$

Minimal Information in the IEP Document 92

Challenges with Social and Interaction Skills $\quad 94$

Challenges with Self-Regulation 96

Perception of IEP Denoted Accommodations $\quad 100$

Non-IEP Denoted Accommodations $\quad 105$

Effectiveness of Accommodations 109

How Accommodations are Derived 112

Experience $\quad 115$

Support from Special Education $\quad 118$

Access to Specific Information $\quad 119$

Post-Script: The Rest of the Story 121

$\begin{array}{ll}\text { Summary } & 123\end{array}$ 
Introduction

Students with Asperger Syndrome Are Unique...

But Their IEPs are Not

High-Fives and "Can Do" Attitudes

Recommendations Based on the Conclusions

Recommendation Number 1

Limitations

Recommendations for Future Research 


\section{TABLES}

Table $\quad$ Page

1. Student Ethnicity $\quad 57$

2. Participant Demographics $\quad 60$

3. Data Collection Process 66

4. Data Collected from Each Participant 66

5. Responsibility for Implementing IEP Accommodations 113

6. How Accommodations are Determined 114 


\section{CHAPTER I}

\section{INTRODUCTION}

Benjamin (pseudonym) was insubordinate in his math class with his teacher regarding his math quiz. He threw it in the garbage, refused to pick it up after two requests by the teacher (and three visual cues from his teacher assistant), and proceeded to tell the teacher to pick it up and then told the teacher assistant to "go away" (Anonymous, 2013).

Benjamin has Asperger Syndrome. He is eligible for special education services under the category of Autism. As noted in his Individualized Education Plan (IEP), Benjamin's nonverbal and verbal communication skills are adversely affected by his disability. He sometimes misinterprets nonverbal communication and his verbal communications are often inappropriate to the situation and can impress the listener as disrespectful, blunt or rude. Academically, Benjamin is a freshman in high school and is appropriately placed in a college preparatory geometry class of thirty-two students. His math skills fall at approximately the $90^{\text {th }}$ percentile when compared to his peers on nationally normed tests. He has an IEP with supports and accommodations which are to be implemented across all educational environments. At times, even with these accommodations Benjamin struggles with everyday situations such as receiving an unexpected grade on a quiz. However, one must also ask, what were the accommodations noted on Benjamin's IEP? Did any of the accommodations address 
Benjamin's anxiety related to getting tests and quizzes back? Was the teacher aware that Benjamin sometimes reacted (tearing up the test; refusing to listen to adult direction; and becoming argumentative) when he received an unexpected grade?

The term "Asperger Syndrome" is no longer a recognized diagnosis in the Diagnostic and Statistical Manual- $5^{\text {th }}$ edition (2013b). However, for the purpose of this study, Asperger Syndrome will describe individuals who have had a diagnosis of Asperger Syndrome prior to the changes in the DSM-5 and/or individuals who generally fall at the higher end of the autism spectrum without accompanying intellectual impairment. Historically, these students would have qualified for special education services under the categories of Autism or Other Health Impaired (Fogt, Miller, \& Zirkel, 2003; Safran, 2008). Due to changes in the DSM-5, students would currently qualify for special education services under the broader category of Autism. This population of individuals is generally recognized to have average to above average intellectual functioning and academic skill levels placing them in general education curriculum for the majority of their school day (Sansosti, Powell-Smith, \& Cowan, 2010; Smith Myles \& Simpson, 2002a). These individuals are often considered to have challenges with executive functioning, cognitive coherence and theory of mind, and as a result require accommodations through the IEP process in order to function within the context of general education (Attwood, 2004; Jacobsen, 2005). 


\section{Background, Context, and Theoretical Framework}

\section{Background}

The school district Benjamin attends is not alone in supporting and serving students with autism spectrum disorders in the public school setting and other environments. The most recent data from the Center for Disease Control (Baio, 2014) suggests 1 in 68 school-age children in the United States have a diagnosis of autism. Only eight short years ago in 2008 , this number was suggested to be 1 in 88 children. It is hard to predict whether or not these numbers will continue to rise, but there is no question that students with autism are present and prevalent in our schools today. The United States Department of Education (2013) reports the special education eligibility category of autism to comprise approximately $8 \%$ of all children receiving special education services during the 2010-2011 school year. The United States Department of Education (2013) also reported that as of $2011,90.9 \%$ of children with autism spent at least some part of their day in the general education setting, while over $37 \%$ of these students spent at least $80 \%$ of their day in the general education setting.

School districts have been charged with educating students in the least restrictive environment as a result of years of legislation, primarily beginning with Public Law 94142 (Education of All Handicapped Children Act of 1975, 1975), in which schools were mandated to provide diagnostic and educational services to students with disabilities. The No Child Left Behind Act (2002) and the reauthorization of the Individual with Disabilities Improvement Act 2004 (2004) have resulted in greater numbers of students with disabilities receiving most of their instruction in general education settings. 
These two acts replaced the word access with the word benefit. This one word changed the playing field for students with disabilities, as the bar was raised for accountability for students identified as having disabilities. Schools were charged with the responsibility of not just providing access to or placement in general education classes, but they also needed to ensure supports and accommodations were in place in order to provide benefit. These laws required that states and local districts include students with disabilities in state mandated assessments, with accommodations (where appropriate), and that IEP teams consider a child's involvement and progress in the general education curriculum and develop IEP goals that promote the child's progress in that curriculum.

Furthermore, the recent addition of the Common Core State Standards (CCSS) charges districts with "an historic opportunity to improve access to rigorous academic content standards for students with disabilities" (p. 1, Common Core State Standards Initiative, 2014). The language in the CCSS raises the bar once again for inclusion in general education curriculum and assessments for students with disabilities, with appropriate accommodations.

\section{Context}

This study seeks to explore the experiences and attitudes of high school general education English teachers who have students with Asperger Syndrome in their classrooms. More specifically, the purpose of this study is to provide a better understanding of these teacher's perceptions regarding the IEP recommended accommodations, as well as understanding the successes and challenges these teachers have experienced with this particular population. Most importantly, one outcome of this 
qualitative study will provide perspective on the phenomenon of having students with Asperger Syndrome in the general education environment. Furthermore, this study will provide recommendations for meeting the needs of the general education teachers who are expected to deliver the required accommodations so students can meet the high standards of the grade level expectations of the CCSS.

Six teachers from the English Departments of a large suburban high school district in the Midwest participated in interviews, were observed, and completed journal entries for this study. At the time of the study, each of the teachers had at least one student with Asperger Syndrome in one of their classes, as well as having had at least three years of experience teaching students with Asperger Syndrome in their general education class. The teachers represented all five schools in the district.

\section{Theoretical Framework}

Accommodations are determined for students with disabilities as a part of their IEP in order to be able to function in the general education environment to the greatest extent possible (Shriner \& Ganguly, 2007; Ysseldyke, Thurlow, Bielinski, House, Moody, \& Haigh 2001). In the general education setting, it is typically the responsibility of the general education teacher to deliver (or ensure delivery of) the accommodations to be implemented. These accommodations serve the purpose of providing opportunities for students with disabilities (and in this study, specifically students with Asperger Syndrome) to achieve success in inclusive or general education environments (deBettencourt, 1999; McLeskey \& Waldron, 2002; Moores-Abdool, 2010). The absence of these accommodations may result in difficulties with social relations with peers, poor performance on assessments and required assignments and may interfere with the ability 
to understand and process information presented in class (R. Jackson, Harper, \& J. Jackson, 2001; Osborne \& Reed, 2011; Worrell, 2008).

Theoretical models for understanding and conceptualizing disability have traditionally been based on perceived deficits within the individual (Mitra, 2006). These models have included the medical model, the social model, and the Nagi model. In the medical model, the disability is considered to be a problem of the individual that is directly caused by a disease, injury or some other health condition and while supports can be put in place to help the individual, they will never get well (Mitra, 2006). Disability advocates criticize this model for the excessive power it gives to the medical and psychology professionals to define and diagnose disability (McKenzie, 2013).

The social model of disability views disability as a social construct and that it (disability) is created by the social environment and requires social change (Mitra, 2006). The social model was rooted in people with disabilities' desire to be fully recognized as members of society while moving away from the biological determinism that situated impairment as the direct reason for restricted access to full participation in the community (McKenzie, 2013). One major criticism of this model is the overemphasis on self-advocacy is sometimes used to minimize support practices where individuals may require assistance (such as IEP accommodations) in order to participate (McKenzie \& MacLeod, 2012).

Finally, Nagi's functional limitations paradigm views disability as an interaction between the individual and societal expectations. If an individual is unable to perform or function based on societal norms, then they are considered to be disabled (Mitra, 2006). Nagi's model emphasized research into environmental factors in the family, community, 
and society that could affect disability as an outcome (Whiteneck, 2006). Nagi's model sought to define conditions and the extent to which a person is considered disabled, but did not suggest factors that might contribute to improving outcomes for those with disabilities.

In recent years, researchers [Mitra (2006), Reindal (2009), Terzi (2005)] who study disability have focused their approach from the previously mentioned models to an opportunity model (Mitra, 2006). This newer model, the capability approach is an economics model first attributed to philosophers Amartya Sen and Martha Nussbaum in the 1980's (Cohen, 1993). In this model, Sen described an approach to well-being that centered on a person's ability to do valuable acts or reach valuable states of being. The term value is defined per the individual, taking into account a variety of factors, including personal characteristics, social arrangements, and the personal objectives of the individual (Sen, 1993).

In the simplest of terms, as it applies to the study of disability, the capability approach takes into consideration that in spite of a perceived societal disadvantage (such as disability), we must take into consideration what people are actually able to be and able to do (Sen \& Nussbaum, 1993). In order to do this, Sen (1993) suggests that we (in this case, educators) need, at minimum to consider what an individual requires to reach the lowest threshold of capability so that they may eventually achieve at the same level as anyone else. Sen suggests that policies and evaluations of programs should focus on what people are able to do and be, on the quality of their lives, and on removing obstacles in their lives (Robeyns, 2005). 
While this theoretical model has been studied and applied across many disciplines (economics, gender equity, social justice), there has been recent attention on its role in disability research, special education and inclusion of students into the general education setting (Mitra, 2006; Terzi, 2005; Toson, Burrello, \& Knollman, 2013). This framework is relevant to this study because if teachers do not believe IEP accommodations are valuable and effective or they find challenges that limit the implementation, students with Asperger Syndrome may not have the same opportunities and experiences as their nondisabled peers. Furthermore, the capability approach as applied to disability would suggest that the purpose of accommodations is not to provide the opportunity for students with disabilities to exceed their classmates' academic achievement. Rather, they are present to provide the minimum standard by which students with disabilities will be able to achieve at the same threshold as any other student enrolled in that particular course.

The capability approach challenges us to consider the obstacles that may stand in the way of the individual's ability to function and consider these obstacles to be overcome in order to "secure the recognition of their entitlements as citizens" (Toson et al., 2013). As the researcher in this study, I approached this study with the philosophical belief that denoted IEP accommodations are essential to have in place and be implemented for students with disabilities to the same extent as any other student in the general education classroom. As with the capabilities approach, I believe these supports are in place to provide students with tools or supports necessary to achieve the minimum standard in the general education setting, as any student without a disability would be afforded. As a researcher, I want to understand the experiences and challenges of general education teachers who are responsible for implementing these accommodations. Greater 
understanding of their experiences may lead to new insights on how as special educators, we can understand the challenges that general education teachers have in implementing these accommodations so that we can help them overcome them, ultimately improving the success of the students. It may be that general education teachers do not understand the value of the prescribed plan, have challenges understanding how to implement the plan or do not understand what is required on their part. Additionally, it is anticipated that this study will provide insight in regards to training or professional development needs of general education teachers may have in order to better understand and implement the accommodations in the general education setting and to provide educational support for all.

\section{Statement of the Problem}

This study focused on the perceptions of general education teachers regarding IEP indicated accommodations to be implemented in the general education setting for students with Asperger Syndrome. Currently limited research exists which focuses on secondary teacher attitudes and perceptions of the specialized accommodations needed to successfully support students with Asperger Syndrome in the general education environment. Research in this area has focused primarily on the experiences of teachers educating students with autism across the spectrum (rather than specifically Asperger Syndrome) and few studies have considered the experiences of the secondary teacher. 


\section{Purpose and Scope of the Study}

The purpose of this qualitative study was to explore the general education teachers' awareness and understandings of IEP accommodations that were developed through the IEP process, and to be implemented in their classrooms for students with Asperger Syndrome, and higher functioning autism. This study also examined the acceptability and perceived effectiveness of the interventions from the lens of the general

education teacher. This was accomplished through semi-structured interviews, classroom observations, and journal entries.

\section{Research Questions}

This study was guided by the following research questions:

- What are the experiences of Secondary English teachers who have students with Asperger Syndrome in their classroom?

- What obstacles do Secondary English teachers experience in working with students with Asperger Syndrome in the general education classroom?

- What are the perceptions of Secondary English teachers of the accommodations for students with Asperger Syndrome in the general education classroom?

- What accommodations are teachers using in the general education classroom, and from where do they derive these (IEP, experience, etc.)?

- How effective do the Secondary English teachers perceive the accommodations are for their students with Asperger Syndrome? 
- What resources do Secondary English teachers require to understand and support the needs of students with Asperger Syndrome in the general education classroom?

\section{Significance of the Study}

To date, the literature has focused on the legal requirements of including students with disabilities in general education; the problems with teacher preparation and ongoing professional development for including students with IEPs in general education settings; and "how to" guides and research studies in regards to best practices for including students with disabilities, Asperger Syndrome and other Autism Spectrum Disorders in general education classrooms. To a much lesser extent, research has focused on attitudes and experiences of these general education teachers who are responsible for educating students with Asperger Syndrome and high functioning autism in their classrooms.

This study intended to dig deeper into the attitudes and perceptions of general education teachers who have students with Asperger Syndrome and high functioning autism in their classrooms. The researcher paid particular attention to teacher attitudes related to the required IEP accommodations. This study will be of interest to special education teachers and administrators, as well as other general education teachers, who are experiencing the joys and challenges of educating this unique population of students.

\section{Definitions}

For the purposes of this paper, certain terms have been used. The following is a list of the terms as they are used in this study: 
Accommodations: Accommodations are practices and procedures in the areas of presentation, response, setting, and timing/scheduling that provide equitable access during instruction and assessments for students with disabilities. Accommodations are intended to reduce or even eliminate the effects of a student's disability; they do not reduce learning expectations (Thompson, Morse, Sharpe, \& Hall, 2005).

Asperger Syndrome: For the detailed criteria as found in the Diagnostic and Statistical Manual -IV-TR (2000), please see Appendix A. The term "High Functioning Autism" has also been used to describe individuals who have many diagnostic similarities to those with a diagnosis of Asperger Syndrome. Asperger Syndrome is considered a medical diagnosis.

Autism: The educational definition of autism, according to the Illinois State Board of Education is as follows:

A developmental disability significantly affecting verbal and nonverbal communication and social interaction, generally evident before age three, that adversely affects a child's educational performance. (A child who manifests the characteristics of autism after age 3 could be diagnosed as having autism if the other criteria of this Section are satisfied.) Other characteristics often associated with autism are engagement in repetitive activities and stereotyped movements, resistance to environmental change or change in daily routines, and unusual responses to sensory experiences. The term does not apply if a child's educational performance is adversely affected primarily because the child has an emotional disturbance (Illinois State Board of Education, 2014b)

Autism Spectrum Disorders (ASD): A developmental disability that can cause significant social, communication, and behavioral challenges. People with ASD may communicate, interact, behave, and learn in ways that are different from most other people. The learning, thinking, and problem-solving abilities of people with ASD can range from gifted to severely challenged. Some people with ASD need a lot of help in 
their daily lives; others need less. A diagnosis of ASD now includes several conditions that used to be diagnosed separately: autistic disorder, pervasive developmental disorder not otherwise specified (PDD-NOS), and Asperger syndrome. These conditions are now all called autism spectrum disorder (Center for Disease Control, 2014).

Individual Education Plan: Also known as the IEP, an Individual Education Plan defines the individualized objectives of a child who has been labeled with a disability. The IEP is intended to help children reach educational goals more easily than they otherwise would. In all cases the IEP must be tailored to the individual student's needs as identified by the IEP evaluation process, and must especially help teachers and related service providers understand the student's disability and how the disability affects the learning process (Individual Education Plan, 2012).

Least Restrictive Environment: "Students with disabilities being educated to the maximum extent appropriate with peers without disabilities" (Kavale \& Forness, 2000, p. 281).

\section{Assumptions}

During the course of this study certain assumptions were made. First and foremost, it was assumed that the participants were honest and forthcoming in regards to their experiences of having students with Asperger Syndrome in their general education classes over the period of their teaching experiences. It was also assumed that as the researcher completing the study, I completed the interview, observation, and follow up interview process with integrity, and that I was properly skilled in reviewing and analyzing data collected in order to draw accurate patterns and understandings of the 
phenomenon being studied. One important aspect of completing the interview process with integrity was revealing my role as a special education professional in the district.

\section{Limitations}

The following may be considered to be limitations of this study:

1. The study is limited to the experiences of English teachers only, and may not be generalizable to other subjects.

2. The study is limited to high school teachers and may not be generalizable to other grade levels.

3. The study may not be generalizable to other populations of disabilities.

4. The study is limited to one school district.

5. The study is limited in size, in that a total of six participants were included in the study.

\section{Summary}

The incidence of children identified with Autism Spectrum Disorders has increased from 1 in 150 in the year 2000, to 1 in 68 in 2014 (Baio, 2014). This significant increase has greatly impacted the number of students with IEPs in both general and special education settings in our schools. School districts have the responsibility of educating students in the least restrictive environment, due to years of legislation and governmental acts that have emphasized access to general education placements for most students with disabilities. However, children with autism, 
specifically those with Asperger Syndrome, have many challenges which may impact their ability to successfully integrate into general education.

It is important to comprehend the general education teachers' understandings of the accommodations that were developed by the IEP team to support students with Asperger Syndrome in the general education environment. This study will examine both the acceptability and perceived effectiveness of these supports from the lens of the general education teacher, through a qualitative research study.

Research and literature are available that reviews why students with IEPs and Asperger Syndrome are in general education to begin with, strategies for effectively educating these students, and even ongoing challenges with teacher preparation and professional development to address the challenges of educating students with disabilities in general education (Crosland \& Dunlap, 2012; deBettencourt, 1999; Moores-Abdool, 2010). However, there is little research that delves into the general education teachers' attitudes toward implementing accommodations in their classrooms for students with Asperger Syndrome or high functioning autism. Teachers' perceived effectiveness of these interventions is also an untapped area of research. This study will not only be of interest to special education staff (teachers and administrators) that recommends the various accommodations to be implemented in general education, but also to general education teachers to gain understandings of why these accommodations are recommended. It may also allow general educators to gain from others' experiences and improve the likelihood of applying that to their own teaching and interactions with students with Asperger Syndrome in future classes. 


\section{CHAPTER II}

\section{REVIEW OF LITERATURE}

In this chapter, literature pertaining to special education, inclusion and autism will be reviewed. Specifically, the review will focus on the history of special education, understanding Asperger Syndrome and Autism, general educator beliefs toward inclusion, and the inclusion of students with autism into the general education environment.

\section{Historical Context of Special Education}

"It was only a little more than 30 years ago that students who have disabilities were routinely segregated without cause, receiving either substandard public education or, in many cases, no education at all" (Blanton \& Pugach, 2007, p. 10). In those thirty (plus) years, education has made great strides in educating students in the regular education classroom. As of 2004, the majority (96\%) of students with disabilities were being included in regular settings and just over half (52.1\%) of these students spent most (79\%) of the day in a general education classroom (McCray \& McHatton, 2011). A brief review of the literature provides a summary of the major acts and initiatives having an impact on the inclusion of students with disabilities in the general education environment.

Prior to the implementation of Public Law 94-142 (Education of All Handicapped Children Act of 1975, 1975), some public schools were voluntarily providing self 
contained special education services for students considered to have mild mental retardation and other mild learning disabilities (Ward, Abernathy, \& Cunningham, 1983). However, in many instances, children with more significant disabilities (moderate to severe mental retardation, deafness, blindness, physical handicaps, and/or mental illness) were largely institutionalized in residential settings or asylums (Dorn, Fuchs, \& Fuchs, 1996). Children with disabilities were often labeled as "insane" or "retarded" in the decades leading up to the implementation of Public Law 94-142. In a biographic account of the history of the asylum, David Rothman (1971) found the attitude towards the disabled in the nineteenth and into the twentieth century was to treat the disabled in institutions, apart from their families. These philosophies of services for children with disabilities during these time periods resulted in a very small group of children being identified to have a disability. Those children that were identified were educated completely separate (either in an institution or a separate special education classroom within a public school) from their non-disabled peers.

Prior to the implementation of P.L. 94-142, there were two major court decisions that eventually had a significant impact on the development of special education services in schools. Brown vs. Board of Education ruled that simply providing exposure to the same curriculum, regardless of location, did not constitute equity (Brown vs. Board of Education, 1954). This major court case was related to the inequitable treatment of minorities in schools, and demanded desegregation of minorities and whites in our public school system. It is a major court case in the history of public education and paved the way for many other civil rights movements, including those for individuals with disabilities. 
A second significant case that eventually had an impact on how services for students with disabilities are delivered in schools is Hobson vs. Hansen (1967). Once again, the basis of this case was the inequitable treatment of minorities, following desegregation in public schools. The primary allegation was that low-income and Black students were denied equal educational opportunity as a result of the district's discriminatory practices of a rigid system that assigned students to three or four homogeneous ability groups (tracks). The court ruled that this was a discriminatory practice, because the lower-track classes provided less educational opportunity. These monumental court cases first paved the way for non-discriminatory practices for minorities in public education. At the same time, leaders in the field of special education were beginning to question whether the "all or nothing" model (institutionalization/selfcontained or no identification) of special education services was effective and appropriate (Reynolds, 1989).

In the early days of special education service delivery in public schools, there were very few service options for students. Students who were identified to have a disability and were able to be educated in a public school were placed in special classes and their non-disabled peers were in the general education classroom. At the time, there was no continuum of services based on educational need. Many children were still excluded from school based on their handicap, resulting in two monumental cases that would eventually shape the future of special education (Pennsylvania Association of Retarded Citizens (PARC), 1971; Mills, 1972). In Pennsylvania Association for Retarded Children (PARC) v. Commonwealth of Pennsylvania, parents of children with mental retardation contested a state law that denied services to children who had not 
reached a mental age of five years by the time they would ordinarily enroll in first grade. The PARC ruling resulted in children with mental retardation receiving a public education up to the age of 21 , and that each child was entitled to an appropriate education in the least restrictive environment (Martin, Martin, \& Terman, 1996). The following year, in 1972, a similar suit was filed in the District of Columbia. The case of Mills $v$. Board of Education encompassed a broader range of disability (including mental and behavioral disabilities) but similar context, in that these children were being denied enrollment in school based on their disabilities. In the course of the hearing, the school district admitted that 12,340 children with disabilities would not be served in the 1971-72 school year alone. In this case the U.S. District Court ruled that school districts could not exclude children with disabilities from school based on the burden of funding their education (Martin et al., 1996). Together, these two cases opened the schoolhouse doors to all children (regardless of disability) and provided basic rights (such as notification prior to a change in placement) to parents of children with disabilities. The outcome of these cases ultimately led the states and federal governments to jointly develop the rules of P.L. 94-142 (Martin et al., 1996; Reynolds, 1989).

The major elements of P.L. 94-142 that apply to the topic of exclusion of students with disabilities in the schools include that the law required schools to: a) find all children excluded from education or unable to keep pace with regular classes, b) evaluate such children in a nondiscriminatory fashion, c) to prepare individual education plans for them, d) to hold due process guarantees and procedures before placement and e) place students educationally in the least restrictive environment (Ward et al., 1983). Least restrictive environment is defined as "students with disabilities being educated to the 
maximum extent appropriate with peers without disabilities" (Kavale \& Forness, 2000, p. 281). For many students this environment had been known as the resource model or the Regular Education Initiative (REI). In this type of service delivery, resource room and special education teachers provided academic instruction for specified time periods to a special education student whose primary placement was the general education classroom (Kavale \& Forness, 2000).

In spite of the mindfulness of the laws and acts that provided students with disabilities the right to be educated in the least restrictive environment, for some students, this environment did not always result in the educational successes that were envisioned. Studies reviewing the effectiveness of making general education the default placement for students with disabilities revealed mixed results. Carlberg and Kavale (1980) found that in general, special class placement was an inferior alternative to regular class placement in benefiting children removed from the educational mainstream. However, the authors also noted that across disabilities and needs, some categories of exceptionality (students with more significant intellectual impairments) fared better in a special education instruction option. This study does support the value of the continuum of special education services, but it also supports the notion that the general education setting is generally appropriate for most students identified with disabilities, to the extent that appropriate services are being delivered to the student.

As a result of P.L. 94-142, the number of children removed from their families and placed in remote institutions declined dramatically in the United States (Lakin, Krantz, Bruinicks, Clumpner, \& Hill, 1982); a continuum of special education services was required to be provided by school districts (Reynolds, 1989); and a philosophic shift 
in the way decisions were made regarding the educational needs of children (Lipsky \& Gartner, 1996). While previous selection/rejection decisions for special education eligibility were based on a single aptitude test, now eligibility decisions are made through an assessment process and placement decisions are made with emphasis on the least restrictive environment that meets the individual needs of students. From a legal perspective P.L. 94-142 was an extraordinary success ensuring with few exceptions, all eligible students with disabilities were provided access to publicly supported education. In the time period between the initial implementation of the Act (1974) and 1996, more than 1.2 million additional students were provided special education services (Lipsky \& Garner, 1996).

In the years between P.L. 94-142 (1974) and the next major legislative movement (The No Child Left Behind Act of 2001), special education rules and regulations were largely shaped by due process and court decisions regarding the interpretation of the original Act. There was a 1986 amendment to P.L. 94-142, which lowered the age of services to children with disabilities to the age of 3, and a 1990 amendment, which required IEP teams to consider the need for assistive technology (Martin el al., 1996).

The next acts of major federal legislation, the No Child Left Behind Act (2002) and the reauthorization of the Individuals with Disabilities Education Improvement Act 2004 (2004) have resulted in greater numbers of students with disabilities receiving most of their instruction in general education settings. These two acts replaced the word access (to general education curriculum) with the word benefit. Schools were charged with the responsibility to not only provide access to or placement in general education classes, but also to ensure appropriate supports and accommodations were in place to 
deliver benefits, which effectively raised the level of accountability for the education of special education students. These laws required that states and local districts include students with disabilities in assessments with accommodations (where appropriate), to report the performance of these students with the same frequency and in the same detail that they use to report performance levels of students without disabilities, and that IEP teams consider a child's involvement and progress in the general education curriculum and develop IEP goals that promote the child's progress in that curriculum (Handler, 2006).

The most recent national movement, the Common Core State Standards, has been adopted by forty-four states, and was designed to establish clear and consistent goals for learning in math and English language arts. The major goal of the CCSS is to ensure students have the knowledge and skills they will need when graduating from high school to be able to succeed in college or a career (Illinois State Board of Education, 2013). Students with disabilities are included in the CCSS expectations and outcome standards. The expectation for students with disabilities is to "meet high academic standards and to fully demonstrate their conception and procedural knowledge and skills in mathematics, reading, writing, speaking and listening" while acknowledging that "their instruction must incorporate supports and modifications" (Common Core State Standards Initiative, 2014, p. 1). Furthermore, the CCSS website notes that teachers will need to be prepared to deliver high-quality, evidence-based, individualized instruction and support services. Finally, the CCSS notes that in order to fully access the CCSS, students will need individual supports for learning for fostering student engagement by presenting information in multiple ways and having access to instructional accommodations and 
assistive technology to allow students with disabilities to learn with the framework of the Common Core (Common Core State Standards Initiative, 2014).

In a relatively short time, students with disabilities have gone from being excluded from entering the schoolhouse doors to participating in the general curriculum and having the same expectations of outcomes as any other student exiting the school system at the conclusion of high school. These expectations apply to all students with disabilities, ranging from those students with Specific Learning Disabilities to students who have Intellectual Disabilities. The focus of this study is how general education teachers experience the inclusion of students with one specific disability, Asperger Syndrome into their general education classrooms. In order to more fully understand why this population of students might have needs unique to other disabilities, it will be helpful to review what Asperger Syndrome is and how some of the unique characteristics may present in the general education environment.

\section{Understanding Asperger Syndrome}

Asperger Syndrome has often been associated with autism. Autism is described as a spectrum disorder, with diagnostic features including impairments in socialization, communication, and restrictive and repetitive patterns of behavior (Attwood, 2004; Frith, 2003; Simpson \& Smith Myles, 1998). People who have been identified as having autism are recognized to function across a range, or spectrum, of severity of deficits in socialization, communication, and behavior (Smith Myles \& Simpson, 2002a). While Asperger Syndrome is a fairly recently recognized disability, it's complexities are important to understand as they relate to school and life functioning. 
In 1944, Hans Asperger, a Viennese physician, was the first to describe a group of children who exhibited social differences and social isolation, yet exhibited average cognitive and language development (Smith Myles \& Simpson, 2002b). Asperger Syndrome has been described as similar to autism, but at the higher functioning end of the continuum (Van Krevelen, 1971; Williams, 2001). Asperger suggested this group of children had similar characteristics to individuals with autism but were set apart primarily by at least average cognition and language development.

It was not until 1981 that Asperger Syndrome became more widely recognized. English psychiatrist and physician Lorna Wing introduced Asperger Syndrome to English-speaking countries through her seminal study, Asperger Syndrome: A Clinical Account (1981), in which she described a study of 34 individuals ranging in age from 5 to 35 who exhibited the pattern of behavior that had been first described by Hans Asperger. This paper piqued the interest of psychologists and educators in the United States, resulting in over 900 studies focused on individuals with Asperger Syndrome between 1981 and 2004 (Wing, 2005).

In 1994, following the increased interest in understanding and studying what was unofficially being referred to as Asperger Syndrome, the diagnosis of Asperger Syndrome was recognized in the fourth edition of the Diagnostic and Statistical Manual (DSM-IV, 1994) as a specific, pervasive developmental disorder. Since that original formal recognition, there has been a reclassification of Asperger Syndrome under the umbrella of Autism or Social Pragmatic Communication Disorder, as indicated in the fifth edition of the DSM. According to the American Psychiatric Association (2013a), "symptoms of people with Autism Spectrum Disorder (ASD) will fall on a continuum, 
with some individuals showing mild symptoms and others having much more severe symptoms" (p.1). Currently when autism is diagnosed, the individual's functioning level is characterized across two domains and by level of severity for each domain. The domains of 1) social interaction and social communication and 2) restricted interests and repetitive behaviors are rated in one of the three levels of severity. The levels of severity are rated as Level 1 (Requiring support), Level 2 (Requiring substantial support), or Level 3 (Requiring very substantial support), depending on the amount of support required on each of the two domains. Additionally, the individual must meet the minimum diagnostic criteria established by the DSM- 5 to obtain a diagnosis of Autism (American Psychiatric Association, 2013a).

Social Communication Disorder (SCD) is "characterized by a persistent difficulty with verbal and nonverbal communication that cannot be explained by low cognitive ability" (American Psychiatric Association, 2013c, p. 1). Eligibility under SCD focuses on "significant problems using verbal and nonverbal communication for social purposes, leading to impairments in their ability to effectively communicate, participate socially, maintain social relationships, or otherwise perform academically or occupationally" (American Psychiatric Association, 2013c, p. 1). This diagnostic category was meant to replace Pervasive Developmental Disorder -Not Otherwise Specified (PDD-NOS), not Asperger Syndrome. It is considered a communication disorder and not on the autism spectrum.

Many questions have been raised regarding what happens now, post-DSM-IV, to individuals diagnosed with Asperger Syndrome, under the criteria set in the new DSM-5. While as an organization, the American Psychiatric Association appears to be silent on 
the topic on its website, several other nationally recognized organizations and leaders in the autism field have been more vocal on the topic. The Autism Society of America (2014) notes on its website “there are still many professionals who consider Asperger's Disorder a less severe form of autism. The website continues to provide diagnostic as well as resource information”. Similarly, Autism Speaks, another nationally recognized organization supporting individuals on the autism spectrum establishes on its website that it is perfectly acceptable to retain an Asperger diagnosis, and that a clinician can indicate both the DSM-5 diagnosis as well as the previous Asperger syndrome diagnosis in an individual's clinical record (Autism Speaks, 2014). Similarly, Thomas Insel, the director of the National Institute of Mental Health and Allen Frances, the editor of the DSM-IV and DSM-5, agree that the new DSM-5 is flawed and Insel suggests using the manual as a "guide", rather than a "bible" (National Institute of Mental Health, 2012). While the formal recognized diagnosis of Asperger Syndrome is no longer included in the current Diagnostic and Statistical Manual (Fifth Edition), both nationally recognized organizations and leaders in the field are cautiously dealing with the changes.

Educationally, students with a formal diagnosis of Asperger Syndrome may be found eligible for special education services under the IDEA categories of Autism or Other Health Impairment (Fogt et al., 2003; Safran, 2008). Often, parents provide the school with a DSM diagnosis from a clinical psychologist and the school district uses that information to determine eligibility for special education services and under which special education classification the student is eligible (Swisher, 2009). Therefore, it is possible for a child to have a clinical diagnosis of Autism or Asperger Syndrome and an 
educational eligibility of Other Health Impairment based on the alignment or lack of alignment with the IDEA eligibility for Autism (Swisher, 2009).

For the purposes of this study, the term Asperger Syndrome is acknowledged to fall under the category of autism. While the American Psychiatric Association no longer acknowledges Asperger Syndrome as a separate disorder, much of the available literature includes the use of the term Asperger Syndrome. When noted as such in the research and literature, Asperger Syndrome will be utilized to describe the unique set of characteristics commonly associated with this disability, including average to above average intellectual functioning with deficits in communication, socialization, and restrictive or repetitive behavior. Asperger Syndrome has also been used in connection to, and often synonymously with the term High Functioning Autism. Regardless of the "label" assigned to these students, they exist in significant numbers in our schools and need recommended accommodations to be successful in their educational programs. The umbrella term "autism" will be used when the literature does not differentiate between Asperger Syndrome, High Functioning Autism and autism.

\section{Conceptualizing Asperger Syndrome}

Three theoretical frameworks have been developed and accepted by scholars in the field to provide a better understanding of the concept of autism spectrum disorders: theory of mind (Frith, 2003), executive functioning (Baron Cohen, Joliffe, Mortimore, \& Robertson, 1997), and central coherence (Baron Cohen, et al, 1997). These structures help conceptualize the unique difficulties individuals with autism experience, as well as 
provide a framework for developing interventions and supports in all environments for individuals on the autism spectrum.

In order to better understand how these frameworks can both be a source of great strength for students on the autism spectrum while also creating significant challenges in the classroom and other settings, the tenets of Theory of Mind, executive functioning, and central coherence will be reviewed. The term Theory of mind (ToM) describes one's ability to infer and acknowledge the mental states of others and to apply this understanding to explain and/or predict the behavior of others (Sansosti, Powell-Smith, \& Cowan, 2010). The effects of problems with ToM are widespread: affected individuals may experience difficulties explaining one's own behavior, understanding emotion, understanding the perspective of others, inferring the intentions of others, understanding that behavior impacts how others think and feel, grasping social conventions, and differentiating fact from fiction (Smith Myles \& Simpson, 2002a). Having deficits in ToM are considered by some to be those which set children with Asperger Syndrome or high functioning autism apart from those with individuals with lower cognitive and adaptive skills (Baron-Cohen et al., 1997; Gillberg, \&Gillberg, 1989; Lawson, BaronCohen, \& Wheelright, 2004). This concept of ToM may explain why some individuals have difficulty with topic maintenance when speaking. Individuals with autism may jump from topic to topic in conversations or only talk about their interests in conversations, taking little interest in others. Furthermore, they may fail to recognize why these behaviors cause frustration or confusion for others. ToM deficits have also been described as "mindblindness" in that, individuals with ToM limitations are unable to recognize and then synthesize multiple pieces of information such as facial features or 
tone of voice that might provide insight into how a person might be feeling (BaronCohen, 1997; Sansosti, et al., 2010).

Executive dysfunction is the second hallmark of Asperger Syndrome. Executive functions consist of a broad group of cognitive strategies which include working memory, planning, mental flexibility, task initiation and performance monitoring, selfregulation, behavior inhibition, and attention skills (Sansosti, et al., 2010). Executive functioning may also manifest as performing poorly on problem-solving tasks that require planning skills (Ozonoff \& Jensen, 1999). Additionally individuals may also have difficulty with working memory and shifting their thinking back and forth between tasks (Bennetto, Pennington, \& Rogers, 1996). In school, students may have difficulty listening to a lecture while simultaneously taking notes, participating in group work, and completing activities which require fast thinking and recall. Deficits in executive functioning have also been attributed to the inability to self-regulate emotions. For example, a student might appear overly anxious or upset when disappointed about a grade. Students might also have difficulty with sensory self-regulation. Students may hand-flap or rock back and forth in their seat (Sansosti et al., 2010). Deficits with executive functioning are not limited to individuals on the autism spectrum. Executive functioning deficits might also be associated with obsessive-compulsive disorder, learning disabilities, or attention-deficit/hyperactivity disorder, and other conditions (Frith, 2003).

The third piece of the Asperger Syndrome framework is central coherence. Central coherence describes "the general tendency of individuals to integrate, or simultaneously process, incoming pieces of information into meaningful wholes" 
(Sansosti, et al., 2010, p. 28). Individuals with autism tend to have difficulty with central coherence and are more likely to sequentially process information by focusing on the fine details or parts, causing them to overlook the big picture (Frith, 2003). This concept has also been referred to as monotropism, meaning that individuals on the autism spectrum exhibit an unusual strategy for allocating attention in that they focus on one thing at a time (Murray, Lesser, \& Lawson, 2005). In school, a lack a of central coherence or a tendency toward "monotropism" may manifest itself as a student being able to memorize a number of facts surrounding an event in American history yet demonstrate great difficulty synthesizing what lessons could be learned from these events. Central coherence may also explain the need for routines typical of individuals with ASD. The act of learning a routine is taxing for a person with weak central coherence; therefore, once a routine is learned, there may be strong resistance when the rules of a routine are altered (Attwood, 2004).

Autism is a complex disorder. Navigating any environment can be challenging for a person on the autism spectrum. It is probably confusing for those observing a person with autism trying to navigate their environment. For instance, when describing a student with Asperger Syndrome's difficulty turning in homework in his general education class, a teacher noted that even the task of turning in homework is not routine, creating anxiety for this student. The student shared with the teacher that the rules for turning in homework were always changing (e.g., sometimes they turned it in at the beginning of class, sometimes the end); therefore, he often didn't turn it in. In this case, limitations in both executive functioning and central coherence likely contributed to what may seem, to many, as a student failing to comply with simple classroom expectations. 
Difficulties with Theory of Mind, executive functioning, and central coherence illustrate the many unique obstacles that students with Asperger Syndrome face in the general education setting. Yet, despite these barriers, special education rules and regulations clearly indicate students with disabilities should be educated in the least restrictive environment. Many students with Asperger Syndrome have at least average intellectual functioning and grade-level academic skills. For these students, the least restrictive environment is often the general education classroom setting for most or all of their school day.

\section{Asperger Syndrome in the Schools}

Students with Asperger Syndrome experience many challenges in the school setting, related to a variety of social and communication deficits, narrow (and sometimes obsessive) interests, inflexibility and difficulty with organization and problem-solving (Smith Myles \& Simpson, 2002b). In describing the essential characteristics of Asperger Syndrome, and their relevance to the educational environment, Barnhill (2001) noted the following as having the greatest impact on school functioning: social impairment, communication impairment, restricted range of interests and/or rigidity, motor clumsiness, academic difficulties, emotional difficulties, peculiar sensory responses, and theory-of-mind deficits. Clearly students with Asperger Syndrome face many unique challenges in and out of the school setting. Yet, considering the central role social relationships play in almost every situation during the teenage years, Asperger Syndrome may cause the greatest disability in adolescence and young adulthood (Tantum, 1990). 
Minimal research has focused on the connection between the deficits related to autism, the impact of students' behavior, and the experiences in the general education classroom for both the student and the teacher. Additionally, the focus of the literature is mixed: while some literature focuses exclusively on those students who have been diagnosed with Asperger Syndrome (Bayliss, 2011; Mintz, 2008), other studies include individuals from across the autism spectrum (Abner, 2013; Crosland \& Dunlap, 2012; Moores-Abdool, 2010; Walters, 2012).

Problem behaviors such as tantrums, aggression, and noncompliance create obstacles to placement in general education classes and limit opportunities for peer interactions and social development (Strain, Wilson, \& Dunlap, 2011). Students with Asperger Syndrome can be rigid in that they may insist things happen in a certain order and/or exhibit inflexible thinking (Attwood, 2004; Simpson \& Smith Myles, 1998). It might be common to observe intense reactions or outbursts as a response to stress or frustration (Williams, 2001). The uncertain structure of various settings, such as high school, can work against a student's need for order or sameness. An escalation in behavior may be seen at the end of a period due to the transition as well as the highly variable nature of the behaviors often occurring in the halls (Sansosti, et al., 2010).

Challenges with verbal communication are often observed in children with Asperger Syndrome or autism, including odd or unusual speech patterns (Gillberg \& Gillberg, 1989; Szatmari, Bremmer, \& Nagy, 1989). Some students with Asperger Syndrome exhibit speech pattern abnormalities in inflection, too much or too little talking, lack of cohesion in conversation, idiosyncratic use of words, or repetitive patterns of speech, (Gillberg \& Gillberg, 1989). Students with Asperger Syndrome may 
also have significant difficulty understanding the orally presented messages of others and arriving at logical solutions to routine real-life problems (such as receiving a poor grade on a quiz).

Students with Asperger Syndrome are more likely than not to be close to or far above grade level in reading and mathematics as their strong visual memory is advantageous to learning to read and remembering information presented visually (Attwood, 2007). However, some students with autism experience academic problems including difficulties with listening comprehension, written language, math procedures and math computations (Smith Myles \& Simpson, 2002a). Students with Asperger Syndrome may demonstrate difficulty with motor skills including handwriting (Manjiviona \& Prior, 1995). At the high school level students are expected to take notes while the teacher is lecturing, as well as write down assignments and other information. Poor fine motor skills may make it difficult for a student to copy information from books, papers, the chalkboard or other formats of displayed information (Sansosti et al., 2010). Finally, an additional challenge often observed with students with Asperger Syndrome is homework completion. Attwood (2007) suggests the combination of being mentally exhausted from navigating the school day as well as deficits in executive function (organizing, initiating, self-monitoring) may make homework aversive for the student with Asperger Syndrome.

It is clear that students with Asperger Syndrome have a number of challenges and challenging behaviors, which might impact their success in any environment. For students who receive their instruction in the general education environment, the general education teacher must play a significant support role. The general education teacher's 
views, behaviors and reactions to these challenges and challenging behaviors are important to understand. The literature provides a foundation for the experience of general education teachers responsible for teaching students both with disability in general and specifically with students with Asperger Syndrome.

\section{General Educator Attitudes and Beliefs about Inclusion}

The No Child Left Behind Act (2002) and the reauthorization of the Individual with Disabilities Education Improvement Act of 2004 have resulted in greater numbers of students with disabilities receiving a majority of their instruction in the general education classroom. As a result of these Acts, schools were charged with not merely providing special education students with access to or placement in general education classes, but rather with ensuring supports and accommodations were in place to provide benefit to the student. Instructional accommodations that would help a student derive benefit from the general education setting may include extended time for tests or homework, copies of notes or lectures, permission to leave class early to avoid the passing period in the hallway, support from a teacher assistant, assistive technology for writing, and permission to take a short break during class if overwhelmed. Accommodations that must be delivered in the general education classroom may influence the teachers' attitudes about having student's with disabilities in their classrooms. Teachers may feel that enacting accommodations is burdensome, particularly since they are not only responsible for the student with a disability, but the classroom as a whole.

In order to better understand the uniqueness of supporting students with Asperger Syndrome in the general education environment, it is helpful to briefly review the 
literature related to how regular education teachers view their role in integrating students with IEPs into the general education environment.

Research regarding teachers' attitudes and perceptions of having children with disabilities in their classrooms dates back as early as 1958 (Scruggs \& Mastropieri, 1996). In a synthesis of research completed between 1958 and 1995, Scruggs and Mastropieri reviewed 28 educator survey studies in which more than 10,000 teachers participated. They found that a majority of teachers agreed with the general concept of inclusion and a slight majority of them were willing to implement inclusion practices in their own classes. A survey completed with teachers in the United Kingdom (Avramidis, Bayliss, \& Burden, 2000) found similar results in that teachers appeared to be generally positive towards the overall concept of inclusion. A qualitative study conducted with four high schools in the United States suggested that general education teachers were committed to inclusion and saw the benefits for all students (with and without disabilities) as well as to their own teaching practices (King \& Young, 2003). One limitation of this particular study is that the high schools were selected for the study based on a high degree of inclusive practices.

However, not all studies concluded that general education teachers support the idea of inclusion. In a 1994 study on the earlier days of inclusion, Teachers' Views of Inclusion: "I'd Rather Pump Gas," the researchers found that the majority of general education teachers had strong, negative feelings towards the upcoming implementation of inclusion in their schools (Vaughn, Schumm, Jallad, Slusher, \& Saumell, 1994). In this qualitative study consisting of focus groups to obtain data, teachers largely described the process as something being done to them. Teachers were very concerned about the 
impact students with disabilities might have on the general education students (concerns of equity) and that they (and others) had received little to no training in "dealing with these children" (p. 24).

Similarly, deBettencourt (1999) found that some general educators did not have a positive attitude toward including students with disabilities in their classrooms. Over $60 \%$ of the teachers in this survey described themselves as not supporting or having no strong commitment to the concept of mainstreaming (an earlier term now equivalent to the modern day term of inclusion). Slightly more than half of the teachers reported they at least moderately agreed mainstreaming was beneficial for students (as long as it was not in their classrooms). Additionally, in a qualitative study of ten teachers in two pilot inclusion elementary schools in Indiana, findings suggested that the belief among general educators was that special education personnel were solely responsible for any supports or accommodations. Furthermore, the benefits of inclusion were primarily to general education peers exposed to peers with disabilities (Fritz \& Miller, 1995). Most recently the "Teacher Attitudes Toward Inclusion Scale" (TATIS), was developed and normed by Cullen, Gregory and Noto (2010). This scale was developed in response to the observations that the success of inclusion relies heavily on positive teacher attitudes and beliefs towards inclusion and that available scales to measure such were outdated and/or inadequate. No studies to date have reported the use of this scale, but the developers are hopeful that it could be useful in future research regarding how to best assist teachers in the formation of positive attitudes and beliefs toward inclusion.

A second focus of the teacher attitude research has measured teacher perceptions of interventions in the regular education classroom. Johnson and Pugach (1990) asked 
general education teachers who had students with mild learning and behavior problems to rate various intervention techniques. The intervention techniques rated the highest for reasonability and integrity of implementation were collecting data from other teachers about the student's behavior problems and emphasizing the good qualities of the student's behavior. Ranking very low on the reasonability and implementation integrity were interventions such as giving more frequent systematic feedback, talking with other classroom teachers about ways to work on the student's behavior problems, and analyzing subskills in the student's academic problem area and teaching prerequisite skills first. Reasons for not using intervention strategies indicated that the teachers were unsure as to whether or not they had the "authority" to implement an intervention. Hegarty (1992) noted this important component of teacher empowerment in the inclusion process: general education teachers need to feel empowered to apply new skills and competencies and take ownership for them.

In other studies regarding teacher attitudes towards inclusion, researchers found that general educators did not feel as confident as special educators in their ability to fulfill tasks needed to support the inclusion of students in their classrooms (Avramidis, et al., 2000; Buell, Hallam, Gamel-McCormick, \& Scheer, 1999; King \& Young, 2003). Additionally, general educators reported a lack of confidence in adapting materials and curriculum, managing behaviors and giving individual assistance.

Later studies focused not just on the attitude or acceptance of having students with disabilities in the general education classroom, but how specific qualities or characteristics of the student can influence the teacher's attitude. One study considered four factors which might influence teacher attitude towards inclusion: preparation in 
serving special populations, academic climate, academic content, and student's social adjustment (Van Reusen, Shoho, \& Barker, 2001). Results of the study found that the factor influencing more positive attitudes regarding inclusion was the level of special education training, knowledge, or experience in working with students with disabilities. Similar results were outlined in the study by Avramidis, et al. (2000), in that the longer the general education teacher had been teaching in classrooms with students with disabilities, the more positive their attitude towards inclusion. These teachers likely had more confidence in adapting materials, managing behaviors, and providing individual assistance, making the experience less overwhelming and more successful for both students and the teacher.

Other researchers began to recognize that it was not the opposition to the concept of inclusion that was a barrier to effective inclusion, but it was the degree to which appropriate curricular and instructional adaptations could be implemented. McLesky and Waldron (2002) studied teacher perceptions regarding curricular and instructional changes in inclusive environments. In this study, teachers had spent one year developing a plan for an inclusive program and professional development was provided to both general and special educators on inclusive practices. Following the year of preparation and implementation, teachers were interviewed to determine their perceptions of this program. Specifically, in relation to their perceptions regarding implementing curricular modifications and adaptations, teachers were overwhelmingly supportive of taking responsibility for curricular adaptations and modifications for both students with and without IEPs. The authors noted that the success of this program could be largely attributed to "teachers working with and learning from other teachers" (p. 51). Of 
importance was the year-long preparation teachers were provided before students with disabilities were included in their classrooms. Other studies have found similar results regarding the connection between professional development and attitudes towards inclusion (Avramidis, et al. 2000; deBettencourt, 1999).

Secondary history teachers were interviewed in order to examine their views and attitudes toward the inclusion of students with disabilities in their classrooms (van Hover \& Yeager, 2003). Teachers in this study expressed frustration with the expectation that they should be responsible for accommodating students with disabilities. This study found that teachers self-reported that they did not view it as their responsibility to differentiate instruction or curriculum, and that they perceived adaptations were superficial, rather than individualized and specific to the student.

In a study exploring the different types of adaptations a teacher might make, either physical or educational, over one hundred teachers in Turkey were asked to complete the "Scale of Instructional Adaptations for Inclusion." (Kargin, Guldenoglu, \& Smith, 2010). Findings indicated that while the teachers reported both educational and physical adaptations to be necessary for students with disabilities, they were more accepting of and actively implemented the physical adaptations (Kargin, Guldenoglu, \& Sahin, 2010). The authors suggested physical adaptations are easier and require less knowledge to implement than their academic counterparts.

\section{General Educator Attitudes and Beliefs towards Students with Autism}

Understanding that there is a wide range of beliefs, attitudes and opinions towards inclusion and supports for any student with a disability in general education, it is worth 
delving specifically into the research surrounding the inclusion of students with autism and Asperger Syndrome. Knowing that students with autism or Asperger Syndrome may have varied degrees of challenges related to the earlier detailed concepts of theory of mind, executive functioning, and cognitive coherence, individuals with autism bring a unique set of needs to the general education classroom. While students with Asperger Syndrome may possess academic and cognitive skills similar to or above those of their classmates, they likely require supports and accommodations to be successful.

General education teachers tend to perceive that inclusion is different for students with autism and specifically high functioning autism spectrum disorders compared to students with other types of disabilities such as Specific Learning Disability or Emotional Disability (Sansosti \& Sansosti, 2012). Teachers who participated in this study noted that students with autism often require more supports than other students with disabilities and often these supports are unique to the student (such as visual schedules or sensory diets). While we can learn from research and literature about the general concept of teacher attitudes regarding inclusion, it is important to study the experience of including students on the autism spectrum as a separate phenomenon, rather than consider inclusion as a global experience for any student with a mild disability. The literature and research surrounding general education teachers' views, behaviors, and reactions regarding students with Asperger Syndrome and the related condition of autism will be reviewed.

One of the earliest efforts to explore teacher attitude towards children with autism was published in 1981 in response to an increased number of children with autism entering the mainstream. After observing varied responses from general education teachers ranging from enthusiasm to apprehension to hostility, the researchers sought to 
develop a reliable attitude measurement scale (Olley, Devellis, McEvoy Devellis, Wall, \& Long, 1981). The Autism Attitude Scale for Teachers (AAST) was developed to assess the attitudes of teachers in schools who were about to include students with autism for the first time and evaluate the effect of professional development for those teachers. While minimal information could be gleaned from this early study, results generally suggested that special education teachers had a more positive attitude towards students with autism than general education teachers.

Approximately thirty years later in 2010, a small scale study using a revised version of the instrument was completed, primarily assessing general education teachers' attitudes towards children with autism (Park \& Chitiyo, 2011). Findings of this study were in contrast to the study completed earlier, in that in general all teachers, both regular and special education, had a positive attitude towards children with autism. The authors suggest that the fact that the majority of the teachers (98\%) had some type of exposure to children with autism and $73 \%$ of them had experience teaching children with autism contributed to this positive attitude.

In another study demonstrating a relationship between positive attitude towards the inclusion of students with autism and experience with children with autism, McGregor and Campbell (2001) found that a higher percentage of teachers who were considered to be experienced believed that children with autism should be included when possible. A third study using a modified version of the Teacher Attitude Toward Inclusion Scale (Cullen et al., 2010) was completed in 2012 (Wilkerson, 2012). Wilkerson made slight modifications to the scale, focusing exclusively on teachers who had students on the autism spectrum included in their general education classes. This 
study found many of the same results as the McGregor and Campbell study, in that there was a general positive acceptance of students with autism into the general education environment

General educators' understandings and ownership of necessary modifications for students on the autism spectrum can vary. In a 2008 case study, teachers reported general confusion regarding the role of the general education teacher versus the role of the special education teacher for implementing IEP adjustments (Humphrey \& Lewis, 2008). One teacher shared "...I think teachers still are left in a pretty difficult situation in terms of what on paper, they should be doing for every pupil with any kind of extra need in the classroom, and what is realistically possible to do" (p. 136). The authors suggest that the lack of differentiation may be linked to some teachers' lack of understanding of the needs of students with Autism Spectrum Disorders.

Recent studies have looked at more contemporary understandings of autism and applied these characteristics to how they may manifest in the school setting. In a study in which researchers explored the tensions general education teachers may experience when having students with autism in their classrooms, Eman and Farrell (2009) explicitly studied the impact of pupils' autism-related manifestations on teacher frustration. Related to the Theory of Mind (ToM) concept, Eman and Farrell studied how students' difficulties in social and emotional understanding impacted teacher attitudes towards these students. For example, the authors suggested that the pupils' inability to take the perspective of others impacts the teacher's ability to form a relationship with the student, resulting in their possibly distancing themself from the student. The researchers also found that difficulties in students' ability to regulate and express emotions created tension 
for the teachers in the study. These difficulties manifested as the students' challenges reading emotions from their teachers, as well as showing minimal affect or excitement at times when most students would be demonstrating excitement for the activity. For example, when most students show excitement for an interesting activity or engaging lesson, students with challenges with Theory of Mind generally do not show any emotion, even if they did enjoy the lesson. This can create confusion on the part of the teacher, who may use nonverbal (and verbal) feedback from students to gauge their own perception of the success of the lesson. These differences in communication and theory of mind did not bode well for general education teachers' desire to develop a relationship with these students.

Soto-Chodiman, Pooley, Cohen, and Taylor (2012) found similar results in their qualitative study regarding general education teacher frustration in understanding the unique receptive and expressive communication needs of children on the spectrum. Finally, general education teachers conveyed frustration related to another manifestation of Asperger Syndrome: students' difficulty transferring learning across different situations (Soto-Chodiman et al., 2012).

Studies have also focused on qualitative research in which the general education teachers were asked to share their perceptions of the challenges they have experienced teaching students with autism in their classrooms and the types of support they might need to be more successful. Through a series of open-ended questions, Soto-Chodiman, et al. (2012) discovered a pattern among the 12 participants of the study regarding the challenges they experienced with included students with Asperger Syndrome. Similar to findings of the studies of general education teachers' attitudes towards inclusion for any 
type of disability, common concerns of specifically supporting students with Asperger Syndrome included: modifications of curriculum and teaching techniques, communication difficulties, and management of problem behaviors. Specific to this population, teachers reported feeling poorly prepared for their responsibilities in supporting students with autism and often relied on gut instinct. Problematic classroom behavior related to their students' autism also posed difficulty for the classroom teacher and influenced the teachers' perceptions of students' success in the inclusive experience. For example, behaviors such as stereotypical movements, inflexible thinking during group work, and need for movement or breaks sometimes interfered with class and limited the development of relationships between the student with autism and his or her peers and teacher(s). Despite their report of some problematic behaviors, the majority of the teachers stated that they did not believe these behaviors should preclude the student from participating in the general education environment.

Wilkerson (2012) also found that being responsible for dealing with challenging behavior could have a negative impact on the general education teacher's attitude towards having children with autism in their classroom. A study of general education teachers' relationships with included students with autism (Robertson, Chamberlain \& Kasari, 2003) found that the presence of maladaptive behaviors (hyperactivity, impulsivity, opposition, defiance) lessened the quality of the teacher-student relationship in the general education setting. The behaviors of screaming and aggression were noted by teachers in a study in Scotland (McGregor \& Campbell, 2001) to be behaviors that would be more difficult to cope with than characteristics such as vulnerability and emotional immaturity. 
A common theme in several of the studies on teacher attitudes towards students with autism was related to the role of the teacher assistant who may accompany the student to serve as a support in the general education environment. The general education teacher's perception toward the role of the teacher assistant may help or hinder teacher attitude towards the included student. Findings of several studies (Eman \& Farrell, 2009; Robertson, et al., 2003; Soto-Chodiman et al., 2012) noted that the primary in-class support available to included students with autism was the teacher assistant. Teachers stated that an experienced teacher assistant could reduce the workload of the general education teacher to manageable proportions. Teachers may also perceive the role of the teacher assistant to "help keep the student focused and on task, to provide any accommodations or modification necessary, to help increase their understanding and minimize any social and/or academic frustration, to reduce behavioral problems, and to provide support to the classroom teacher" (Robertson et al., 2003, p. 127). Teacher assistant turnover and inexperienced assistants were noted as barriers to successful inclusion experiences for the student.

A theme in another study indicated that while the teachers generally agreed that the presence of an assistant is a useful support, they did not perceive a child as fully included if they had an assistant with them in their class (Sansosti \& Sansosti, 2012). Indirectly, it is possible that the presence of the support of the teaching assistant improves the attitude toward the student with autism. A teacher's reflection in one study noted: "I think if the support (teacher assistant) is removed I will be disappointed...Andy is doing very well in the lesson but he does need support" (Eman \& Farrell, 2009, p. 416). It is clear that in the eyes of the general education teacher, the presence of the teacher 
assistant is important to the acceptance and success of students with autism in the general education classroom.

Studies have also gleaned the perceptions of general education teachers on the benefits of inclusion for students on the autism spectrum and their regular education peers. Benefits for students on the autism spectrum include observed progress in social skills due to the interaction with peers (Eldar, Talmor, \& Wolf-Zuckerman, 2010; Sansosti \& Sansosti, 2012). General education students, in turn, may benefit from strategies that are in place for a student on the spectrum. Classes of younger students may generally benefit from a visual schedule originally devised for a student with Asperger Syndrome (Sansosti \& Sansosti, 2012).

Almost every piece of literature reviewed regarding teacher attitudes towards including students with autism in the general education classroom recommended professional development as a key factor in improving services for students and providing teachers with a better understanding of how to support students on the spectrum in general education (Abner, 2013; Bayliss, 2011; McGregor \& Campbell, 2001; Park \& Chitiyo, 2011; Sansosti \& Sansosti, 2012; Soto-Chodiman et al., 2012). These studies noted a link between the lack of teacher preparation for supporting students with autism in the general education environment and negative attitudes towards supporting students on the autism spectrum. Specifically, in order to better prepare teachers to support students on the autism spectrum, Sansosti and Sansosti (2012) suggest that professional development include three key components: the unique instructional implications for students with ASD, assessment strategies for analyzing specific support needs, and an overview of strategies known to be effective for improving the behavioral, 
social, and academic outcomes for students with autism in the general education environment.

\section{Summary}

The research regarding children with disabilities in the general education environment, and more specifically, children with autism has evolved over the years. Studies first focused on teacher attitude regarding the acceptance of children with any disability in the general education environment. These studies then began to focus on the strategies teachers were willing to employ and actually execute for these students, as well as explore the barriers to success. In recent years, additional research has been published concerning teacher perceptions of inclusion of children with autism in their classroom, the barriers to inclusion of these students, and the impact of the unique characteristics of autism on the learning environment. Yet, gaps in the research continue. Minimal research focuses on teacher attitude and perception of the specialized accommodations and modifications needed to successfully support students with autism in the general education environment. The research acknowledges that supporting students with autism in the general education classroom is unique, and cannot be a one size fits all approach. Connecting the unique characteristics of students with Asperger Syndrome (Theory of Mind, executive functioning, and central coherence) to the actual accommodations and modifications implemented in the general education classroom and the perception of the general education teachers' view of the acceptability and effectiveness of these supports is paramount to gaining a better understanding of what teachers need in order to assist students. 
Students receiving special education services in schools today are held to high accountability standards and are expected to make growth within the general education curriculum. Students with Asperger Syndrome often attend those general education classes and may present outstanding strengths, as well as challenges, that might impact general educator attitudes and beliefs towards the necessary supports for these students to access their education. The methodology of this study of general education teacher's experiences and perceptions with students with Asperger Syndrome will be presented in Chapter III. 


\section{CHAPTER III \\ RESEARCH DESIGN \\ Statement of the Problem}

Students with Asperger Syndrome and High Functioning Autism face unique challenges in the general education classroom due to varying degrees of challenges with Theory of Mind, executive functioning, and cognitive coherence. While these students may have the cognitive and academic skill levels to be successful in general education coursework, deficits in these areas may impact social interaction skills, organization skills, understanding and execution of social norms when interacting with teachers and peers and completing course expectations. Most often, these students have an IEP denoting the needed accommodations and modifications necessary to access the curriculum and environment. Even with an IEP with noted accommodations and modifications to support these deficit areas, little research has focused on how teachers perceive the accommodations and to what extent they perceive these strategies to be helpful to the student. This phenomenological qualitative study will add to the research in order to better understand the experiences of secondary level general education teachers supporting students with Asperger Syndrome in their classrooms. This study consisted of a variety of qualitative techniques including semi-structured interviews, classroom observations, and collection of artifacts and participant journaling.

This study was guided by the following research questions: 
- What are the experiences of Secondary English teachers who have students with Asperger Syndrome in their classroom?

- What obstacles do Secondary English teachers experience in working with students with Asperger Syndrome in the general education classroom?

- What are the perceptions of Secondary English teachers of the accommodations for students with Asperger Syndrome in the general education classroom?

$\circ$ What accommodations are teachers using in the general education classroom, and from where do they derive these (IEP, experience, etc.)?

- How effective do the Secondary English teachers perceive the accommodations are for their students with Asperger Syndrome?

- What resources do Secondary English teachers require to understand and support the needs of students with Asperger Syndrome in the general education classroom?

\section{Rationale for Qualitative Research}

Qualitative researchers are interested in understanding how people interpret their experiences, how they construct their worlds, and what meanings they attribute to their experiences (Merriam, 2009). Merriam (2009) noted four characteristics as keys to understanding qualitative research, including the focus (of the research) is on process, understanding, and meaning; the researcher is the primary instrument of data collection and analysis; the process is inductive; and, a richly descriptive product is the end result. Creswell (2013) and Rumrill, Cook, and Wiley (2011) provide similar considerations in conceptualizing qualitative research. 
A qualitative approach for this study was chosen because it is important to know what teachers think about supporting the needs of students with Asperger Syndrome in their general education classrooms. Quantitative research could suggest whether or not there is a greater likelihood this group of students are successful in these classrooms compared to other settings. However, quantitative research would not provide insight into the challenges teachers experienced in supporting these students, their perceptions of the prescribed IEP accommodations, nor what supports the teachers believe would assist them in better understanding and supporting these students. For this particular study and the research questions posed, a qualitative research design is preferred.

\section{The Role of Qualitative Research in Education}

Qualitative research in education as a means to understanding the complexities of everyday educational predicaments has become popular over the past four decades (Cooley, 2013). Phillip Jackson's Life in Classrooms (1968) was one of the earlier qualitative studies in education and utilized this method to build theory. Harry Wolcott's (1973) The Man in the Principal's Office was one of the earlier uses of ethnography as a qualitative method in education and influenced researchers at the time to view qualitative work as a viable form of inquiry (Cooley, 2013). Paul Wills' (1977) Learning to Labour: How Working Class Kids Get Working Class Jobs is considered to be an exemplar of the use of social and critical theory in an ethnographic study. Willis' work continues to be influential in the field of qualitative research in education on two fronts: the partnering of social theory with qualitative methods and the idea that social theory needs qualitative research to remain grounded in the real world (Cooley, 2013). 
Historically, quantitative research methods have been the preferred method of research in special education (McPhail, 1995; Pugach, 2001; Rumrill et al., 2011). Pugach (2001) suggests several reasons why qualitative research was not embraced earlier in special education. He suggests researchers in the field of special education were unfamiliar with qualitative methods, and most special education organizations and publications were philosophically and methodologically conservative. Pugach went on to suggest that perhaps a general lack of understanding of qualitative research and the criticism of the reliability and validity of this type of research fed the reluctance to embrace qualitative research. Finally, few strong qualitative studies were submitted to journals resulting in very few published studies and low-quality studies among those published.

A movement described by Denzin and Lincoln, known as the "crisis of representation" in the 1980's (as cited in Pugach, 2001, p. 443) was the beginning of a turning point in special education research. As other marginalized populations (including women, people of lower SES and people of color) began to be included in published studies, the door opened for other previously underrepresented groups (such as individuals with disabilities) in qualitative literature (Pugach, 2001). Special education researchers became interested in creating a more complete understanding of traditionally marginalized populations within the field. Researchers began considering students and their families who had traditionally been marginalized in the educational system. One example was a study of the lived experiences of individuals with intellectual disabilities, conducted by Bogdan and Taylor (1982). 
Qualitative research as a vehicle for understanding marginalized populations continues to be popular today. Brantlinger, Jimenez, Klingner, Pugach, and Richardson (2005) provide insight on the importance of qualitative research to the field of special education. They suggest the value of such work is related to the importance of exploring attitudes, beliefs, and opinions of those involved in special education, as well as the general public. Brantlinger et al. (2005) suggest personal reactions to special education contexts and teaching strategies can be studied. Qualitative research can also explore the nature and extent to which a practice has an impact on individuals with disabilities, their families, and on settings where they tend to work, reside, or are educated. In recent years, qualitative research has often been associated with the study of a particular teaching practice (such as co-teaching) and its impact (Scruggs, Mastropieri, \& McDuffie, 2007) or how participants (such as male adolescents with autism) experience a phenomenon in school (Daniel \& Billingsley, 2010).

Clearly, qualitative research has found its place within the field of special education. From the importance of understanding the voice of marginalized populations to understanding the thoughts, opinions and experiences of families, educators and others who interact with individuals with disabilities there is a place for robust qualitative research to provide these insights.

\section{The Phenomenological Design}

Within the field of qualitative research, there are a number of research design methods from which to choose. Popular qualitative research methods in special 
education include case studies, ethnography, grounded theory, and phenomenology. Based on the research questions for this study, phenomenology is the selected method.

The phenomenological method reveals a common meaning for several individuals of their lived experience of a concept or a phenomenon (Creswell, 2013). Understanding common experiences can be valuable for groups such as therapists, teachers, and health personnel. In a phenomenological study, the researcher collects data from people who have experienced the phenomenon and develops a description of the experiences across individual subjects focused on identifying the essential qualities of their collective experience (Creswell, 2013). The process of phenomenological research involves methodologically, carefully, and thoroughly capturing and describing how people experience a phenomenon (Patton, 2002).

Phenomenological studies generally include a number of features as described by Creswell (2013). The critical elements of phenomenological studies as defined by Creswell (2013) are a) the analysis of a lived experience shared by a group of individuals b) the philosophical ideas that underpin the research are explored c) data collection typically includes individual interviews with those who have lived the experience under consideration and d) data analysis that systematically moves from narrow units of analysis to broader units and finally detailed descriptions of individual experiences and their reactions to it. Identifying and describing the essence of the individual reports of the shared experience is the end result of a phenomenological study and that those results include both a description of what was the experience as well as how it was experienced (Creswell, 2013). 
In order to study teachers' experiences and perceptions in working with students on the autism spectrum in the general education classroom, other researchers have used phenomenology as the qualitative research method. In a study of general educators' lived experiences in the inclusion of elementary students with autism, Abner (2013) conducted semi-structured interviews and completed classroom observations to answer the research questions. While components of Abner's study can be used to inform this study, Abner's study focused more globally on students falling anywhere on the autism spectrum and focused solely on elementary education teachers. Walters (2012) completed a phenomenological study with six secondary teachers on their attitudes regarding the inclusion of students on the autism spectrum in the secondary classroom. While this study did focus on the high school level, it consisted only of interviews and did not include other methods of validity checking, such as observations or review of artifacts. Other studies (Soto-Chodiman et al., 2012; Sansosti \& Sansosti, 2012) have also focused on the attitudes and perceptions of general education teachers working with students on the autism spectrum at the elementary school level.

Phenomenology consistently appears as a preferred method when studying the experiences of teachers who support students on the autism spectrum in their classrooms. However, the mentioned studies have limitations which this study addressed. This comprehensive phenomenological study focused on secondary teachers who have students with Asperger Syndrome in their classrooms. Specifically, this study first explored the experiences these teachers have when teaching students with Asperger Syndrome in their classrooms, and then asked them to reflect on their perceptions of the IEP denoted accommodations for this population of students. Data was triangulated 
through classroom observations, follow-up communication, journaling and the collection of artifacts, to better inform secondary level educators supporting this population of students.

\section{Research Sites and Participant Selection Process}

For this study, a total of six teachers from a large high school district in the suburbs of a large city in the Midwest were interviewed, observed, and asked to submit a written reflection of their experiences of providing accommodations to high school students with Asperger Syndrome.

\section{Research Site}

The district chosen for the study was comprised of approximately 12,000 students in five high schools during the 2014-15 school year. District website data and the State Report Card (2014a) indicate that individual school enrollment ranges from 1,938 to 2,797 students. Each of the five schools have received the United States Department of Education's Blue Ribbon Secondary Schools Award and three of the schools have been named among the "Top 99" high schools in the country by U.S. News and World Report. For the 2014-15 school year, the district spent $\$ 15,593$ per pupil on operational-related costs. For the same school year, the district ACT examination composite score was 22.2, placing the district above the 20.6 statewide composite, and 20.9 national composite scores. Regarding student demographics, the following table (Table 1) represents the ethnicity of the total current student population: 
Table 1

Student Ethnicity

\begin{tabular}{|ll|}
\hline Ethnicity & Percent of Total Student Population \\
\hline Asian & $16.7 \%$ \\
Black/African American & $6.6 \%$ \\
Hispanic/Latino & $20.7 \%$ \\
American Indian & $0.2 \%$ \\
Pacific Islander & $0.1 \%$ \\
White & $53.5 \%$ \\
Two or More Races & $2.1 \%$ \\
\hline
\end{tabular}

The district reports $29.8 \%$ of its students qualify as low income, 3.8\% as English learners, and $11.1 \%$ of the students throughout the district have an IEP. During the year in which this study was completed, the district was in its first year of full implementation (following two pilot years) of district-provided iPads for every student.

\section{Research Participant Selection Process}

Six English teachers from the district were selected through purposeful sampling to participate in the study. Data obtained from the district website and the State Report Card (2014a) indicate that the district employs 971 certificated staff members, with over $89 \%$ of them having master's degrees or beyond. Of those, 125 are employed as certificated teachers in the English Departments across the district. English was chosen as the targeted content area for several reasons, including: a) students are required to take four years of English as a graduation requirement, which allows a large sample of teachers to be included as potential participants; b) English/Language Arts is one of the 
core areas included under the new Partnership for Assessment of Readiness for College and Careers (PARCC) assessment and is integral to the Common Core State Standards; and c) English courses typically require a significant amount of writing, homework, and interpersonal interaction all of which can require accommodations to support these students in the classroom. This study focuses on one academic area in order to provide some likelihood of patterns and common experiences when completing data analysis.

Because it was important that participants had experienced the phenomenon of having students with Asperger Syndrome in their classrooms (currently and at least three additional years), purposeful sampling as described by Patton (2002) was used to identify the subjects. The specific type of purposeful sampling used was intensity sampling, which is defined by using intensity of previous experiences with the phenomenon as a key criterion for selecting subjects (Patton, 2002). Teachers who had multiple experiences of having students with Asperger Syndrome to draw on when completing this study to gain rich and meaningful information were sought. The specific operational criteria used for selecting study participants included a minimum of three years teaching students with Asperger Syndrome in their general education class as well as teaching at least one student with Asperger Syndrome during the course of the study. The requirement of a minimum of three years of relevant experience defines intensity sampling in this study. A minimum of three years experience with this phenomenon would suggest they have encountered a variety of students with Asperger Syndrome in their courses and could base their experiences across time and students.

In order to recruit these targeted participants the researcher contacted Special Education Department Chairs in each of the buildings and briefly described the study and 
the criteria I had established for potential participation in the study. Names of English teachers who they believed met the criteria for participation in the study were solicited. Then e-mail invitations (Appendix A) were sent to potential participants, explaining the study, what their involvement would entail and asking them if they would be like to be considered to participate in the study. For the recipients who indicated they were willing to participate, a short questionnaire (Appendix B) was sent to verify they have had at least three years experience working with students with Asperger Syndrome, and currently have a student with Asperger Syndrome in one of their classes. This questionnaire also asked for demographic data, such as education and the number of years teaching.

Throughout the recruitment process, a few of the participants were delayed in responding and a few of the potential participants declined the invitation to be a part of this study. During this process, it was unclear as to whether or not there was going to be a participant from School "C" as one participant decided not to participate and another was not communicating their interest in the study. At that point, a second participant from School "A" was contacted to meet the criteria of the study's proposed five participants. A short time following the second participant from School "A" agreeing to be a part of the study, the participant from School "C" agreed to participate. At this point the study was increased to six participants, in the event that one or more participant would not complete all of the components of the study. Table 2 provides a demographic summary for the six participants in this study. 
Table 2

Participant Demographics

\begin{tabular}{|llll|}
\hline Participant & School & $\begin{array}{l}\text { Total Number } \\
\text { of Years } \\
\text { Teaching }\end{array}$ & $\begin{array}{l}\text { Number of Years Teaching } \\
\text { with Students with Asperger } \\
\text { Syndrome }\end{array}$ \\
\hline Beth & A & 25 & 20 \\
Payton & A & 8 & 8 \\
Richard & B & 22 & 7 \\
Jamie & C & 10 & $3-5$ \\
Ann & D & 13 & 10 \\
Ron & E & 26 & 10 \\
\hline
\end{tabular}

\section{Data Collection}

The study consisted of three types of data collection in order to obtain comprehensive understanding of the studied phenomenon: interviews (initial and followup) of the participants, observations of the participants, and written reflections by the participants. The primary source of the data collection was the interviews, with the observations and written reflections utilized to triangulate and validate the findings.

As noted by Merriam (2009), “interviewing is necessary when we cannot observe behavior, feelings, or how people interpret the world around them" (p. 88). The utilization of the semi-structured interview process allowed the opportunity to explore the research questions, as well as the opportunity to explore unanticipated themes that arose through the semi-structured interview process. Semi-structured interviews typically involve a) a mix of more and less structured interview questions, b) questions used flexibly, c) usually specific data is required from all participants, d) the largest part of the interview is guided by lists of questions to be explored, and e) there is no predetermined wording or order of questions (Merriam, 2009). This research study consisted of twentyfour questions (Appendix C) that were used as a guide for the initial interviews. 
Questions were developed for the semi-structured interviews using practices recommended for framing interview questions and interviewing by Dana, Dana, Keslay, Thomas, and Tippins (1992) and Merriam (2009). These guidelines include keeping questions short and precise, asking one question at a time, avoiding questions in which the answer was given or implied, being aware of the interviewees' use of language, and avoiding "why" questions. Finally, as recommended by Maxwell (2005), member checking was utilized to ensure credibility of the researcher's analysis after the initial analysis was completed. The process of member checking consisted of asking two of the participants to review the preliminary findings to determine if the findings correctly interpreted and represented their perspectives.

As recommended by Patton (2002), this study intermixed interviews, observations, and document analysis in order to strengthen and validate the findings in the study, commonly referred to as triangulation. The triangulation method I utilized was the triangulation of qualitative data sources, as described by Patton (2002).

Observations consisted of one observation per participant and were onlooker observations, rather than participant observations. Patton (2002) differentiated these types of observations, describing onlooker observations as those in which the observer is not an active participant in the setting being studied. The observations were narrow in focus, in that the purpose was to observe accommodations being implemented for the student(s) targeted by the teacher in the initial interview process. Given the consideration that the purpose of the observation was to triangulate data from the interviews and journal entries, full emersion in the classroom experience was not necessary. Creswell (2013) suggests using an observation protocol during observations, 
which consists of both descriptive notes and reflective notes. An observation form was developed for this study (Appendix E), which included demographic information regarding the physical elements of the classroom; a description of lessons and activities; and a chart for recording accommodations that were observed to be provided during the observation.

The third major component of data collection was reflective journal entries completed by each participant. Each participant was asked to complete one journal entry (Appendix E) consisting of open-ended questions regarding a specific situation in which they used accommodations for a student with Asperger Syndrome they currently had in their class. The purpose of this written response activity was to provide insight and reflection on the teacher's part that was not communicated in the initial interview. Data from journal entries allowed me to validate the response patterns noted through the interview process and observations, thus triangulating the data.

\section{Data Collection Process}

Participants were asked to suggest a convenient time and location for the initial interview. Participants were informed the interviews would require 45-60 minutes of their time and were asked to choose a private, quiet location for the interview. Verbal and written informed consent was obtained prior to the start of each interview (Appendix G). Participants were informed that the interviews would be audio recorded and that they had the right to refuse to answer any question. Participants were informed that the written notes, field notes, transcriptions, and audio recordings would be kept in the researcher's home in a locked file cabinet that only the researcher can access. They were also 
informed that the final product of the research study would be a published dissertation for a Doctorate in Education, which would also include an oral defense of the findings. They were informed that no identifying information would be included in any aspect of this study. As a gesture of appreciation for participating in the study, participants were informed at the outset that they would be given a $\$ 25$ iTunes card upon completion of data collection for the study.

Prior to the interview, the participants were informed of the potential risks, which were considered to be minimal, but included the potential perception by participants that information revealed as part of the study may impact their relationship with special education staff. To minimize the risks, the interviews were conducted in settings that provided the maximum amount of privacy and confidentiality. Pseudonyms for the schools, participants and students were used in the analysis.

The participants were sent a brief electronic survey prior to the initial interview as a means to gather basic demographic information. These surveys (Appendix C) included such information as years of teaching experience, years of experience working with students with Asperger Syndrome, and degrees and special certifications.

The interviews were conducted in a semi-structured format, using twenty-three pre-determined questions (Appendix D). Because the interviews were semi-structured, in addition to the pre-determined questions, additional questions were included during the interviews, based on the unique perceptions and responses of each participant. Types of follow up questions included clarification of participants' statements to ensure the researcher fully understood what a participant was communicating and additional 
questions based on something a participant brought up that was not related to any of the interview questions but relevant to the study.

Following the initial interview, a classroom observation was scheduled with each participant. In order to increase the likelihood of observing accommodations, the researcher worked with the teacher to determine a class session that was going to be instructional and/or interactive, such as a day involving a lecture, group work, and/or written work. Classroom observations were scheduled such that the participant and agreed to a few potential days for observation, but they did not know the exact date, to make the experience as natural as possible. Teachers were asked to inform the researcher if there was going to be a schedule change and that could impact the observation and might not provide much meaningful data. A few of the participants did e-mail to eliminate potential dates with this request in mind.

Documents the teacher provided the student (such as written notes or outlines of lectures) following the observation were collected. Some teachers provided electronic versions of the documents given to students and some provided paper copies. Field notes were taken during the observations, striving for thick, deep and rich descriptions as suggested by Patton (2002). Following each observation, the researcher reflected on the observation, adding their own experiences, thoughts and feelings to the field notes.

An observation form (Appendix D) was developed to utilize during each of the observations to provide uniformity of data collected. The areas noted during each observation included a description of the physical elements of the classroom and a description of the lessons/activities during the observation. Each incident of the delivery of a support or accommodation during the observation was denoted, with the time, the 
actual support, if it was targeted for all students or directly for the student with Asperger Syndrome, who delivered it (teacher/teacher assistant/someone else) and notes or observations. Examples of accommodations included visual (the schedule for the day on the whiteboard); verbal (redirection; clarifying of information; 1:1 interaction), and environmental (assignment of groups during the lesson; teacher circulating around the room). Notes from classroom observations, journal entries, artifacts, and e-mail exchanges were coded along with the transcribed interviews. These data sources are included in the results, analysis and discussion in Chapter IV.

Following the initial interview and observation, each teacher was asked to complete one guided reflection regarding the implementation of accommodations in their teaching practice. The guided questions (Appendix F) consisted of the teacher first describing the accommodation(s) he or she implemented during a specific lesson or activity. They were then asked to respond to a series of prompts such as a) was it planned or unplanned, b) how often do they use that accommodation, c) what prompted him or her to use it; d) was it a part of the IEP or not, e) did it work, f) what were their barriers to using the accommodation, and g) would they use or recommend that accommodation again? Three of the six participants submitted journal entries as noted in Table 3.

While no formal follow-up interviews were completed following the interviews, observations and journal entry submissions, the researcher did have informal short discussions with a few of the participants before or after their classroom observations (in which hand-written notes were taken). There were also a few e-mail exchanges that became part of the evidence collected for the study. 
As previously described, member checking was also utilized to ensure validity.

Table 3 provides a visual summary of the data collection process. Table 4 provides a summary of the data collected from each participant.

Table 3

Data Collection Process

\begin{tabular}{|ll|}
\hline Method & Process \\
\hline Initial Interview & Semi-structured interviews with each of the participants \\
Observation & Direct classroom observation of each of the participants \\
Guided Reflection & Guided reflection by each participant \\
Follow-up Interview & $\begin{array}{l}\text { As needed, follow up interviews for clarification and } \\
\text { deeper understanding } \\
\text { Member Checking }\end{array}$ \\
& $\begin{array}{l}\text { Two participants were asked to review and provide } \\
\text { feedback of initial findings to check validity }\end{array}$ \\
\hline
\end{tabular}

Table 4

Data Collected from Each Participant

\begin{tabular}{|llllll|}
\hline Participant & School & Interview & Observation & $\begin{array}{l}\text { Journal } \\
\text { Entry }\end{array}$ & Artifacts \\
\hline Beth & A & X & X & X & X \\
Payton & A & X & X & & \\
Richard & B & X & X & X & \\
Jamie & C & X & X & X & X \\
Ann & D & X & X & & X \\
Ron & E & X & X & & X \\
\hline
\end{tabular}

\section{Data Analysis}

A significant amount of data, which consisted of interviews, observations, journal entries, was collected and then analyzed for this study. Creswell (2013) describes data analysis in qualitative research to consist of preparing and organizing data, reducing data into themes through the process of coding and condensing the codes, and then representing data in figures, tables, or a discussion. As described by Creswell (2013), the 
first step of the process involved reading and memoing. Creswell suggests the researcher should begin by getting a sense of the whole database of information, which would include reading the transcripts in their entirety several times and writing notes or memos in the margins of field notes and transcripts as an initial step of exploring a database.

Following the completion of the participant interviews, the interviews were transcribed from digital audiotapes by an online transcription service. The initial process of exploring all of the data collected began with first listening to the audio recordings of each of the interviews, as some time had passed since the actual interviews had occurred. Then the transcripts were read in their entirety two times and the process of jotting down some initial thoughts and ideas was initiated. After that, the process of coding, which involved building detailed descriptions, developing themes or dimensions, and providing an interpretation based on my own views or perspectives in the literature (Creswell, 2013) was started. Miles, Huberman, and Saldana (2014) describe 25 different approaches to coding methods, each serving a different function or purpose. They suggest these coding approaches can be mixed and matched as needed. As recommended by Miles et. al. (2014), a short list of 25-30 tentative codes that matched text segments was developed.

It is also accepted in qualitative research that not all data collected in the research process will be used in data analysis, which was true in this study. Creswell (2013) discusses several decisions that can be made, including whether or not to "count codes" (frequency count), and whether or not to use prefigured (pre-determined) codes or to develop the codes as they emerge, also known as "in vivo" codes. Creswell (2013) recommends using a combination of prefigured and in vivo codes which would represent 
information expected to be found before the study, surprising information that one did not expect to find, and information that is conceptually interesting or unusual to researchers. For example, in the data analysis of this research, it was expected to have several categories related to specific accommodations, as that is the heart of the study. Following the coding process, data are then separated into five to seven general themes or categories, which represent broad units of information that consist of several codes aggregated to form a common idea (Creswell, 2013). This process of combining codes into broader themes is termed Pattern Coding (Miles, et al., 2014).

For this study, codes began to emerge and were then developed into themes and aligned to the research questions. Appendix G provides a breakdown of the codes aligned with their themes. Not all codes and themes were used in the discussion and analysis. There were a few instances of a code initially appearing to be a theme, but was then not validated among all participants and data. An example of this falls under codes for improving the experience of the general education teacher; just one teacher noted better training for teacher assistants. In the end, the full data set was reviewed a total of six times (one time listening to the transcripts and five separate reviews of all written material) to ensure the researcher had fully captured all of the themes and data points.

The final step of data analysis was to represent and visualize the data in matrices, networks, figures, and or text form (Creswell, 2013; Miles et. al., 2014). Prior to the study it was difficult to identify exactly how data would be visualized, as the process of collecting and interpreting the data would provide natural guidance to this process. Once patterns emerged and aligned to the research questions, six matrices aligned to each of the general themes of the research questions were created. The matrices had the codes or 
sub-themes on the left-hand side and each of the participants across the top. Each piece of evidence (statements from interviews and journal entries; observational data; and collected artifacts) was denoted by the page number of where that occurred within each participant's packet of data (the observation sheets, journal entries and artifacts were numbered). These matrices provided a foundation for the organization of the actual writing process. An example of one matrix is provided in Appendix $\mathrm{H}$.

Once data had been visually represented in the matrices, the process of the narrative analysis, or putting the data analysis into words and telling the story of the phenomenon began. This process was approached by answering each of the research questions using the codes and themes as described. Descriptions of what the participants experienced with the phenomenon were charted, and included verbatim examples, and provided examples that validated or invalidated these through observations and journal analysis. This was the essence of the data analysis component, as it provided the deep, rich description of what the participants experienced and what the researcher observed and noted through interviews, observations, and artifacts.

Partial transcripts for two of the participants and the analysis of the first research question were submitted to my dissertation chair for peer review. The purpose of this peer review was to "scan some of the raw data and assess whether the findings are plausible based on the data" (Merriam, p. 220). Following feedback from my dissertation chair, I proceeded with the remaining analysis and discussion of the findings. 


\section{Trustworthiness and Authenticity}

Reliability, often referred to, as consistency and dependability in qualitative research, were addressed through first ensuring quality data collection. Interviews were recorded and transcribed verbatim, and the transcriptions denoted trivial pauses and overlaps as recommended by Creswell (2013). When completing interviews, the researcher ensured that they did not influence participants' responses in such a way that their responses did not truly reflect their actual experience by developing rapport with the interviewees and maintaining neutrality during the interviews, as described by Patton (2002). Utilizing recommended practices for framing interview questions and interviewing (Dana, et al., 1992; and Merriam, 2009), questions were developed and pilot tested before using them in the actual study. Some researchers (Creswell, 2014; Yin, 2009) suggest first piloting the interview questions with a participant not involved in the study for the purpose of refining research questions and adapting research procedures if necessary. Prior to the first interview with the participants of the study, the researcher piloted the entire interview with a teacher in the district who met the requirements for the study (English teacher with three or more years experience working with students with Asperger Syndrome) but not participating this study. Immediately following the interview, the researcher asked this teacher to provide feedback regarding the questions themselves as well as the style of the researcher as an interviewer. Based on this teacher's feedback, a few questions were slightly modified for wording but not content. For example, "philosophy" was replaced with "general attitude" in the question, "What is your general attitude in regard to the inclusion of students with Asperger Syndrome in 
general education classrooms?" The teacher suggested the word "philosophy" might be intimidating to the participants.

To ensure data was consistent and dependable, data were triangulated through the completion of the semi-structured interviews, observations, and collection of journal entries. For example, the researcher requested examples of accommodations general education teachers have implemented for students with Asperger Syndrome in the general education environment (e.g., copies of notes they provided, or a modified assignment). These methods ensured the researcher had gone deep enough into the research to thoroughly understand the phenomenon as well as to ensure the findings were consistent with data collected and that the audience regards the findings as meaningful and important, as suggested by Merriam (2009).

Ensuring the study has validity, or transferability relies heavily on confirming the participants have truly experienced the phenomenon studied while also ensuring an adequate number of participants so that findings can be stated with a degree of confidence. Teachers from all five of the high schools in the district were included, in order to account for maximum variation in the sample, enhancing the transferability. Finally, the results will include relevant and rich descriptors.

Member checks were completed with two of the participants to ensure that the researcher had not misinterpreted the meaning of what participants reported. Participants Beth and Ann were asked to read Chapter IV and respond to the following questions:

- Does the interpretation of the general education teachers match your experience? If not, please explain. 
- As you read the chapter, what were your reactions? Did anything stand out?

- Are there any other comments/questions/suggestions as it relates to your experiences?

In response to the first question, Beth responded with, "Yes, I believe you have captured what most teachers do and feel about their positions in the classroom and working with Autism". Ann replied, "Yes, I think you captured my experience accurately". Beth also shared that she enjoyed reading the chapter and seeing the many similarities between the teachers who participated in this study. Additional reflection and comments made by these participants will be reviewed in upcoming chapters as they relate to specific findings and conclusions.

\section{Ethical Issues}

As an administrator in the district in which this study was completed, as well as an invested member of the special education departments across the District serving students with Asperger Syndrome, the researcher tried to remain diligently aware of their own biases. Studying the topic of the experience of general education teachers' experiences of having students with Asperger Syndrome in their classrooms as well as their perceptions of the IEP mandated accommodations is of professional interest to me. The researcher chose this topic because I have been a part of several situations in which behaviors and tendencies of individuals on the autism spectrum resulted in either disciplinary situations (because of an event that occurred in the classroom) or frustrated parents because IEP noted accommodations were not implemented in the general 
education class. The researcher is also aware of many students with Asperger Syndrome who are successful in their general education classrooms. The researcher was interested in understanding the experiences, successes, frustrations and needs of the general education teachers, documenting the patterns of needs and recommendations that emerged in this study, in order to better inform IEP teams and general education teachers. The researcher has a vested interest in the applicability and efficacy of any recommendations resulting from this work so I will do my best to ensure reliable results.

Ethics in qualitative research are the responsibility of the researcher, and Merriam (2009) suggests the validity and reliability of a study depend on the ethics of the investigator. The extent to which the researcher upholds rigor in the research is the extent to which it will be respected. While Merriam (2009) refers to these principles as ethics, Patton (2002) describes similar principles as credibility. Patton further suggests there are three elements by which the qualitative researcher should be evaluated: use of rigorous methods that yield high quality data; the credibility of the researcher which is dependent on training, experience, track record and status; and philosophical belief in the value of qualitative inquiry. Patton emphasizes upholding to high standards in the research as a foundation of ethical principles. Patton (2002) provides an "Ethical Issues Checklist" which identifies ten items to be considered when conducting qualitative research. These issues include: the consideration of risk involved for the researcher and participants, confidentiality of research, informed consent, data access and ownership, interviewer mental health, data collection boundaries, and ethical versus legal conduct. Merriam (2009) also concludes that the credibility and ethical behavior of the researcher must exist together in qualitative research studies. 
Adhering to ethical principles is non-negotiable when conducting research with humans. Before beginning the research, the proposal was reviewed and approved by the Institutional Review Board, as well as approved by the District's Administrative Council (comprising of the Superintendent, Associate Superintendents and the five high school principals). In doing so, the Board, the dissertation committee, and the District Administrative Council was assured that the researcher upheld the ethics of research, and maintained the approved format of the study. Ethics involves taking no shortcuts when completing the fieldwork or analyzing data and reporting findings. In doing so, this researcher can stand behind this work, and more importantly, respect the stories of the participants.

\section{Summary}

This phenomenological study explored the awareness and understanding of IEP accommodations implemented in the general education classroom, through the lens of the general education teacher. The semi-structured interview format was used for this qualitative research study. Using practices recommended by Dana et al. (1992), and Merriam (2009), interview questions were developed for the purpose of researching this topic. In order to ensure credibility and validity of the data analysis, data were triangulated using direct classroom observations and collection and analyses of documents and guided journal entries from participating teachers. The results of such analysis will be found in the following chapter. 


\section{CHAPTER IV}

\section{RESULTS, ANALYSIS AND DISCUSSION}

As a collective group the teachers who participated in this study acknowledged the idea that no two students with Asperger Syndrome are alike, yet also have had very similar experiences supporting these students. Through interviews, classroom observations, the collection of artifacts and journaling, teachers' experiences, attitudes and perceptions of teaching high school English to students with Asperger Syndrome in the general education setting were explored. This section will present the results of this research study and provide an analysis and discussion of those results. A context for each teacher's experience will be featured first by providing a brief profile of each participant.

\section{Participant Profiles}

"Beth"- Beth has been teaching for twenty-five years in the district, with fourteen of those years at her current school. She estimates she has had students with Asperger Syndrome or High Functioning Autism in her classes for twenty of those years. Beth holds a Bachelor's Degree in English Education; a Masters Degree in Educational Administration; and a Masters in Reading with the Reading Specialist Endorsement. Beth teaches freshmen and sophomore college preparatory English course and a junior/senior level English elective. When reflecting on her experiences teaching students with Asperger Syndrome in her classes, Beth shared, “They’ve always been 
loaded in my classrooms 'cause I love them, and I guess counselors know that and Special Ed knows that and they're like, Ooh, put them in Beth's room".

"Ann"- Ann has been teaching for thirteen years, at the same school where she currently teaches. Ann holds a Bachelor's in Secondary English Education; a Masters in Language and Literacy; and her Reading Specialist endorsement. Ann is also a Nationally Board Certified Teacher. Ann teaches an accelerated freshman English course; a team-taught remedial freshman English and Reading Course; and a senior English elective. The team-taught course is a double-period course taught by two English teachers, with an emphasis on improving reading and writing skills. In response to the question, how has teaching students with Asperger Syndrome changed you as a person?

Ann reflected:

I think it's made me more patient and understanding. And I already mentioned how it's changed the way I teach as a whole. Just working with kids with special needs, period has changed the way that I structure in my classroom as a whole. I'm still working out that balance, though, because now I feel like I've moved away from such rigid structure to allow a little bit more freedom of time and allow them to take little breaks in their focus, mentally, you know, settle down and reconnect. But then now I have to find a way to move back a little bit in the other direction for the kids who need more of a rigid structure...it's just making me a better teacher.

"Jamie"- Jamie has been teaching for ten years, with four of those years outside

her current school and district. She estimates that she has had students with Asperger Syndrome in her courses for three-to five years of her teaching experiences. Jamie holds a Bachelors Degree in Speech Communication/Dramatic Arts with a Minor in English; a Masters in Interpersonal and Public Communication; and a Masters Degree in Educational Leadership. In addition to teaching in the K-12 education system, Jamie has taught for three years at the post-secondary level. Jamie currently teaches multiple 
sections of freshman level college preparatory English. When asked about the impact of teaching students with Asperger Syndrome on her as a person, Jamie shared, "It's made me much more patient, more calm and actually forced me to think about things a little different".

"Ron"-Ron is the most experienced teacher of the participants of this study, with twenty-six years of teaching at the same school and district. Ron estimates he has had students with Asperger Syndrome in his classes for at least ten of those years. Ron holds a Bachelor's Degree in English and Sports Medicine; a Masters in Educational Administration; and a Masters in Curriculum and Instruction. Ron shared that he took somewhat of an alternative path into education, as he completed the double-bachelors degree in English and Sports Medicine so he could also be an athletic trainer. In addition to being a teacher, Ron has been an athletic trainer at his high school for his entire career. Ron co-teaches (with a special education teacher) remedial level freshman English; college preparatory sophomore English; and Advanced Placement Literature. Reflecting on his career, Ron shared:

...For someone who went into education as a round about way to get into sports medicine, I can't imagine myself doing anything else. You know, and that I'm making my living from teaching is awesome. And, again, 26 years in and you start thinking, "You're coming to the end". I don't know if I want it to end yet. I'm not there. I still love being in the classroom and the 101 level (remedial freshman English) is still my favorite. That's level I think I have the most impact.

"Richard"-Richard has been teaching for a total of 22 years, with 21 of those years at his current school. Richard estimates that he has had students with Asperger Syndrome in his general education courses for seven of those years. Richard holds a Bachelors Degree in English and Secondary Education with a Minor in Chemistry; a Masters in Educational Administration; and a Masters in Curriculum and Instruction. 
Richard teaches all senior-level English electives. When asked to reflect on the impact teaching students with Asperger Syndrome has had on his teaching, Richard replied:

I don't know that I've been changed as much as just, affirmed. You go into this business saying, all kids can learn. You can make a difference with all kids and you're gonna not change the world with every kid, but you can take them from point A, and move them forward on their journey. And so, I think that just the affirmation that you have built a relationship, and you've moved them forward in a positive way as a result of your interactions.

"Payton"-Payton has been teaching for eight years, with seven of those years in her current school and district. Payton teaches at the same school and department as Beth. Payton estimates she has had students with Asperger Syndrome in her classes for each of her eight teaching years. Payton holds a Bachelors in English/Secondary Education with a Minor in Communication; a Masters in Reading and holds her Reading Specialist Endorsement. Payton teaches a remedial sophomore-level reading strategies class; a college preparatory junior level literature class; and a senior English elective. When reflecting on her experiences with having students with Asperger Syndrome in her classes, Payton talked about the importance of the work done on the front end,

Typically, I get about one child per year in one class that has Asperger's....In the very beginning of the year, I find out what he needs or what she needs. I usually talk to the parents before school starts if I'm able to, or at least get some communication with them.

As a group, the participants have a total of 104 years of teaching experience and at a minimum, 58 combined years of having students with Asperger Syndrome in their classrooms. These teachers certainly have thoroughly experienced the phenomenon of having a student with Asperger Syndrome in their classes to be able to speak to the questions and topics that are a part of this study. 


\section{Research Issue and Findings}

This study focused on the perceptions of general education teachers regarding IEP mandated accommodations to be implemented in the general education setting for students with Asperger Syndrome. Limited research currently exists which focuses on secondary teacher attitudes and perceptions of the specialized accommodations needed to successfully support students with Asperger Syndrome in the general education environment.

To begin to understand the perspective from where the participants derive their experiences, we must first turn to Research Question 1, What are the experiences of secondary English teachers who have students with Asperger Syndrome in their classroom?

The teachers who participated in this study did not define or label the unique characteristics often used to describe how Asperger Syndrome may manifest in educational and other settings (Theory of Mind, executive functioning and central coherence). However, through the interviews, artifacts, observations and journals, these characteristics were described and acknowledged by the participants as contributing to the unique needs of students on the Autism spectrum. Common experiences of the participants of this study included: the acknowledgement that students with Asperger Syndrome are unique, in comparison to other students or other students with disabilities; forming a relationship with these students can be challenging, yet is important; the general education teacher's role in the IEP meeting is minimal; and their role as an advocate for the student, as well as teaching the student self-advocacy skills is an 
important component of their experience. The following sections will examine these common experiences in detail.

\section{Uniqueness/Individuality of Students with Asperger Syndrome}

And I think what's so unique about having kids with Asperger's is, everyone is different... so we had this label, and we have all these things we look at, but no two are alike. And you can't handle two kids the same way, because what works for one doesn't work for the other. And that's what I really noticed. (Ron)

Similar to a common saying in the world of autism that goes something like this:

"the only thing that is the same about individuals with autism is that they are all different", each participant noted that this phenomenon contributes to their experiences as a teacher when having a student with Asperger Syndrome in their classes. Most often, this observation was noted when asking teachers if there are particular accommodations they prefer to use with this population. Ann noted “...there's not one accommodation that I would say would say never works or always works. You know, it's really kid by kid". She even went on to state later in the interview, "well, I think there are no cookie cutter Asperger students" This was a common theme among the participants; they are apprehensive to generally state accommodations that work for their students with Asperger Syndrome. Beth responded to this question with "It all depends on the kid".

When asked what she would like to know about a student with Asperger Syndrome before the class starts, Jamie noted, “I guess what their actions are. I don't know how to phrase this. How does it represent within them. Right, because every kid is slightly different". Payton reflected in a similar manner, noting that she would like information "more unique to their habits" when the school year starts so she can plan accordingly to the student's needs. In contrast to the findings in a study by SotoChodiman et. al (2012), the teachers in this current study did not express frustration due 
to the unique characteristics related to supporting students with Asperger Syndrome in their classes. In describing the challenges associated with having a student with Autism Spectrum Disorder in their classes, Soto-Chodiman et. al (2012) summed up the experience from the general education teacher perspective as being "extremely difficult" (p 102). Rather than expressing their frustration, the participants in this study stated upon knowing they will have a student with Asperger Syndrome in one of their classes, they anticipate there will be some unique qualities, and are interested in knowing how the student "presents" so they can plan accordingly.

\section{The Importance of Relationships}

Each participant implied there is no magic formula for connecting with his or her students on the Spectrum. They each acknowledged the challenge, yet emphasized the importance of forming a relationship with this group of students. Beth compared her experiences in teaching students without Asperger's to students with Asperger's: “...it is actually getting through to the kid that is the hardest. It's not preparing any lessons or anything, it's breaking that barrier of them isolating themselves".

Jamie talked about a current student, "John" with whom she has formed a relationship with this year:

One of the students I have right now, he takes a long time to warm up to people. But you know you got him when you get a nickname. And I'm on my third nickname. So I, for me personally right now, that's a huge success because he has a hard time connecting with people. And so now he's connected with me enough to find three little things he likes about me and can create a nickname. Seriously I think that's positive. He's not going to get that far with a lot of people.

A few weeks later Jamie sent me an e-mail describing an interaction she had with this particular student: 
John gave me a high-five today $(-)$. He told me about a piece of info he found in his book and I put my hands up and said "what a banner day!" and while my hand was up he raised his right hand and tapped mine. This was our first high-five $:$.

In most teacher-student interactions, a high-five between a teacher and student is an ordinary and common moment. However, this was not an ordinary or typical interaction that is often experienced between a student with Asperger Syndrome and a teacher, given the disinterest and/or inability to have these reciprocal relationships often present in individuals with autism. Jamie recognized this as a moment in her relationship with John to be important, in that John not only initiated an interaction with Jamie, but also then even took it a step further and engaged in the high-five with her.

"I think greeting them (student with Asperger Syndrome) each day and making that eye contact and trying to reach them at a personal level is so important" (Ron). Ron also discussed the importance of connecting with his students with Asperger Syndrome and the importance of really reaching out directly to those students, even though it can be challenging at times to make those two-way connections.

During the interview, Richard even went on to acknowledge that the importance of developing a relationship with students with Asperger Syndrome specifically might be a common theme in my study. When asked to describe his experiences in having students with Asperger Syndrome in his classes over the years, he replied, "It's all about relationship building for me. So, you probably hear that a lot in your questions". He went on to talk about the challenge, yet importance of building the relationship with this group of students:

I'd say the most effective thing you can do as a teacher, as I told you, I say this a lot, but, is to build that relationship with the student, you know? Is to one, not take things personally, and two, just really talk through what they are currently feeling, needing, understanding, not understanding. And so, just that one-on-one 
conversation, although is the most difficult...that is the most effective one (accommodation).

The impact of teacher-student relationship has been evaluated in more general terms in regards to the effect teacher-student relationship has on student achievement. In a synthesis of over 800 meta-analysis of research related to factors impacting academic achievement, student-teacher relationship was ranked $11^{\text {th }}$ (with an effect size of .72) of 138 factors that had been studied (Hattie, 2009). The effect size of .72 suggests there is a high correlation between a positive teacher-student relationship and student achievement in general. Hattie notes that in classes with person-centered teachers, engagement is improved; there is more respect of self and others; there are fewer behavioral challenges; and there are higher achievement outcomes. Specific to students with IEPs who are in general education classrooms, relationships that students form with teachers are associated with subsequent peer relationships and students' levels of social inclusion (Robertson et. al., 2003). A summary of findings in this study also noted an association between the quality of the relationship with the general education teacher and overall quality of the inclusion experience of the child with Autism Spectrum Disorder in the class. The importance of relationship is evident in the research relative to this topic, but also evident in the experiences of the teachers who participated in this study.

These general teacher beliefs and attitudes are supported by recent research (Park \& Chitiyo, 2011) in which $73 \%$ of the general education teachers included in the study reported a positive attitude surrounding the inclusion of students with autism in general education. Unlike Eman and Farrell's 2009 study, in which they found general education teachers tended to distance themselves from students with autism spectrum disorders, due to the challenge in forming a relationship, the teachers included in this current study have 
acknowledged and embraced the challenge of forming a relationship with these students in order to make them more comfortable and successful in their classes.

Along the lines of forming good relationships, some teachers expressed concerns that not making interpersonal mistakes was as crucial as making connections. Payton noted that she would like to know the things to prevent doing at the start of the school year that might start their relationship off negatively,

...Things they don't like...those types of things, I would definitely appreciate as a teacher just because I would not want to start the year off in a bad situation where I am putting him or her in an uncomfortable situation.

Similarly, Ron spoke of how he is more aware of his own tendencies when he has a student with Asperger Syndrome in a class:

You know, I tend to have a very sarcastic approach, and those kids just don't get it. And, I, you know its really made me aware of how they're perceiving my jokes. Because really, they are jokes. But these kids don't get it. And they're so literal sometime you have to look at what you are doing to get across to them because so much of my humor and how I teach is lost on them.

In order to develop and maintain a relationship with students with Asperger Syndrome, Ron adjusts his interaction style with all students in his class when he has a student with Asperger Syndrome in that particular class.

Based on the research observations, these teachers are purposefully going out of their way to form relationships with students with Asperger Syndrome in order to promote academic and social success. The academic and social successes experienced by the students is not the only benefit of the teacher-student relationships; the teachers expressed the impact these relationships have had on their own teaching and acceptance of all students who come through their classroom doors as well. Throughout the 
interviews, there was a sense that developing relationships with some of the hardest to reach students offered validation to the teachers both personally and professionally.

\section{Involvement in the IEP Process}

"Now, this, this boy that I've worked incredibly hard for had an IEP yesterday and I wasn't invited" (Beth). An overwhelming common experience of the participants is the disconnect between themselves and the IEP process, in spite of wanting to be invited to the IEP table. They often view the purpose of their role in the process is to fulfill a legal requirement and not as a way to give or receive meaningful information about the student.

Ann noted:

...There isn't in the IEP meeting, a lot of opportunity for feedback. I do like when I can talk to the parents about accommodations that are working in my classroom. But most of the time when you get down there, it's, you know, "What's their grade in this class? What are your major concerns? And then I might say, "Hey we've been doing this. This works, it's great", and then I'm out of the meeting and I don't get to hear from the other teachers...you know, the case manager and the social worker, the counselor...all the people who are involved. There isn't a lotta discussion down there.

Not only do the general education teachers perceive the IEP process and decisionmaking as something that happens outside of their involvement, they view the IEP requirement of having a general education teacher present as simply that. A requirement. Ann spoke of going out of her way to ensure she or her teaching partner attend IEP meetings for her students with Asperger Syndrome:

I have been teaching a team-taught class and we have an Asperger's student in there just about every single year. And so my partner in that, we pretty much always... one of the two of us tries to go to that, even if we are not invited... and whenever possible, even if I'm free during the IEP, even if I wasn't invited to it, I do try to go. 
In spite of the 1997 amendment to IDEA, which required teams to have general education teachers present in IEP meetings, the spirit of the law does not appear to be consistently occurring for these teachers. According to IDEA 1997, IEP meetings in which a student is or may participate in general education, a general education teacher must be present. Furthermore, IDEA 1997 delineates the role of the general education teacher to include "the determination of supplementary aids and services, program modifications, and supports for school personnel that will be provided for the child consistent with the IEP content requirements in $\S 300.347(a)(3) ”$. The law also denotes that the general education teacher need not be present at the entire meeting and it is up to the Local Education Agency (LEA) to designate which general education teacher attends the meeting.

While the general education teachers who participated in this study acknowledge that a general education teacher is always included in the IEP meetings, they expressed frustration with their perceived role in the meeting. “...So I don't know that it's (the IEP meeting) the greatest place for feedback" (Ann). When asked about her role in IEP meetings, Jamie noted, “...it’s basically..."Well tell the gen Ed teacher to talk first so they can get back to class." Right?". She went on to describe herself as "pushy" and that she will add different things such as improvement she has seen from one semester to the next. When asked if he is asked to give feedback as to whether or not accommodations are working for his students, Richard replied, "No, usually they're just percentage-type things". Payton reported a similar experience when asked if she is offered to give feedback on accommodations, "um, not really. We're asked to give feedback on how they're doing behaviorally... academically mostly. And then how they 
are doing on their goal that they've stated in the IEP, but nothing about accommodations". Ron was the only participant who has had the experience of being asked to comment on accommodations at IEP meetings, "We can actually comment on their accommodations and do they think they take full advantage of them and do they use the resources".

The combinations of findings from a 1982 research study (Ysseldyke, Algozzine, \& Allen) and the comments from the participating teachers suggest that not much has changed in over thirty years, with the following statement concluding the study of general education teacher involvement in IEP meetings:

It can be concluded that team meetings are being held in which teachers either do not participate. Or do so only in a superficial manner. Team leaders must purposely encourage teacher participation; in particular they should solicit from teachers their recommendations for both placement and intervention. (p. 366)

Strikingly, this study was completed prior to the 1997 mandate that delineated the role of general education teachers in the IEP meeting. Menlove, (1999) reported similar results in the perception and satisfaction of general education teachers in the IEP process. In this study, teachers at the secondary level reported the lowest satisfaction with the IEP process when compared to other grade levels. Additionally, participants in this study were concerned that what they were doing in general education was not being discussed at the IEP meetings. The experiences of the teachers involved in this study suggest similar findings, in that their input in the IEP process is not valued and they are not satisfied with the process as it currently stands. Recommendations on how to improve the role and input of the general education teacher in the IEP meetings and development of the document will be discussed in Chapter V. 


\section{Role of Advocacy}

The teachers in this study spoke of advocacy through two prongs: their role in advocating specifically for students with Asperger Syndrome and their responsibility for helping students become their own advocates. Specifically, many of the teachers spoke of some of the characteristics of students with Asperger Syndrome (such as issues with organization or socialization) and how they have been advocates for the student to prevent frustration or failure and to encourage success. When speaking of one of her students who has had significant difficulty with organization and writing, Beth reflected,

And I keep telling him (Nick) everyday, "You can do this. Don't be afraid. You can do this". ...I don't know if anybody ever treated him the way I treat him. I think everybody has let him sink, you know, and do his own thing because he doesn't talk.... met with (his) mom in the Fall and I told her, I said, "I'm not going to let, going to let him get away with it. He will write. I'll have him writing." And he is.

In her journal entry, Beth reflected "my (first) goal was to get Nick to write a paragraph...we are trying to get him the skills to succeed in junior year English, where he will be required to complete a lengthy research paper". Beth provided three samples of this student's written work from the beginning, middle and end of the school year as part of the artifact collection, and she reflected on a specific accommodation she provided for the journal entry. In her journal entry, Beth noted that all students were provided with an organizer to help them write paragraphs as they were writing the research paper. Beth provided a similar worksheet for Nick, but also included leading questions and broke the broader areas up into smaller parts. She pushed this out to Nick on his iPad, thus other students were not aware that Nick had this specialized accommodation. 
Ann described her experience of going out of her way to be sure the appropriate

accommodations were included in the IEP document as well as teaching students to be

their own advocate:

I have one student who one of the common accommodations is to provide extra copies, have something written somewhere. Well, I have a class website with a Google calendar. We also use Schoology (web-based classroom management system) so everything's posted in Schoology. And now that we have the iPads, everything's pushed out through some app. So I don't even have papers I hand out anymore. The nice thing about that is, if they lose it, there's always another copy. They can always access that information. The bad thing about it is that it requires you to sometimes go to multiple places, and there are a lotta steps, and, and some of my Asperger's students struggle with those multi-step processes. So that has been a little bit of a challenge. I was asked to make sure that everything was written down, and it had to be written. I said, but and it said, "Written on the chalkboard." I said, "Some of the classrooms don't even have chalkboards (laughs) anymore." So it was one of those accommodations that was...it was a little out of date. And I said, "Do I really need to write down everything on the chalkboard, or is it enough that I'm typing it and projecting it? Or that if I have it in the calendar already and I project it at the end of the class period as a reminder it's on the calendar. Or I show where it's on our Schoology page because I feel like if it's written on the chalkboard that students still ... They leave the room, those notes are gone you know, I think it would do more to show them how to find those resources online." To which the resource teacher went, "Yeah, that makes more sense." You know, so the accommodations specifically said, "Write it on the chalkboard every day but then we modified that I said, "I think ... it would be more beneficial for the student to see where it actually is posted for everybody else and how it's posted, so that she could start to learn how to get there herself".

Jamie reflected about a student she had in class several years ago who began the

year by jumping on a table while he was reading aloud a scene from a play:

Well that first person that I talked about (earlier in the interview) who wanted to climb up on the table. I asked him right away if you would be interested in speech team. He started on speech team, by the end of his senior year he was in two out of the three productions for our theater group at our school. And so I thought that was really successful and now he's doing broadcast at (the local community college). So that little thing where he was about to climb up on the table and I didn't freak out about it but actually you know, encouraged him to do more of that just outside of my classroom. (Laughs) Right, kind of became like a little bit of a gateway. And of course it wasn't all me, because he's very talented. But I think pushing him in that direction was a very positive thing. 
Ron reflected on his role as the advocate on his role in implementing accommodations:

Well, that's my responsibility. I know they have an IEP and if I don't read it, that's my fault. If I'm not giving it to them, that's my fault. And you can say all you want, they (the students) should be a self-advocate...so as much as we want to put it on them, it all starts with me...You know, I can encourage them....'If I missed something, please come and see me".

Payton spoke about the responsibility of increased communication with case managers and parents when she has a student with Asperger Syndrome in one of her classes:

...Constant communication with case manager and the parents. It's difficult when it's a mainstream class and especially in the higher-level classes when it's a lot of projects, a lot of writing... where they're kind of on their own. So if I'm not constantly on them, if I'm not constantly communicating with their case manager or their parents, they do tend to lose track of what they're supposed to do.

Richard prefers to talk to students privately and communicate to him or her, "I'm your advocate, not your adversary, and so you tell me what you need... and so, whatever it is, then that's what we'll work with".

A recent focus-group study of elementary through secondary teachers supports these reflections of the importance of self-advocacy (Able, Sreckovic, Schultz, Garwood, \& Sherman 2015). Teachers in this study noted that students with Autism Spectrum Disorder need to be able to point out their own strengths and weaknesses because it can take teachers and peers time to figure out the more individualized traits on their own. This idea of embracing the needs of students with Asperger Syndrome is promising, as much of the literature suggests that general educators do not feel as confident in their ability to support the inclusion of students in their classroom, as compared to special educators (Avramidis, et al., 2000; Buell, et al., 1999; King \& Young, 2003). Perhaps the 
years of experience as both educators and supporting students on the autism spectrum in the general education setting has contributed to this particular groups" "can do" attitude when it comes to advocating for and teaching self-advocacy to students with Asperger Syndrome. It should be noted that the participants do not perceive themselves to be experts, as will be explored in the upcoming research questions findings, discussions and analysis. However, their passion and commitment to these students is evident as they embrace these students in their classroom environments.

In addition to understanding general education teacher experiences, it was relevant in this current study to understand the obstacles Secondary English teachers experience, thus leading to research question two, What obstacles do Secondary English teachers experience in working with students with Asperger Syndrome in the general education classroom?

Research studies focusing on general education teachers who have students with Asperger Syndrome in their general education classrooms have described several challenges the teachers experience when meeting the needs of these students. Among the challenges noted included understanding what their role was in supporting students in the general education classroom (Humphrey \& Lewis, 2008); the challenge of autismspecific behaviors, such as difficulty forming social relationships with peers (Eman \& Farrell, 2009; Soto-Chodiman et al, 2012); and difficulty when students were having problems with self-control or self-regulation in the general education classroom (McGregor \& Campbell, 2001).

Similar to challenges experienced in reviewed literature, the participants of the current study shared obstacles they face in best supporting students with Asperger 
Syndrome in the general education classroom. The participants also described the interferences this group of students presents in order to seamlessly access and experience the general education classroom, specifically related to their Asperger Syndrome diagnosis.

\section{Minimal Information in the IEP Document}

"I just feel like the IEP, excuse my language, is like you're covering your ass" (Payton).

As reviewed in research question one, general education teachers experience a disconnect with the IEP review process itself. Perhaps even more startling is the common theme of what works is often not in the IEP document and the difficulty of reading the document to determine where the information is provided. Ann went as far as to say that she typically does not look at IEPs prior to the start of the school year,

...And that's part of why I don't look at them (IEP) because the IEPs in general are pretty generic... and I just kinda know that. ...I haven't seen a whole lot outside of that that's really specific to the kids.

Ann noted that when she is having difficulty supporting a student with Asperger

Syndrome she then seeks out the student's case manager to get more information,

...So we're getting really generic ones (accommodations) coming in (freshman year). And eventually they (case manager) start to get things like, "Oh, the kid has a stress ball or needs to be able to doodle, or needs to take breaks every ten to fifteen minutes and be allowed to go into this particular app or read this book, or whatever, you know, but that stuff's never written into the IEP. That's the stuff you get when you're talking to the case manager and you're talking to the home. And those are the things that I think have bigger impacts on the kid's performance in the classroom, those really customized accommodations, and you don't ever see them written into the IEP...there's really nothing specific.

Jamie shared that just locating information within the IEP document can be a challenge, "it's just that the IEP plan sometimes are so convoluted that you don't necessarily know where to look for it". She also noted a similar experience to Beth's in 
that she rarely sees information in an IEP document that is specific to the student with Asperger Syndrome, “...they haven’t given me anything that's out of the norm of an IEP in general for a special ed student...things have not been specific to autism. It's the general things you would see in an IEP”. Jamie went on to explain that she would like to be informed of "those accommodations that you want to be warned about, they are harder to do, that are very unique to their own individual needs, to their characteristics and how they present". She also noted sometimes the accommodations are vague in that they are typically a one-line statement, and this can be a challenge to interpret and had a suggestion for improvement: “...like (providing) examples...that it's not limited to a statement...that you have some ideas regarding what this means, like extended time. Sometimes they say double the time and sometimes they just say extended time. And I don't know what that means".

Ron shared that his experiences with the IEP document was varied. He noted "hopefully the information in there (IEP), it's going to start them out on the right path". He too noted that he doesn't usually see accommodations other than preferential seating and extended time for students in their IEP. He often relies on his own experience to overcome the challenge of limited information in the IEP document, "Just knowing they're on the spectrum, I can try strategies and I can approach them like I've done in the past and have success with them".

In regards to challenges experienced with the information provided in the IEP document, Beth also noted the common presence of more generic accommodations such as extended time, "They always given them extended time, and these kids don't need it. It's just like a standard thing that is checked off". She went on to suggest "the classroom 
teachers actually should list the accommodations they make and give them to the next year. I think we would do a whole heck of a lot of good for that".

In contrast to the perspectives of the participants, a 2006 survey of general education teachers' perceptions of the usefulness of IEPS for the general education teachers found that most teachers did report satisfaction with the information provided in the IEP document (Lee-Tarver, 2006). This study did not report the demographics of the categories of disabilities the teachers were referring to when they took the survey, so perhaps this need for specificity is more unique to the IEPs for students with Autism Spectrum Disorders. However, in a 2015 research study targeted specifically at general education teachers who have students with Autism Spectrum Disorder in their general education classrooms, the need to make IEPs more accessible and useful by outlining each students' characteristics and needs with corresponding accommodations needed was suggested by the teachers who participated in the study (Able, et al., 2015).

\section{Challenges with Social and Interaction Skills}

At times, supporting students with Asperger Syndrome in the general education classroom can present unique challenges, due to Asperger/Autism-specific tendencies, such as difficulty connecting and building relationships with their peers. Deficits related to Theory of Mind include grasping social conversations, topic maintenance, and understanding social convention (Sansosti et al., 2010; Smith Myles \& Simpson, 2002a). These noted deficits might assist in explaining why students with Asperger Syndrome have difficulty integrating socially and when interaction is required in class activities. Not only have these teachers acknowledged the challenges these students experience, 
they are committed to helping these students be successful in group activities, as noted in experiences shared by the participants

In regards to challenges with connecting with peers and building peer

relationships, each of the six participants noted this might be a challenge when supporting

students with Asperger Syndrome in their classes, particularly with group work:

Grouping is probably the most difficult, just because socialization is not always easy. Friends don't always come easy. Sometimes just un-comfortableness from the student with Asperger's, and then some un-comfortableness with the other students. So, grouping kids where, sometimes as a teacher you might just say, "Pick a partner." It's not very easy to that all the time, so that sort of thing has to be more thoughtful, as an instructor, when you have a student with Asperger's. (Richard)

When completing the classroom observation in Richard's class, upon walking into the classroom Richard explained to me that they would be doing peer work that day (in pairs) and he specifically assigned the student with Asperger Syndrome to work with a "real good kid". In his journal response in which Richard described implementing the accommodation of grouping for the student with Asperger Syndrome, Richard wrote:

Joe struggles with friends, communication and emotional control. I created Joe's group to be smaller than the others and placed him with very kind and patient students who are good listeners. He sits close to the door, as when he gets frustrated he can hit his desk or his forehead repeatedly with his hand. I keep his group near the door. This makes it easy to ask Joe to step outside for a brief chat with me, should it be necessary, and it prevents him from being paraded out of the room in front of the rest of the class.

Similarly, Ron pre-grouped students the day I observed in his classroom, not only assigning students who he knew would work well with the student with Asperger Syndrome, he also physically placed that group in a location in which the student would not feel "closed in", as shared by Ron immediately following the observation. Payton 
described a similar challenge when thinking about group activities and her students with Asperger Syndrome:

...They don't like working in groups. And we try to work in groups throughout the year, and it's a huge struggle...to work with people who are different, not their friends. And I know that's one of their biggest struggles. So in general, I think, by the end of the year, if the class is respecting the child and vice versa, I think that is the biggest achievement there because, whatever they're going to do in life, it going to have to be in a group.

Jamie spoke of the importance of the tone she sets in the classroom when having a student with Asperger Syndrome in one of her classes, “...I like to create a very positive classroom atmosphere. And so one thing that could be a challenge for a lot of these students is the reaction of the students around them. But for the most part, I've been really able to dampen that". The theme of the participants not only acknowledging the challenges these students face in social interactions and group work and then initiating supportive accommodations is encouraging because they are providing students with Asperger Syndrome a supportive place to practice engaging in these essential skills for life.

\section{Challenges with Self-Regulation}

Characteristics associated specifically for students with Autism Spectrum Disorder include challenges with self-regulation/self-control, which can pose additional obstacles for the general education teacher and the students' peers. The participants in this study observed these challenges both generally, and specifically with technology related to the district's 1:1 iPad initiative. Soto-Chodiman et al. (2012) suggested that problematic behaviors (such as poor self-control and inflexible thinking) that interfere with class participation had an impact on the general education teachers' perceptions of success for students with Asperger Syndrome in the general education environment. 
Likewise, these more overt behaviors on the part of the students with Asperger Syndrome were perceived to be obstacles to successful participation in general education by the participants in this study.

Most of the participants commented on the challenges they have observed with the distraction of the district iPad initiative, in its first full year of implementation. While many of the participants noted that there have been challenges with distraction that exist beyond students with Asperger Syndrome, several participants experienced additional challenges specific to students with Asperger Syndrome. Payton described her observations specifically related to students with Asperger Syndrome:

...Both my students who have Asperger's have a very difficult time with time management with the iPad. And just like being appropriate with what they're doing on the iPad whether it's staying away from games, whether it's staying on the same app, following along, like look at the screen when I'm working or looking at their own. So I don't necessarily think the iPad has helped the two children I've worked with.

When asked to describe accommodations that she finds to be less effective, Payton brought up the iPad as an example:

...I think the iPad actually hinders a lot...I feel like we need to put more restraints on the iPad, so it's more focused, because right now, he can access anything at this point. Again, that self-control isn't there. So I feel that it takes away from what he or she needs.

Richard described a situation in which he noticed his perceived interference of the

iPad from the teacher's perspective and spoke with the student about it:

...I have one Asperger's student who is really on the iPad constantly. (He) does his work, but I talked to him about that, because I don't want to treat him differently, and part of that is, and whether he is smart enough to just tell me this, or not, but he said it helps soothe him...it calms him down, which is true about him. He's easily frustrated. He's quick to act out and it helps him, it soothes him. So he tells me and I believe that, and so we've just worked out a deal, not worked it out, not like we were bartering, but you know we've talked about my expectations versus his. And so, when we're doing group work in particular, 
when he absolutely has to make sure he is listening and participating in small groups, that iPad can't be out....but if it's more of an independent exercise, and he gets done with it, and that sort of thing, then I will look the other way, so to speak, it that helps him, you know, maintain his composure throughout the class.

When asked if this information about the iPad was included in the IEP document, Richard responded,

No, it is not. It's not in his IEP at all. But, and of course when I mentioned it, he got really angry. He's quick to anger because he thought I was gonna call home right away...I think some of that social cues about when someone's trying to help you, not just necessarily correct you is not easily interpreted all the time.

Had this information been shared with Richard, he may have been able to be proactive in setting up a plan with this student in regards to what would be acceptable in his classroom with when he could and could not be on his iPad.

Jamie described an observation in which the iPad was a tool to help a student with Asperger Syndrome maintain focus, while with another student with Asperger Syndrome, the iPad was a distraction:

...Some kids need the stimulation... so one of the boys will turn on a game and he has completed the assignment and he's totally fine with me and he is completely listening to me and he's totally fine with me, but he's also doing this (gestured focusing on the iPad). But he can hold a complete conversation with me while he does this. And so for him, I'm ok with him using that. The other boy in the class gets so into the game that he wouldn't even know that I was near him unless I put my hand in front of his face. So it, it's different just like your regular ed students, it's different for each kid. I don't mind when this kids uses it because it's actually, I guess an accommodation so that he will listen or can listen, because his hands are busy. But for the other boy, his mind is busy already and so he has to put his (iPad) away.

In addition to the iPad being a source of difficulty with self-regulation for some students, participants described other situations in which a student with Asperger Syndrome's ability to self-regulate are, at times, an obstacle for the teacher, the student with Asperger Syndrome and/or his or her general education peers. In describing one of 
her first experiences with a student with Asperger Syndrome who had particular difficulty with self-regulation/self-control, Jamie shared:

...The first student I had at our high school volunteered to read every single time. We read out loud, and he actually took it upon himself to start acting out a scene. I actually had to ask him, "oh, oh, we're gonna sit down for this one". Because he started to climb up on top of the table and so he's about to get up on his desk and I just had to bring him back a little bit. ...It's things like that where there are outbursts, but they're normally related to something we are doing in school. They just don't necessarily know that it's not okay to take that step beyond...they just socially don't know that the next step is not okay.

A few of the other participants brought up terms such as "outbursts", "tics" and "class disruptions" to describe these challenges with self-regulation or self-control in the general education setting, which at times, can be distracting to the student himself as well as peers in the classroom. Participants noted these are typically short in nature, and sometimes students will have a teacher assistant to either help them maintain focus or take them into the hallway for a short break.

Over the course of this study and through the process of analyzing and reviewing the experiences of the participants, the results, analysis and discussion for Research Question 3 and Research Question 4 lead in a different direction than anticipated when the study was designed. As a reminder, Research Questions 3 and 4 are as follows: (3) What are the perceptions of Secondary English teachers of the accommodations for students with Asperger Syndrome in the general education classroom; (3a) What accommodations are teachers using in the general education classroom, and from where do they derive these (IEP, experience, etc.)? And (4) how effective do the Secondary English teachers perceive the accommodations are for their students with Asperger Syndrome? 
To begin this discussion, it may be helpful to take a glimpse into a portion of the interview with Beth:

Researcher: So in other words, you're saying, the accommodations that are actually put in place aren't necessarily what's in the IEP?

Beth: Definitely. Yeah. I kind of do my own thing, I figure out whatever's going to make that kid successful. And of course, if they need extended time, I give them the accommodations that they're eligible for, but I also do other stuff.

Overwhelmingly, as reviewed in the previous section, the participants perceive the accommodations provided in the IEP document to be very general, and most often lacking specificity to the student with Asperger Syndrome. With that, the short answer to Research Question 3 is that the general education teachers perceive the accommodations to be too general in nature, and sometimes actually limiting to students. To answer these research questions, it may be helpful to discuss Research Questions 3 and 4, followed by Research Question 3a, as the participants do not find the IEP denoted accommodations to be specific enough for students on the autism spectrum and are most often implementing accommodations that are not derived from the IEP document. The analysis of Research Questions 3 and 4 will be framed with the IEP document in mind, while the analysis of Research Question 3a will focus on the accommodations that the participants are using and from where those are derived, as the majority of the accommodations are not from the IEP itself.

\section{Perception of IEP Denoted Accommodations}

When asked the interview question, "Thinking about these students, can you describe or list some of the accommodations that were to be implemented in your classroom as part of these students' IEPs?" the responses from the participants were as follows: 
Beth: "They always give them extended time"

Ann: ...IEPs are generally pretty generic...it's you know, extra time, preferential seating, extra copies of things.

Jamie: "Extended time. It's weird because they seem very sparse...they just don't really match how the kid presents".

Ron: "(Nothing) beyond the seating, the small setting for test taking and for homework..."

Richard: "Mostly it's (extended) time".

Payton: "Um, not really. I feel, like every year, its just...Yeah".

Without exception, each of the six participants who were a part of this study had very similar responses to this question. Perhaps the participants would have had different responses had they been provided a printed list of IEP accommodations they might have seen on IEP documents. Four of the six participants noted extended time as an accommodation they had seen on IEPs. Their perception of the extended time accommodation was similar. Richard shared that he provides the extended time option to all of his students, with or without an IEP. Beth reported that in her observation, “.... lot of these kids don't need it, it's just like a standard thing that is checked off'. Beth also shared that she will give any student extended time if they need it to complete tests or assignments, as long as they talk to her about it beforehand.

While none of the participants offered the support of a one-to-one teaching assistant (TA) as an IEP accommodation, that support was either brought up by each of the participants at some point during their interview or it was brought up by the researcher if the participant did not share their experience with teacher assistants. Richard was the only participant who has not had the experience of having a student requiring a one-to-one TA in any of his classes. The perception of the accommodation of 
the teacher assistant was mixed. Beth shared varied experiences with the teacher assistants (provided by the Special Education Department) in her years of teaching. She spoke of one TA who spent more time on her laptop than being attentive to the needs of the students. Beth described another experience in which she described the teacher assistant as "being the eyes when I'm working with others", and that this particular TA would initiate what needed to be done with the student to support the student without disrupting the flow of the class. Jamie shared a situation in which the student did not like to be singled out by the teacher assistant, so "... and then (he) kind of gently eases himself toward these students (with Asperger's) to make sure they are on track or, where they're at and then he can alert me if there is something exceedingly wrong". Jamie also described a situation in which a student was upset about a video he had seen in another class and came into her class very disregulated:

...And the TA was there before I was, so he was able to handle the situation, which I don't even know what I would have done. The TA was great and just took him for a walk...but if there was no one there with me, I don't know how I would've been able to give that kid the time he needed to process what had just happened.

Ann shared that she values the TA to assist her in knowing what works for the student in other classes. She values the importance of working closely with the TA, “...I think if we weren't working together, then these kids would, it would be a lot harder for them". Ann has had mixed experiences with her opinion of the necessity of the one-toone TA for some students:

...Of the two students I have right now, one of them I don't think needs a TA at all, at least not in my class. From what I understand she needs a TA more in other classes, but I almost don't want the TA in there because I think now she's (the student) just sort of sitting back and going, "Well, she'll (the TA) do that", you know?....and so she's not doing all that she is capable of. The other one absolutely needs a TA. We would be lost without him. And I don't' think that this kid 
would be able to be mainstreamed if he didn't have a TA... so it's really important to his success in the classroom that he have that TA.

Ron also spoke of the importance of communicating with the TA when a student has been provided with that support:

Your TA's aren't going to be effective for you or the student unless they know what's going on. You have to share that information with your TA. They are professionals, they have degrees...but just to say, "He's on the spectrum. Watch him," What does that mean? You know? You've gotta talk to them and you've gotta make your TA understand the issues and what's expected of them. "I'd like you to redirect them by...touching the desk in front of them, or touching their hand," Or, whatever that might be. You have to communicate to them. Because if you're not, that TA is not going to be effective at all and the student isn't going to benefit.

Finally, Payton remarked, "I definitely see the benefit in how they progress throughout the year versus just a regular kid. So I definitely think the one-to-one adult is helpful".

During the classroom observations for this study, three of the students had a oneto-one teaching assistant assigned to them during the observed class period. One additional student typically has a one-to-one in that class with him, but the assistant was absent that day and a substitute was not provided. One student in particular required nearly all directives that the teacher had provided to the entire class to be repeated by the TA. It also appeared that the TA was helping the student stay focused and on task. The observations noted during these class periods validate the insights provided by the participants during the interviews.

Little research has focused on the general educator's perception of their observations and opinions of the role of the teacher assistant, particularly related to supporting students with Autism Spectrum Disorder. A 2010 qualitative case study suggested a key factor to general education teachers and teacher assistants effectively working together in the general education classroom is collaboration (Devecchi \& 
Rouse), which in turn, is beneficial to both the adults and the children they support.

Other factors that support effective use of the teacher assistant in supporting students with Autism in the general education setting include access to expertise, which may include colleagues, outside agencies and training (Symes \& Humphrey, 2011).

The participants were also asked to speak to the ease of implementation of IEPdenoted accommodations as a general education teacher. Rather than answering this question, they more often spoke of accommodations that might be or are more difficult to implement. Beth offered that creating alternative assignments would be "very difficult". Along this theme of classroom work, Payton noted that it can be a challenge to support a student who requires a considerable amount of communication with the case manager and possibly the parents on larger assignments:

... So right now, we're doing a project. And I know this kid needs extra time and he needs extra help. So it is very difficult managing a class of 30 of every type of kid and this one child who I need to constantly check in with their case manager if they're doing it in resource. I need to check in with his parents. I need to check in with him. And it's a lot of pulling in different places, and I can't be everywhere at once.

Ron and Richard reflected on accommodations that might require adult support outside of the classroom when they are the only adult present in the class and are responsible for maintaining the flow of instruction. Richard spoke to the accommodation of a student needing to go into the hallway for a few minutes to relax to be "....more challenging, because it takes you (the teacher) away from your instruction and your plan as you're trying to manage this time in the class". Ron had similar perceptions of implementing the accommodation of a student needing to leave the classroom as a difficult to implement accommodation, 
...If I couldn't step out of the room and read to a student...because there's no one to sit with him, I can't leave my big class... So I think that's the most frustrating part is when you have a student in a not in a co-taught class where you have to figure out how to make it work.

It appears as though accommodations that may require extended time on the part of the general education teacher or teacher supports without resources (such as a teacher assistant or co-teacher) are perceived as accommodations that might be more difficult to implement from the perspective of the general education teacher. Or perhaps, as found in studies regarding teacher attitude towards inclusion, the general educators may not feel as confident as special educators in their ability to adapt materials and give individual assistance (Avramidis, et al., 2000; Buell, et al., 1999; King \& Young, 2003).

\section{Non-IEP Denoted Accommodations}

If the general education teachers who participated in this study do not rely on the IEP to guide the accommodations provided, one must ask the question, how are they supporting these students in their general education classrooms? As alluded to previously, time and time again the participants mentioned accommodations they are initiating or seeking out through other resources to put in place for students. Consistently during the interview process the participants mentioned the accommodations of visual supports, increased structure, sensory supports, and additional communication with parents.

Beth talked about a student, Nick, who was having significant difficulty with writing, to the extent that he was not producing any writing:

...I have created countless number of different kinds of pictorial worksheets... so to organize a paper, it would be different shapes for different areas of the paper. I would make boxes and I would tell him exactly what needs to be in each box. 
She provided visual supports or a visual map in order for this student to be able to organize his writing. Beth gave me a copy of the visual task organizer she provided this particular student with the day of the classroom observation. The default assignment for the class was to write a three paragraph essay comparing the setting, themes and characters of two books they had recently finished reading. Beth e-mailed Nick a stepby-step visual guide with prompts for each sentence he needed to write to complete this essay. Following the observation in an e-mail exchange between myself and Beth, she confirmed that this accommodation was not in Nick's IEP, but she has found this to be very effective in helping Nick increase the breadth and depth of his written production.

Like Beth, Jamie shared that she often breaks large papers into chunks for her students with Asperger Syndrome. She shared that proactively she will provide examples and give students their tasks in smaller chunks, rather than the larger global assignment she might give the rest of the class. Jamie also shared that she checks in more frequently with these students during the writing process to be sure they are on track.

Ann also shared the experience of providing students with additional structure and visuals when having students with Asperger Syndrome in her class:

...I do notice that I'm a little bit more organized in the classes where I have students with Asperger's because I have to be. And that means, when I say organized, that means I'm going into class and the assignment is already posted on our class calendar. It's already posted online and I'm sitting in class and I'm typing notes the kids can see as I'm talking; whereas, a lot of time I'm sort of like a free-spirited teacher, (laughs) you know, fly by the seat of your pants... you know, on the fly changing my lesson plans a million times. But I can't do that quite as much in the classes with the Asperger's kids because I feel like I need to have more structure in my delivery.

Likewise, Ron noted the additional support of structure can be very helpful on longer writing assignments with this population: 
...We use a graphic organizer, it works out really well. And nothing is more satisfying then having someone who struggled with a good topic sentence and finding evidence in a story to put it all together, to write a good paragraph. And we have more success with that than I think a lot of people would expect us to have. And I think that's really the neatest part is when it finally clicks with them. Cuz once it does with an Asperger's kid, it sticks with them.

Richard shared that he tries to provide "something visual" when having students with Asperger Syndrome in his classes. He also shared that he has found breaking larger assignments into smaller steps to be an important accommodation to put in place for students with Asperger Syndrome.

Payton has found providing detailed information about assignments and expectations on the board has been helpful:

One thing I started doing when I had that one-to-one child a few years back, I put everything that we're doing on the board and, here's the goal, here's where we need to go. This is what you're turning in, or this is what's due tomorrow... if they wander, if they are working in groups and they forget, or they need prompting... it's right there. So if it's not me telling them, at least something in the room is telling them what they need to do.

Challenges with sensory regulation/self-control have been observed by several of the participants in this study, yet the teachers reported they often do not see these accommodations in the IEP process. As noted earlier, Ann rarely sees sensory items or breaks (such as using a stress ball or taking a short break within class) written into the IEP document, but those are the accommodations in her observations that have the biggest impact on students. In her journal entry, Jamie described an accommodation she put in place when she noticed the student was upset about a burning smell "permeating the class". Jamie described the process:

He fixated on the smell and continued to mutter about it under is breath (I was sitting next to him on purpose). The accommodation I often make is to ask if he needs to take a walk or get a drink so he can refocus. He normally tells me no that he will be ok, but on this day he said, "Yes, I think that will help. I just can't 
focus" so he left and came back and with only a few minutes in between and said he felt much better.

Ron related accommodations he might put in place for students with Asperger

Syndrome who have difficulty taking tests in larger environments due to their own ability

to deal with the environment,

I think for a lot of kids (with Asperger Syndrome) focusing is so difficult for them...the small setting for test taking I think is important...they just need some place where they can come in and just zone in their own spot and take their time. And I think you have to pay attention to that...you leave them in a big room, they're so easily distracted. Someone's coughing, someone's rustling their paper. Someone's tapping their pencil. So we try to keep it very focused and quiet. And I think that goes a long way in helping them have success.

Finally, most of the participants noted the importance of parent contact when they have a student with Asperger Syndrome in their class. Again, this is not an accommodation or support denoted in the IEP, but several of the participants commented on the home-school communication being an important link for the student having success in the general education class. While Ann noted that the IEP meetings are not necessarily the best medium, based on her experiences for sharing information about students, she noted, "I do like when I can talk to the parents about accommodations that were working in my classroom". Ann also noted she likes to attend IEP meetings to connect with parents when the student is doing really well or is struggling:

...If I've been trying to reach home and I've talked to the parents, it seemed like, “Okay, okay, okay. Yeah, we'll do this.." but we're not seeing changes, and I like to go down there and be able to meet them face-to-face... it makes a difference and I can follow up. Or if it's a kid who I've seen a lotta progress from, but I know is struggling elsewhere, I sometimes just go down there and say, "You know what? He's not doing everything wrong...this kid's been doing an awesome job on this"...so when I attend IEP meetings it is frequently because I either want to make sure that this kid's growth has been celebrated. Or it's a kid we've had a real difficult time connecting with and I want to meet the parents face-to-face and see what's going on. 
Payton noted that when she finds out she will have a student with Asperger Syndrome she tries to contact the parent before the school year starts. She usually sends them an e-mail and then often sends assignments and other class pertinent information that she would typically only share with students to the parents of the student with Asperger Syndrome. Because the IEP often lacks the specific information about the student, Payton shared "you have to have constant communication with the parents...otherwise the IEP are just words".

Likewise, Ron reaches out to parents early in the school year:

I think calling home and talking to the parents is very important...and one of the strategies I like to do is say, "Hey I have your son in class, and I just wanted to say hi". And this was before the (district) open house. And even though we have open house early I think it is so important to touch base and say, "If you need anything, I'm a resource." And I think reaching out goes along way in helping them feel comfortable for their child, and also they can say, "Hey, go talk to Mr. X."

The shortage of information in the IEP document has not stifled this group of teachers from implementing accommodations for their students with Asperger Syndrome in these general education English classes. Their understanding of the unique needs of students with Asperger Syndrome is apparent, as the teacher-directed accommodations appear to be effective and in alignment with needs specific to the individual student.

\section{Effectiveness of Accommodations}

Going into this study, it was expected that the participants would provide a list of accommodations they have noted to be included in the IEP documents for students with Asperger Syndrome and then share their perceptions of the accommodations and how effective they perceive them to be for the students. This researcher was not expecting that the overwhelming response from the teachers that the IEP accommodations they 
have observed are not tailored to the students with Asperger Syndrome and through their experience as teachers, they have determined and have implemented teacher-determined accommodations on their own. The participants did speak to the accommodations of preferential seating and extended time, which are common IEP denoted accommodations for many students, not just students with Asperger Syndrome, as pointed out by several of the participants. And while the participants noted the lack of specificity in regards to what these more general accommodations actually mean for a particular student, they described tailoring these accommodations to meet the specific needs of the student with Asperger Syndrome.

In regards to preferential seating, several participants spoke of intentionally seating students in the vicinity of peer role models both in general classroom seating and when grouping students for class activities:

...he will sit in a group and...he listens really well. The kids are accepting of how he is and if he's writing down something, somebody might look over his shoulder and go, "Hey, that's a great answer." So I always put him with positive kids. (Beth)

In her journal entry when describing a group activity from the lesson in which she was reflecting on providing an accommodation for a student with Asperger Syndrome, Jamie wrote, "any time we do group work, I manipulate the groups and the location in the room". Jamie determined this accommodation on her own, as she noted, "it is noted that he has calming behaviors like pacing so I just adjusted it so he could pace to a location instead of the middle of the room (by seating him on the periphery of the room)". Jamie also indicated that "he came back ready to watch and listen to other presentations" in regards to the impact of the accommodation, and that she will continue to use this accommodation in the future to help the student focus. 
In his journal entry, Richard reflected on a student whom has the general accommodation of preferential seating denoted on his IEP, but the IEP document did not specifically state what that meant for this particular student, Brian. In his reflection, Richard elaborated how he has determined how and why that best meets the needs of this student:

Brian struggles with friends, communication and emotional control. I created Brian's group to be smaller than the others, and I placed him with very kind and patient students who are good listeners. He sits close to the door, as when he gets frustrated he can hit his desk or his forehead repeatedly with his hand. I kept his group near the door. This makes it easy to just ask Brian to step outside for a brief chat with me, should it be necessary, and it prevents him from being paraded out of the room in front of the rest of the class.

Richard also noted that he found this accommodation to be appropriate and beneficial to his student, Brian.

The purposeful grouping, as described in a similar study to the current one was also noted by teachers at the high school level to be an important accommodation for students with Autism Spectrum Disorder (Able, et al., 2014). It seems as though the accommodation of preferential seating is effective, as described by the participants, when they take the time to understand what that means to the specific student and tailor it to his or her individual needs. Three of the participants in this study noted (in a side conversation at the time of the classroom observation) that they had purposefully grouped students for the group activity they were completing that day. Each teacher shared that they wanted be sure the student with Asperger Syndrome was placed with a group of students who would work well with him or her.

With regards to the accommodation of extended time, perhaps the lack of discussion and minimal acknowledgement of its existence as an accommodation 
suggests, at best, neutrality towards the perception of the effectiveness of this accommodation. Or perhaps, as reported by most of the participants, they provide extended time for tests for any student who might require it; therefore it is not perceived of as something special or unique for students with Asperger Syndrome. Beth was the only participant who reported not even observing extended time as necessary for most of her students on the spectrum but acknowledged it might be denoted on the IEP for the purpose of college entrance testing:

...I would say $95 \%$ of the autistic kids that I have had do not need extra time on tests. But it's there and it's helpful. Like particularly where it's going to come in helpful is if they keep it on the IEP, then for ACT testing they've got that.

Ron described a conversation he has had with a student about using the extended time accommodation and why he does not always find this accommodation to be effective:

...I think they (accommodations) become ineffective when the accommodations don't get used. Whether that's not necessarily from me but when you have a student who rushes through an assignment or quiz who doesn't take that extended time. (Ron) "Hey, you get a couple of extra days to work on this, do you want it", (Student) "No, I'll just turn it in." (Ron) "Don't you want to take another look at it?". Because you can tell just by what they hand into you that it's not gonna fly. (Student) "No, I'm good." That's when it becomes frustrating is when they don't take advantage of it on their end.

\section{How Accommodations are Derived}

Before delving into how accommodations are derived by the general education teacher, it may be helpful to first review the participants' perception of who is responsible for implementing accommodations. When asked, each participant noted that they are the one responsible for implementing the accommodations delivered in the general education classroom. This ownership is in contrast to findings of a qualitative study of secondary history teachers (van Hover \& Yeager, 2003) who expressed 
frustration with the expectation that they should be responsible for accommodating students with disabilities. Not one participant in the current study expressed frustration in regards to their responsibility of implementing the accommodations. If any frustration was noted, it was related to the lack of student-specific information in the IEP document. To illustrate the participants' recognition that it is their responsibility, Table 5 provides their responses to the question, "Who is responsible for implementing the accommodations?"

Table 5

Responsibility for Implementing IEP Accommodations

\begin{tabular}{|ll|}
\hline Participant & $\begin{array}{l}\text { Response to "Who is responsible for implementing the } \\
\text { accommodations" }\end{array}$ \\
\hline Beth & $\begin{array}{l}\text { "Every teacher, every person who has contact with the student" } \\
\text { Ann }\end{array}$ \\
& $\begin{array}{l}\text { "Everybody. I'm responsible; obviously...it's the responsibility of the } \\
\text { parties within the classroom. The resource teacher's not there to make } \\
\text { sure that's getting all those accommodations, so I have to } \\
\text { make sure that I'm giving the students what they need" }\end{array}$ \\
Jamie & $\begin{array}{l}\text { "I guess it's me in my classroom" } \\
\text { Ron }\end{array}$ \\
$\begin{array}{l}\text { "Well that's my responsibility...if I know they have an IEP and I } \\
\text { don't read it, that's my fault. If I'm not giving it to them, that's my } \\
\text { fault" }\end{array}$ \\
Richard & $\begin{array}{l}\text { "Teacher, of course" } \\
\text { Payton }\end{array}$ \\
\hline
\end{tabular}

As noted previously, several of the teachers also spoke of the importance of taking the implementation of who is responsible for the accommodations at step further and noted that it is important for the student to develop the skill of self-advocacy, particularly when it comes to requesting accommodations such as extended time.

When speaking to where the accommodations the participants have been implementing are derived, their responses extended well beyond the resource of the IEP document it self. Table 6 provides a frequency count of the participant's responses 
(through the interviews, observations and journals) in regards from where IEP accommodations they implemented were derived:

Table 6

How Accommodations are Determined

\begin{tabular}{|ll|}
\hline How Determined & $\begin{array}{l}\text { Frequency of All } \\
\text { Participants' Responses }\end{array}$ \\
\hline IEP & 26 \\
Special Education Teachers & 13 \\
Determined by participant with no input from others & 30 \\
Internet Research & 3 \\
Other teachers (department colleagues, etc.) & 7 \\
\hline
\end{tabular}

Participants were asked to respond to this question directly through the interview question, "What resources do you feel you have access to that helps you teach students with Asperger Syndrome in your classroom"; in the journal questions, "what prompted you to implement these accommodations during the lesson" and "were these accommodations part of the student's IEP'. Participants offered from where they derived accommodations throughout the interviews as part of the discussion as well. When reviewing the responses as a whole, teachers are relying slightly more often on resources outside of special education (self-determined $[n=30]$, internet $[n=3]$, or other teachers $[n=7]$; total $\mathrm{n}=40$ instances) than resources within special education, such as the IEP $(n=26)$ or consulting the special education case manager $(n=13)$, for a total of 39 instances. This does support the participants' perception that they are responsible for implementing the accommodations for these students, and have taken the responsibility a step further in that they are seeking out resources that extend beyond the IEP document 
and special education teachers or the student's special education case manager.

Unfortunately, it also suggests the perception that the general education teachers feel they are responsible for seeking out the special education teachers, rather than vice versa. Some participants did note that while they believe the special education teachers are responsive when they do reach out, they would feel more supported if the special education teacher would be able to spend time in their classroom on occasion and provide feedback specific to a student who is struggling.

Two of the final pre-determined questions in the participant interviews for this study were, "What resources do you feel you are lacking to help you teach students with Asperger Syndrome in your classroom?" and "What suggestions do you have to make it easier as the classroom teacher to implement accommodations?" These two questions in part provide insight into Research Question 5, What resources do Secondary English teacher require to understand and support the needs of students with Asperger Syndrome in the general education classroom?

\section{Experience}

"You learn to work with people by working with people" (Ann). As an introduction to answering this question, it may be helpful to describe one of the most important resources these participants believe they bring to their classrooms each day: their prior experience in working with students with Asperger Syndrome. In speaking to the impact experience has when working with these students, Jamie reflected:

...If this was ten years ago, I wouldn't be able to do that (support a student with Asperger Syndrome); I wouldn't know how to do that. But because I've had a few kids along the way help me for this student to understand where I needed to go and tend to get something positive instead of something negative. 
Payton also spoke to the role experience as a teacher in general as well as having had additional adult support in her classroom have played in helping her be more prepared to work with students with Asperger Syndrome:

I definitely think it's a lot to put on a teacher with no experience... when I first started I had a one-to-one (teacher assistant for a student with Asperger Syndrome). So I think I was very fortunate to have somebody else to help me out... and as I got more familiar with what I was doing in the classroom, it got easier with identifying what that particular kid needed. But I definitely see, at least, for any younger teacher coming in, if they don't have that one-to-one, if they don't have that additional help, it is extremely difficult to keep that kid on track and make sure that he doesn't fail in areas that he might have before.

Ron also spoke to the impact of experience as a teacher as well as supporting

students on the spectrum:

...I do think that a lot of success I've had does come with trial and error and experience and what works for me may not work for you or worked for one student doesn't work for the other. But it's just having that experience and trying this, and it didn't work. Let me try tomorrow. And I don't think the frustration level on my part is as high as maybe it was 15, 20 years ago.

For Ron, experienced coupled with time has been important in his ability to support students with Asperger Syndrome. In spite of the fact that he probably has more students with autism in his classrooms (given the increased incidence of autism), the value of experience has outweighed the burden of numbers.

Beth spoke to the empathy she has for new teachers who do not have these experiences:

...If I were a new teacher, I would be lacking knowledge and help. And I know Special Ed teacher, they've got loads and mounts and different sections in one class. I know that they have tons and tons of stuff to do. But at the same time, if I'm walking in (new), I need help. I need help from somebody who knows.

A 2012 (Wiggins) dissertation study surveyed teachers regarding their attitudes toward inclusion. The results of this quantitative study did not find statistically 
significant differences related to years of experience and teacher attitude toward inclusion. This study was targeted across disability categories, as opposed to specifically targeting general education teachers who support students with Asperger Syndrome in their classroom. As a special educator with over twenty years of experience, it is hard for me to refute the value of experience, particularly when working with students on the Autism Spectrum. As discussed in earlier findings, the participants of this study acknowledge that students on the spectrum are not alike and often require individualized accommodations defined to the uniqueness of the student. Not only did the participants provide examples of times when their experiences with teaching students with Asperger Syndrome assisted them in putting supports in place, they explicitly stated it in the interviews.

Aside from the benefit of experience not only as a teacher, but also in having students with Asperger Syndrome in their classroom, the teachers also spoke to other resources and supports that would assist them in better meeting the needs of students with Asperger Syndrome in their classes. The two supports that were most often mentioned and referred to were those of human resources (such as increased contact with the special education teacher) and more specific information regarding the students' needs prior to having them in class. These two recommendations almost go hand in hand, as one would expect that during that face to face time, the general education and special education teacher would be communicating about the student's more individualized needs and how to support them in the general education classroom. 


\section{Support from Special Education}

Ann noted that the resource of the special education teacher has been invaluable

her ability to support this population:

...It would be ideal to have resource teacher who had more free periods and could go into the rooms and see how these kids are functioning and work more one on one with those teachers. Especially teachers who are in their first few years of teaching or are getting those kinds of students for the first time. Maybe they've been teaching for ten years, but they've never had a student like that in their classroom. They really need that. I think that's why I'm more comfortable working with these students because I ended up having that. It was horrible at first, you know, they just couldn't function and I didn't know how to work with them. And I luckily ended up having some good people in our Special Ed Department who sorta talked me off the ledge and, you know, gave me tips.

Likewise, Beth noted that, “...talking to people who deal with these kinds of students all day long" would be beneficial to her as a teacher. Richard also spoke to the need to connect with "...the counselor, talking to the case manager, talking to Special Ed teacher. We share, we will talk to each other, "Hey, has anyone had this similar student that's been successful?"...so human resources, no book resources or anything like that". In contrast, Payton shared that at times she has felt, "it's just you're kind of on your own" and would appreciate more face time with the case manager outside of the IEP meeting.

In this current study it appears as though the opportunities for collaboration between the general education teacher and special education teacher are inconsistent, unless it is a situation of team- or co-teaching. Findings from a 2015 report from the US Department of Education on school practices and accountability for students with disabilities indicate that schools that use common teacher planning time in supporting included students in general education have increased educational outcomes (US Department of Education, 2015). Most participants implied this common planning time is not a current practice in place in their schools. 


\section{Access to Specific Information}

The teachers spoke of their final recommendation not only throughout the interviews, but also in response to the specific questions of the resources that are lacking and what could be done to improve the experience of supporting students with Asperger Syndrome in the general education environment. Not surprisingly, the need for more specific information about the individual student and his or her needs as it relates to Asperger Syndrome were frequently mentioned. A 2015 also study recommended that specific differentiation strategies to accommodate students with Autism Spectrum Disorder is a necessary change from current practice to better support these students in the general education setting (Able, et al., 2015).

Jamie acknowledged that providing this specific information could be a challenge, related to the uniqueness and complexity of each student:

They (the accommodations) don't really match how the kid presents. You know but really it's, I think that super tough to do anyway... I couldn't imagine it (IEP) saying, "So and so truly enjoys irony. So if you can point out moments in your relationship that are ironic, he will favor you." You know, I can't see that written in an IEP, but that's one of the ways I got one of my students you know...Having patience and explaining small noises. You know, like that would be something that would be perfect in this kid's IEP. But...you know, no one's going to write that down.

Jamie later went on to note, "...it's those accommodations that you want on there to be warned about, they are harder to do, that are very unique to their characteristics and how they present”. Jamie also suggested that when accommodations are noted (such as extended time) it would be helpful to provide examples in the IEP document in regards to what that actually means for that particular student.

Payton shared the same sentiment as Jamie, that in order to improve the 
experience of supporting students with Asperger Syndrome in her general education class, she needs more information about the very unique qualities of each particular student:

...Additional information...like, if you do this, this might trigger this reaction. I find that so much more helpful that "here's his IEP". So maybe more follow-up from the previous teacher, so whoever this kid's sophomore teacher was, if they were able to give me some feedback, that would be a little bit more helpful...I just think feedback from what occurred the previous year.

Ann shared that the specific information about the student could come from the IEP document, case manager or someone who worked directly with the student in the past. She also pointed out that face to face time with other professionals could be a barrier to this process:

...one on one time with someone who has actually worked with those students before, had them in class, has had successes and failures and can talk about those.... and having time to meet with them...you need somebody coming in and saying "Try this", or, "You need the time to go and observe another teacher with that same student or with students with those same needs and see what they're doing that's working.

Beth noted that specific information that was previously provided is not currently provided:

...We used to get a lot more information on the kids. Now we get, here's a whole big list of things that they might do, they're antisocial and they're this, but we used to get helpful hints, like the verbal redirect and we don't get a lot of that anymore, just like a couple of things... and now it's so confusing.

Ron, who is the most experienced teacher of the participants included in this study, had a different opinion than his peers, “...I mean, I'm pretty happy with the information I get. And I do think that a lot of the success I've had does come with trial and error and experience". Ron talked of the ownership he must take in getting more 
specific information about a student through initiating those conversations with other general education teachers who currently work with the student.

It seems as though there is room for improvement in how and what is communicated to the general education teachers specifically related to the unique characteristics and accommodations that are specific to the individual student. The teachers did not have strong feelings as to whether or not that information should be specifically included in the IEP document; they also noted that the student's case manager reaching out to them before the school year starts to provide the distinctive needs and accommodations would be acceptable as well.

\section{Post-Script: The Rest of the Story}

Before delving into the conclusions of this study, it is relevant to share additional reflections from two of the participants in the member check feedback. Beth and Ann shared the current status of the students they were focusing on during the school year this study took place. Beth shared the following:

It's sad - but the boy, Nick, is having a very hard year. His case (manager) left this school, his current case (manager) is new to him and going on maternity leave and he will get another. He did not receive the same woman T.A. as I suggested to Special Education. This woman knew him and worked well with him. And even though I hand-chose his English teacher, she struggles in dealing with him. I wish I taught that class. I think any sort of familiarity would have been much better for him.

I don't know all there is to know or understand about the organization of Special Education, but the people who are dealing with the autistic students should probably teach less classes so they can see the students in action, work with teachers and complete all the paperwork involved (and add much more about the individuals). Just a thought.

Ann had a similar experience and even more to share:

When I first read this (Chapter IV), I was surprised by the fact that some of the research contradicts what your interview subjects reported. I often turn to research 
for guidance when dealing with challenges in my classroom, so I started wondering if perhaps the research concerning mainstreamed students on the Spectrum is outdated.

However, I was sadly just informed that the autistic student, Ryan, who I had in class last year and talked to you about during the interview, was moved to a support center English and reading class. At the beginning of the year, he was assigned a new case manager and a new TA for every class period of the day. He also, obviously, had new classes and teachers from last year. As a result, he regressed. Even though he is no longer in our class, my team-teacher and I did our best to communicate with his new teachers about accommodations and strategies that worked and made him really successful let year. They were not able to establish the same rapport and could not make a personal connection with him.

For some unknown reason, his case manager and counselor decided to rearrange his schedule again several weeks into the 1st quarter and place him in a new reading class with a new teacher and new classroom procedures and routines that he had to learn. His academic performance dropped and then his behavior worsened, too. I worked so hard on trying to make Ryan successful academically and socially last year and considered him one of my success stories in June. It is so sad to see that all of my efforts and those of the other teachers, TAs, and case managers last year have been erased because he was unlucky enough to end up with individuals who viewed him as a "disruption to the other students" and a burden. So, perhaps the majority of teachers really do view working with students like Ryan as "extremely difficult", as the research suggests. Oh, I should mention that when I see Ryan in the hallway, he still says hello to me and points out that I no long have a baby in my belly (I went on maternity leave last winter while he was in my class). I also saw him working on a reading selection in the hallway outside of his former reading class prior to his move to support center and I engaged him in a discussion about his reading. He was able to communicate to me the main idea of the selection and a supporting detail, while also indicating his awareness that there were two sides of the debate and he agreed with one side over the other. He even went on to ask me a question about the topic that extended beyond the text. These are all indications that he possesses the skills necessary for a mainstream English or reading course. The student-teacher relationship is what made all the difference with Ryan last year.

The reflections of the two teachers who participated in the member check further emphasize the importance of several of the key findings of this study, which include the value of the relationship between the student and the general education teacher; the importance of the IEP accommodations being clearly defined (such as the role of the teacher assistant); and the role of attitude or acceptance on the part of the general 
education teacher in regards to how the student with Asperger Syndrome is welcomed into the general education environment.

\section{Summary}

Teaching high school students with Asperger Syndrome in general education English courses requires commitment, understanding, and willingness to go above and beyond what might be required for the typical mainstreamed student. In spite of the challenges incurred by these teachers: including a lack of specific information related to the students' needs; the unique traits related to autism that can interfere with social and group work; and challenges with self-regulation, particularly related to the iPad, these teachers are committed to figuring out "what works" for the students at the individual student level. These teachers look well beyond the IEP document itself to determine accommodations, including their own experiences, seeking out special education staff and other teachers within the school and their department. They have taken ownership for implementing the accommodations in their general education classroom, rather than expecting a resource teacher or teacher assistant to take on this responsibility. In order to more efficiently and effectively support students with Asperger Syndrome in the general education classroom, these teachers would like to have more specific information at the individual student level in regards to the student's traits and needs related to their disability and how they can specifically accommodate those needs in the general education classroom. 


\section{CHAPTER V \\ SUMMARY AND CONCLUSION}

Introduction

Benjamin (pseudonym) was insubordinate in his math class with his teacher regarding his math quiz. He threw it in the garbage, refused to pick it up after two requests by the teacher (and three visual cues from his teacher assistant), and proceeded to tell the teacher to pick it up and then told the teacher assistant to "go away".

(Anonymous, 2013).

The situation noted above was pulled from an actual discipline write-up for a student with Asperger Syndrome. This incident resulted in the student leaving the classroom, running through the hallways while being chased by several staff members, including several building administrators. This escalated because the student was upset about a math quiz score and proactive supports were not in place to help Benjamin process through his frustration. Benjamin's IEP did not denote accommodations for receiving grades. While this situation escalated to a very significant level, had the general education teacher been aware that Benjamin needed an accommodation for receiving grades (such as meeting privately with the teacher or his case manager) it is possible this situation would not have occurred, or at minimum, not escalate to the level of requiring building administration involvement. 
It was incidents such as these that piqued my interest in wanting to better comprehend the experiences and perspectives of general education teachers who are responsible for supporting students with Asperger Syndrome in their classrooms. The findings of this study provide general educators, special educators and administrators a much clearer understanding of this perspective, as well as offer recommendations for better supporting these students and teachers in the future.

The purpose of this study was to better understand the experiences of high school English teachers who have students with Asperger Syndrome in their classes and to gain understanding of their perceptions of IEP denoted accommodations. To ensure this concept was fully investigated, semi-structured interviews, classroom observations, journal entries and artifacts were used for data analysis. In this chapter, conclusions regarding the analysis of the data as it relates to the research questions will be revealed, limitations to the study will be described, and recommendations for future research will be provided.

\section{Conclusions}

Three major conclusions can be drawn from this study, as listed below and will be discussed in detail in this section. The conclusions of this study are:

- The IEP document and IEP process from the lens of the general education teacher do not provide adequate information when considering the unique needs of students with Asperger Syndrome;

- General education English teachers are committed not only to forming relationships with students with Asperger Syndrome, but often take it a step 
further, taking on the role of advocating for the student as well as encouraging the student to advocate for him or herself; and

- General education English teachers are committed to doing what works for the student, regardless of what information can be found in the IEP document.

These conclusions will be further described in the following sections.

\section{Students with Asperger Syndrome are Unique...But Their IEPs are Not}

As a special educator who works with teams to ensure the IEP document meets legal requirements and also facilitates IEP meetings that are consistent with the mandated elements, this conclusion was shocking to me. I have always considered myself to hold teams to high expectations, and that the IEP process is not just about meeting the requirements of the law, but having meaningful discussions about the student and writing documents that are specific to the student. Prior to this study, I would not have predicted the common observation the general education teachers experience with the IEP document and the IEP process itself.

Without prompting, each of the participants reinforced the understanding in the world of autism that "the only thing that is the same about individuals with autism is that they are all different". The teachers commonly shared that they want to know how "it (autism) represents within them" (Jamie) for the purpose of being able to proactively plan for the student. For example, they want to know if a student might be likely to shout out (and what might prompt that shout out) or need to have space to pace within the classroom setting. The participants also want to know specifically what "preferential seating" might mean for that particular student, not just "preferential seating" listed as an accommodation. The participants shared that they do not have a preference if this 
information comes from the IEP document itself, the case manager or previous teachers; they simply want the information.

A few of the participants noted that they commonly do not review the IEP prior to the start of the school year because the "IEPs in general are pretty generic" (Ann). Participants also shared that sometimes locating the information within the IEP document can be a challenge. A 2015 research study noted similar results to the current study's conclusion; IEPs need to be more specific for students on the Autism spectrum and the authors suggested outlining characteristics (specific to Autism) and the associated needs in the accommodations section (Able, et al.).

The participants also spoke to their involvement in the actual IEP meetings. They do not view the IEP meeting as an opportunity to gain or provide information about the student with Asperger Syndrome; rather, they see their role as meeting the legal obligation of having a general education teacher present for IEP meetings. They are generally asked to give their input at the start of the meeting and then excused. Just one participant (Ron) noted that he is given the opportunity to comment on accommodations in the IEP meeting. As I completed the interviews, I did get the sense that the participants have a perception that the special educators might not place value on the type of information the general education teacher might be able to provide, such as specialized accommodations they have put in place. Yet, these participants do have not only a curiosity about the entire meeting process but believe they have valuable information to share and obtain would prefer to be invited to stay and participate, rather than being dismissed. 
Speaking from personal experience as a life-long special educator, I can understand why general education teachers may feel this way, but I also do not believe that is the message general education teachers are intending to present. I believe if we circle back to the difference between the mandated intention of the general education teacher participation in IEP meetings and common practice, we can better understand the dichotomy of this perception on both "sides". It is not common practice for general education teachers to participate in the entire IEP meeting (at least in my observations across many years and several school districts). It is common for general education teachers to provide their input at the start of the IEP meeting and then be dismissed. From the lens of the special education team, we are attempting to respect the time of the general education teacher who either needs to get back to class or their planning time, therefore we "dismiss" the general education teacher.

In order for more meaningful participation in IEP meetings on behalf of the special education student, better communication and reflection on practice must occur. If nothing else, general education teachers should be asked to provide more information than just an update of grades and performance. Perhaps a guide of what information the general education teacher should be prepared to share, or a list of questions for the case manager or meeting facilitator to ask the general education teacher could provide a more meaningful role for the general education teacher and dispel the perceptions regarding meeting participation from both the general education teacher and the special education team. 


\section{High-Fives and "Can Do" Attitudes}

Research has indicated there is a high correlation between a student-teacher relationship and achievement (Hattie, 2009). Research has also noted an association between the quality of the relationship between a general education teacher and a student on the Autism spectrum can be correlated to the overall quality of the inclusion experience for the student (Robertson et al., 2003). The participants in this study talked about what might be seen as a routine teacher-student interaction (such as exchanging high-fives) is a moment to be celebrated in that those interactions represent so much more; a true relationship between the student with Asperger Syndrome and the teacher. As reviewed in Chapter II, individuals with Asperger Syndrome often exhibit varying degrees of challenges with Theory of Mind (ToM). ToM refers to the ability to infer and acknowledge the mental states of others and to apply this understanding to explain and/or predict the behavior of others (Sansosti, Powell-Smith, \& Cowan, 2010). Deficits often present as challenges in reading the emotions of others (verbal, facial expressions, and tone) and appropriately responding, particularly when there is little time to process. No reaction or a minimal reaction to a teacher's positive statement to a student might be perceived by the teacher as a lack of interest in a relationship, even though that may not accurately reflect what that student is thinking or able to express. When a teacher gets the feedback from a student with Asperger Syndrome that is socially expected, the teacher may feel more "connected" to the student and make more attempts to interact with the student.

The participants also described the actions they take to prevent offending or upsetting a student with Asperger Syndrome, such as avoiding using sarcasm in a course 
in which a student with Asperger Syndrome is enrolled. The participants in this study firmly expressed their desire to connect with these students, which they viewed not only as assisting the student in being more successful and interactive in their class; but also described the validation they experienced as a result both personally and professionally. Perhaps it is the relationship or bond the participants have formed with their students that leads to their desire to both advocate for the needs of the student as well as working with the student to be a better self-advocate. The participants shared many stories about the steps they have taken to help a student progress, including going from writing paragraphs to an entire essay; questioning accommodations written into the IEP that didn't seem aligned to student's needs; and guiding a student to the speech team (who eventually majored in broadcasting in college). The teachers shared that when they have a student with Asperger Syndrome in one of their classes that they often reach out to the parents at the start of the school year, to introduce themselves and open up communication, as they reflected that there is often more parent communication with this population than other students. As shared by the participants who participated in the member check for this study, their observations in regards how their student with Asperger Syndrome was during the time of the study in their class versus the current school year, the educator-student relationship does matter and plays a significant role in the success (or lack of) for these students in the general education setting.

Each of the teachers shared that they have not ever had a student with Asperger Syndrome who they did not feel was appropriately placed in general education. This group of teachers shared numerous stories and examples of dealing with some challenging behaviors and needs of students with Asperger Syndrome by working with 
students, researching on their own, and reaching out to other educators as examples of their "can do" attitude in supporting their students.

When speaking about her student, Nick, Beth shared stories and artifacts that represent the extent to which she went to give Nick extra assistance in the writing process. She provided Nick with outlines, guides and individual support to move him from writing one sentence at the start of the year to full paragraphs by the end of the school year. How many students have a teacher like Beth saying to them: "You can do this. Don't be afraid. You can do this"? And he did.

Knowing that his student, Joe, struggles with "friends, communication, and emotional control", Richard purposefully places Joe with students who are "kind and patient" in order to provide a more successful experience for this student with Asperger Syndrome. Other participants described how they seek out information when they are unsure of how to best support a student. Ann related, "And I luckily ended up having some good people in our Special Ed Department who sorta talked me off the ledge and, you know, gave me tips". The steps these teachers took to go beyond the IEP document to support their students in the general education environment was shared throughout all six of the interviews, observed in the classroom observations and evident in the artifacts provided by the teachers.

\section{Mostly, It's Extended Time}

In spite of the perception that the IEP document itself does not provide specific information and accommodations related to students with Asperger Syndrome unique needs, the participants in this study shared experiences of finding what works for students, rather than adhering to the common accommodations of extended time and 
preferential seating with little explanation about what those might mean. It is worth noting that the IEP accommodation of a teacher assistant was described with mixed reviews. The participants noted that it really depends on the ability and quality of the teacher assistant in regards to how the participants perceived the effectiveness of the accommodation of a one-to-one teaching assistant.

The teachers shared that the non-IEP denoted accommodations were often more effective than what could be found in the IEP document. Knowing that the IEP document might provide some information as a starting point, the participants in this study offered numerous other resources they might tap into in order to put supports in place to assist their student. These resources included special education teachers (typically the case manager), on their own (often based on prior experiences), internet research, and other general education teachers (most often department colleagues). The participants shared they believe they most often have to reach out to the student's case manager rather than the case manager checking in with them to find out how things are going. The participants noted that the case managers have been very helpful when they were contacted, but also said that they would prefer the case manager reach out to them, and possibly even spend some time in their classrooms to offer recommendations.

In regards to the accommodations that the general education teachers are most often implementing in their classrooms, the accommodations of visual supports, increased structure, sensory supports and additional communication with parents were referred to most often. Examples of supports that were initiated by the participants included creating scaffolded visual organizers for increasing written output; posting a schedule on the board of the day's activities and expectations; providing opportunities for 
sensory breaks in the classroom or in the hallway; and determining what preferential seating means for students based on their specific needs. For example, one teacher described preferential seating for a student based on his need to pace during class. Rather than have him seated in the middle of the classroom, he was seated in a location so he could easily get up and pace without disturbing his peers. Several teachers noted that when they have activities in which students will be required to work in small groups, they often assign the groups with the student make-up of the group taken into consideration when placing the student with Asperger Syndrome. At the high school level, students are more frequently allowed to self-select their groupings. This is another example of the thought and consideration these teachers put into their planning and implementation for students with Asperger Syndrome.

Much information was gleaned from this study. The most salient conclusions based on my experiences as a special educator and as a person who spent significant time trying to better understand the experience of the general education teacher who has students with Asperger Syndrome have been described in this section. To review, the conclusions of this study include: the IEP document and IEP process from the lens of the general education teacher do not provide adequate information when considering the unique needs of students with Asperger Syndrome; general education English teachers are committed not only to forming relationships with students with Asperger Syndrome, but often take it a step further, taking on the role of advocating for the student as well as encouraging the student to advocate for him or herself; and general education English teachers are committed to doing what works for the student, regardless of what 
information can be found in the IEP document. The recommendations based on the conclusions of this study will be described in the following section.

\section{Recommendations Based on the Conclusions}

\section{Recommendation Number 1}

The general education teacher should be more meaningfully involved in the IEP meeting. Special education law denotes the role of the general education teacher in the IEP meeting as being a part of determining supplementary aids and services, modifications to programming and supports for school staff (IDEA 1997). The amendment also notes that the general education teacher need not attend the entire IEP meeting. The practice the participants described in which they were often asked to speak first at the IEP meeting and then excused is a fairly common practice. I have worked in several districts and have attended IEP meetings in districts outside of the one in which the study was completed, and this is common, almost as if it is an unwritten rule. Yet feedback from the participants in this study indicates that they want to be more fully included in the meeting-both in the time they are present and the opportunity to offer their input on what is working for the students. They would also like to see this information included in the IEP document.

Special education case managers should be working with the general education teachers in advance of the IEP meeting to prepare for the meeting. General education teachers should be asked to provide not only an update how the student is performing in their class, but also include information in regards to what IEP accommodations are being used and the extent to which they are effective; what accommodations is the teacher 
implementing that are not part of the IEP (along with a discussion as to whether or not that should be denoted in the IEP); and if there are unique characteristics or needs that might be helpful to document in the IEP for future implementers of the IEP.

The unwritten rule of dismissing the regular education teacher after their brief input during the first few minutes of the IEP team needs to be reflected upon. Perhaps it makes sense for students who have more complicated needs (inclusive of students with Asperger Syndrome and other more intensive needs) to arrange IEP meetings at a time that is more conducive to the full involvement of the general education teacher. General education teachers have much to offer to the IEP team; their involvement should be invited and embraced.

\section{Recommendation Number 2}

The IEP document should have more specific information related to the needs and accommodations for students with Asperger Syndrome, and it should be easier to locate. It is possible that some of the IEPs the teachers have reviewed have had more specific information, but that information could be in a variety of locations within the document, including present levels of performance, additional notes, the behavior intervention plan (if a student has one) and/or the accommodations section. Understandably, one participant shared that the IEPs are so "convoluted" that she doesn't know where to find information. It may be helpful to include as much of this information as possible within the accommodations section, as that seems to be one section of the IEP most general education teachers know they should review when they have a student with an IEP in their classroom. 
As mandated federally, IEP accommodations need to be specific to student's individual needs, rather than a list of very general accommodations as reported by the experiences of the participants. One participant suggested not only defining what an accommodation means, but also providing examples. The specificity of these accommodations should be reviewed at each annual review to determine whether or not they are still relevant as written. If not, they should either be revised or eliminated. One of the participants shared that she realized it would be difficult to put everything that is known about the student in the IEP document. In those cases, in which a student has some more unusual behaviors associated with their autism and/or unique needs, there should be a vehicle for sharing this information from one year to the next. For example, the special education teacher could create a web-based document denoting relevant information about the student and his or her needs that could be shared as teachers change from one semester or one year to the next.

Neither of the recommendations based on the conclusions of this study would be difficult to implement, yet they could potentially make a significant difference for the general education teacher who is trying to navigate the needs of all students, and for the individual student with Asperger Syndrome.

\section{Limitations}

The limited number of participants (six) and the fact that all participants came from within the same school district (but five different schools) are factors that impact the generalization of this study. Additionally, the district that was selected for the study is a resource-rich district, spending more than $\$ 5,000$ in operational costs per student than the 
state average. This would suggest the district might have more resources available to students and staff than the average school district, and the participants in this study might have had different experiences when working with students with Asperger Syndrome than teachers who work in districts with fewer resources. Increasing the number of participants and including teachers from other school districts could provide more definitive data in regards to the analysis of and conclusions drawn in this study.

Participants of the study were chosen based on the intensity of their experience (intensity sampling), rather than on a more randomized approach. Using this purposeful sampling method, in which participants were required to have at least three years of experience in working with students with Asperger Syndrome provided rich experiences, but is limiting because teachers with fewer years of experience in working with this population may have had very different experiences to report. In the member check feedback, Beth suggested this idea in the following reflection:

I think your interview subjects were recommended by others who knew us (participants) to have had success working with individuals on the Spectrum for many years. I wonder if and how your findings would change if your subjects were chosen at random or were relatively inexperienced in working with these students.

A study that did not place a minimum number of years in teaching students with Asperger Syndrome would likely provide a wider perspective of the experiences. Additionally, the pool of potential participants was gathered from the recommendations of special education department chairs. One might assume that these teachers might have been more student-friendly and accommodating than other teachers. The participants in this study may or may not fully represent the experiences of the average general education teacher. 
This study was also limited to secondary general education English teachers. This is limiting as the findings can really only be applied to high school English teachers. For example, math teachers might have a very different perspective because most math courses do not require the same accommodations for writing and group work that might be involved in English classes. Expansion across subjects and/or grade levels would strengthen the findings of the study, as well as offer the differing experiences and perspectives of teachers of varying subjects.

\section{Recommendations for Future Research}

There are many directions in which this research could continue. First and foremost, it would be interesting to expand the number of participants, academic subject areas, and school districts in this particular research to evaluate whether or not the same patterns defined in this dissertation continue to emerge or, with additional participants, patterns that were not evident with these six participants begin to emerge. It would also be interesting to more randomly choose the participants for the study, with the only requirement being a minimum of a year having a student with Asperger Syndrome in their classes. While all participants may not be able to speak to the needs of students with Asperger Syndrome as these participants did, it would provide the perspective of the teacher who may have had more random experiences with students with Asperger Syndrome.

If one were to assume that the patterns that emerged in this study are reflective of the experience of high school general education teachers who have students with Asperger Syndrome in their classes, further research could dive into the individual 
patterns. For example, the use of the classroom teacher assistant could be further investigated in a qualitative study. General education teachers could be interviewed specifically about their perception of the role of the teacher assistant for students with Asperger Syndrome, and what does and does not work when supporting these students in general education.

Finally, students themselves could be interviewed to determine their perception of the accommodations and modifications that are put in place for them to support their participation in general education. Their thoughts on the acceptance and non-acceptance of particular interventions could be explored, as well as the degree to which they find the accommodations or accommodations to be effective. It would certainly be interesting to compare the teacher perceptions to the student input.

\section{Summary}

The challenge schools face today in meeting the required rules and regulations of special education law and balancing that with the practical challenges of educating students in the "least restrictive environment" is daunting. Special education rules and regulations mandate that an IEP meeting must include the special education teacher and the general education teacher. Accountability for student progress impacts every teacher who support students at all levels, including federal, state and the local school district. General education teachers are required to provide accommodations and modifications determined by the IEP team to students in their classrooms. Students with Asperger Syndrome are often educated in general education environments, and the purpose of this study was to examine the attitudes and perceptions of the general education teachers 
responsible for supporting this particular population of students, using a

phenomenological semi-structured interview approach.

Conclusions drawn in this study suggest that the IEP document and IEP process do not provide adequate information when considering the unique needs of students with Asperger Syndrome; general education English teachers are committed to forming relationships with students with Asperger Syndrome and helping students become better advocates for themselves; and general education English teachers are committed to doing what works for the student, regardless of what information can be found in the IEP document.

Recommendations to improve current practices in schools include more meaningful participation in the IEP meeting on the part of the general education teacher, in that the special educators should invite the general education to the table for the entire meeting and provide them with a true opportunity to participate and offer input. Finally, the IEP document itself should provide more specific information related to the accommodations and should be located in one consistent section of the IEP document.

Returning to Benjamin, imagine that the IEP document did specifically note that he should be told of quiz or test scores lower than a $\mathrm{C}$ before class or in a more private location. Imagine that the IEP also noted that Benjamin might react poorly to lower test or quiz scores, but when he has the ability to process for a few moments, he is able to better deal with the disappointment. Is it possible that Benjamin would have accepted his grade, had an opportunity to use his coping strategies if necessary and participated in class with no disruption to his class or school administrators? I would like to think so, based on the experiences the participants shared with me throughout this study. It seems 
as though a little bit of proactiveness can go a long way, in particular for students with Asperger Syndrome in general education settings. 


\section{REFERENCES}

Able, H; Sreckovic, M.A.; Schultz, T.R.; Garwood, J.D.; \& Sherman, J. (2015). Views from the trenches: Teacher and student supports needed for full inclusion of students with ASD. Teacher Education and Special Education, 38(1) 44-57. doi:10.1177/0888406414558096

Abner, K. D. (2013). A study of general educators' lived experiences in the inclusion of elementary students with autism. (Doctoral dissertation). Retrieved from Proquest Dissertations and Thesis databases. (UMI No. 3589232).

American Psychiatric Association. (1994). Diagnostic and statistical manual of mental disorders $\left(4^{\text {th }}\right.$ ed.). Arlington, VA: Author.

American Psychiatric Association. (2013a). Autism spectrum disorder [Fact sheet]. Retrieved from http://www.dsm5.org/Documents/Autism\%20 Spectrum\%20Disorder\%20Fact\%20Sheet.pdf

American Psychiatric Association. (2013b). Diagnostic and statistical manual of mental disorders (5th ed.). Arlington, VA: Author.

American Psychiatric Association. (2013c). Social communication disorder fact sheet. Retrieved from http://www.dsm5.org/Documents/SocialCommunication DisorderFactSheet.pdf

Avramidis, E., Bayliss, P., \& Burden, R. (2000). A survey into mainstream teachers' attitudes towards the inclusion of children with special educational needs in the ordinary school in one local education authority. Educational Psychology, 20(2), 191-211.

Attwood, T. (2004). Asperger's syndrome: A guide for parents and professionals. New York, NY: Jessica Kingsley Publishers.

Attwood, T. (2007). The complete guide to Asperger's Syndrome. Philadelphia, PA: Jessica Kingsley Publishers.

Autism Society of America. (2014). Changes to the autism spectrum disorder in the DSM-5. Retrieved from http://www.asw4autism.org/pdf/

Changes_to_ASD_Criteria_in_the_DSM_5.pdf 
Autism Speaks. (2014). Answers to frequently asked questions about DSM-5. Retrieved from http://www.autismspeaks.org/dsm-5/faq

Baio, J. (2014). Prevalence of autism spectrum disorder among children aged 8 years autism and developmental disabilities monitoring network, 11 sites, United States, 2010 [Technical report]. Atlanta, GA: Center for Disease Control and Prevention. Retrieved from http://www.cde.gov/mmwr/preview/mmwrhtml/ Ss6302al.htm?s_ss6302al_w

Barnhill, G. P. (2001). What is Asperger syndrome? Intervention in School and Clinic, 36(5), 259-265.

Baron-Cohen, S. (1997). Mindblindness: An essay on autism and theory of mind. Cambridge, MA: MIT Press.

Baron-Cohen, S., Jolliffe, T., Mortimore, C., \& Robertson, M. (1997). Another Test of theory of mind: Evidence from very high functioning adults with autism or Asperger syndrome. Journal of Child Psychology and Psychiatry, 38(7), 813-822.

Bayliss, M. (2011). Instructional Accommodations for Students with Asperger Syndrome in the General High School Classroom. Online Submission.

Bennetto, L., Pennington, B. F., \& Rogers, S. J. (1996). Intact and impaired memory functions in autism. Child Development, 67(4), 1816-1835.

Blanton, L. P., \& Pugach, M. C. (2007). Collaborative programs in general and special teacher education. Washington, DC: Council of Chief State School Officers.

Bogdan, R., \& Taylor, S. (1982). The social meaning of mental retardation: Two life stories. New York, NY: Teachers College Press.

Brantlinger, E., Jimenez, R., Klinger, M., Pugach, M., \& Richardson, V. (2005). Qualitative studies in special education. Exceptional Children, 71(2), 195-207.

Brown vs. Board of Education, 347 U.S. 483 (1954).

Buell, M. J., Hallam, R., Gamel-McCormick, M., \& Scheer, S. (1999). A survey of general and special education teachers' perceptions and inservice needs concerning inclusion. International Journal of Disability, Development, and Education, 46(2), 143-156.

Carlberg, C., \& Kavale, K. (1980). The efficacy of special versus regular class placement for exceptional children: A meta-analysis. The Journal of Special Education, 14(4), 295-309. 
Center for Disease Control (2014). Autism fact sheet [Fact sheet]. Retrieved from http://www.cdc.gov/ncbddd/actearly/pdf/parents_pdfs/autismfactsheet.pdf

Cohen, G. A. (1993). Equality of what? On welfare, goods, and capabilities. In M. Nussbaum \& A. Sen (Eds.), The quality of life (pp. 9-29). Clarendon Press: Oxford, England.

Common Core State Standards Initiative. (2014). Application to students with disabilities [Fact sheet]. Retrieved from http://www.corestandards.org/assets/CCSSonSWD-AT.pdf

Cooley, A. (2013). Qualitative research in education: The origins, debates, and politics of creating knowledge. Educational Studies, 49(3), 247-262.

Creswell, J. W. (2014). Research design: Qualitative, quantitative and mixed methods approaches. Thousand Oaks, CA: Sage Publications.

Creswell, J. W. (2013). Qualitative inquiry and research design: Choosing among five approaches. Thousand Oaks, CA: Sage Publications.

Crosland, K., \& Dunlap, G. (2012). Effective strategies for the inclusion of children with autism in general education classrooms. Behavior Modifications, 36(3), 251-269.

Cullen, J. P., Gregory, J. L., \& Noto, L. A. (2010, February). The teacher attitudes toward inclusion scale (TATIS) technical report. Paper presented at the Eastern Educational Research Association, Orlando, FL.

Dana, N. F., Dana, T. M., Kelsay, K. L., Thomas, D., \& Tippins, D. J. (1992, January). Qualitative interviewing and the art of questioning: Promises, possibilities, problems, and pitfalls. Paper presented at the meeting of the Qualitative Research in Education Conference, Athens, GA.

Daniel, L. S., \& Billingsley, B. S. (2010). What boys with an autism spectrum disorder say about establishing and maintaining friendships. Focus on Autism and Other Developmental Disabilities, 25(4), 220-229.

deBettencourt, L. U. (1999). General educators' attitudes toward students with mild disabilities and their use of instructional strategies: Implications for training. Remedial and Special Education, 20(1), 27-35.

Denzin, N. K., \& Lincoln, Y. S. (2000). Handbook of qualitative research. Thousand Oaks, CA: Sage Publications.

Devecchi, C., \& Rouse, M. (2010). An exploration of the features of collaboration between teachers and teaching assistants in secondary schools. Support for Learning, 25(2), 91-99. 
Dorn, S., Fuchs, D., \& Fuchs, L. S. (1996). A historical perspective on special education reform. Theory Into Practice, 35(1), 12-19.

Education of All Handicapped Children Act of 1975, Pub. L. No. 94-142 (1975)

Eldar, E., Talmor, R., \& Wolf-Zuckerman, T. (2010). Successes and difficulties in the individual inclusion of children with Autism Spectrum Disorder (ASD) in the eyes of their coordinators. International Journal of Inclusive Education, 14(1), 97-114.

Eman, M. M., \& Farrell, P. (2009). Tensions experienced by teachers and their views of support for pupils with autism spectrum disorders in mainstream schools. European Journal of Special Needs Education, 24(4), 407-422.

Fogt, J. B., Miller, D. N., \& Zirkel, P. A. (2003). Defining autism: Professional best practices and published case law. Journal of School Psychology, 41(2003) 201216.

Frith, U. (2003). Autism: Explaining the enigma. Malden, MA: Blackwell Publishing.

Fritz, M. F., \& Miller, M. (1995, April). Teacher perceptions: Impacts of planning for Inclusion. Paper session presented at the meeting of the Annual International Convention of the Council for Exceptional Children, Indianapolis, IN.

Gillberg, I. C., \& Gillberg, C. (1989). Asperger syndrome--some epidemiological considerations: A research note. Journal of Child Psychology and Psychiatry, 30(4) 631-638.

Handler, B. (2006). Two acts, one goal: Meeting the shared vision of no child left behind and individuals with disability education improvement act of 2004 . Clearing House: A Journal of Educational Strategies, Issues, and Ideas, 80(1), 58.

Hattie, J. (2009). Visible learning: A synthesis of over 800 meta-analyses relating to achievement. New York, NY: Routledge.

Hegarty, S. (1992). Educating children and young people with disabilities: Principles and review of practice. Retrieved from ERIC database. (ED364024)

Hobson vs. Hansen, 269 F.Supp. 401 (1967).

Humphrey, N., \& Lewis, S. (2008). What does 'inclusion' mean for pupils on the autistic spectrum in mainstream secondary schools? Journal of Research in Special Educational Needs, 8(3), 132-140. 
Illinois State Board of Education (2013). Frequently asked questions [Fact sheet]. Retrieved from http://www.isbe.net/common_core/pdf/ccs_faq.pdf

Illinois State Board of Education (2014a). Illinois report card. Retrieved from: http://www.illinoisreportcard.com

Illinois State Board of Education (2014b). Special education services: Disability areas. Retrieved from http://www.isbe.net/spec-ed/html/disability-areas.htm

Individual Education Plan. (2012, November 22). In Wikipedia. Retrieved from http://en.wikipedia.org/wiki/Individualized_Education_Program

Individuals with Disability Education Act Amendments of 1997 [IDEA]. (1997). Retrieved from http://thomas.loc.gov/home/thomas.php

Individuals with Disabilities Improvement Act 2004, Pub. L. No 108-446 (2004).

Jackson, P. (1968). Life in classrooms. New York, NY: Holt, Rinehart and Winston.

Jackson, R., Harper, K., \& Jackson, J. (2001). Effective teaching practices and the barriers limiting their use in accessing the curriculum: A review of recent literature [Monograph]. Peabody, MA: Center for Applied Special Technology, Inc. Retrieved from http://aim.cast.org/learn/historyarchive/ backgroundpapers/effective_teaching_practices\#.VE0fKIcQ51I

Jacobsen, P. (2005). Understanding how Asperger children and adolescents think and learn. Philadelphia, PA: Jessica Kingsley Publishers.

Johnson, L. J., \& Pugach, M. C. (1990). Classroom teachers' views of intervention strategies for learning and behavior problems: Which are reasonable and how frequently are they used? The Journal of Special Education, 24(1), 6984).

Kargin, T., Guldenoglu, B., \& Sahin, F. (2010). Opinions of the general education teachers on the adaptations for students with special needs in general education classrooms. Educational Sciences: Theory \& Practice, 10(4), 2455-2464.

Kavale, K. A., \& Forness, S. R. (2000). History, rhetoric, and reality: Analysis of the inclusion debate. Remedial and Special Education, 21(5), 279-296.

King, M. B., \& Young, P. (2003). Classroom teachers'views on inclusion. (Report No. RISER-7). Washington, DC: U.S. Department of Education.

Lakin, K. C., Krantz, G. C., Bruinicks, R. H., Clumpner, J. L., \& Hill, B. K. (1982). One 
hundred years of data on populations of public residential facilities for mentally retarded people. American Journal of Mental Deficiency, 87(1), 1-8.

Lawson, J., Baron-Cohen, S., \& Wheelwright, S. (2004). Empathising and Systemising in Adults with and without Asperger Syndrome. Journal of Autism and Developmental Disorders, 34(3), 301-310.

Lee-Tarver, A. (2006). Are individualized education plans a good thing? A survey of teachers' perceptions of the utility of the IEP in regular education settings. Journal of Instructional Psychology, 33(4), 263-272.

Lipsky, D. K., \& Gartner, A. (1996). Inclusion, school restructuring, and the remaking of American society. Harvard Educational Review, 66(4), 762-796.

Manjiviona, J., \& Prior, M. (1995). Comparison of Asperger syndrome and highfunctioning autistic children on a test of motor impairment. Journal of Autism and Developmental Disorders, 25(1), 23-39.

Martin, E. W.; Martin, R., \& Terman, D. L. (1996). The legislative and litigation history of special education. Special Education for Students with Disabilities 6(1), 2539.

Maxwell, J. A. (2005). Qualitative research design: An interactive approach $\left(2^{\text {nd }}\right.$ ed). Thousand Oaks, CA: Sage Publications.

McCray, E. D., \& McHatton, P. A. (2011). "Less afraid to have them in my classroom: Understanding pre-service general educators' perceptions about inclusion. Teacher Education Quarterly, 38(4), 1, 35-150.

McGregor, E. M., \& Campbell, E. (2001). The attitudes of teachers in Scotland to the integration of children with autism into mainstream schools. Autism, 5: 189207.

Mckenzie, J. A., (2013). Models of intellectual disability: Towards a perspective of (poss)ability. Journal of Intellectual Disability Research, 57(4), 370-379.

Mckenzie, J.A., \& Macleod, C. I. (2012). Rights discourses in relation to education of people with intellectual disability: Towards an ethics of care that enables participation. Disability \& Society, 27(1), 15-29.

McLesky, J., \& Waldron, N. L. (2002). Inclusion and school change: Teacher perceptions regarding curricular and instructional adaptations. Teacher Education and Special Education, 25(1), 41-54.

McPhail, J. C. (1995). Phenomenology as a philosophy and method: Applications to 
ways of doing special education. Remedial and Special Education, 16(3), 159165.

Menlove, R. R. (1999). Individualized education program (IEP) team member satisfaction with the IEP development process for students with disabilities (Doctoral dissertation). Retrieved from from ProQuest Dissertations \& Theses Full Text. (304529213)

Merriam, S. B. (2009). Qualitative research: A guide to design and implementation. San Francisco, CA: Jossey-Bass.

Miles, M. B., Huberman, A. M., \& Saldana, J. (2014). Qualitative data analysis: A methods sourcebook. Los Angeles, CA: Sage Publications.

Mills v. Board of Education, 348 F. Supp. 866 (1972).

Mintz, J. (2008). Working with children with Asperger's syndrome in the mainstream classroom: A psychodynamic take from the chalk face. Psychodynamic Practice, 14(2), 169-180.

Mitra, S. (2006). The capability approach and disability. Journal of disability policy studies, 16(4), 236-247.

Moores-Abdool, W. (2010). Included students with autism and access to general curriculum: What is being provided? Issues in Teacher Education, 19(2), 153-169.

Murray, D., Lesser, M., Lawson, W. (2005). Attention, monotropism, and the diagnostic criteria for autism. Autism, 9(2), 139-156.

National Institute of Mental Health. (2012). Director's blog: Autism progress. Retrieved from http:/www.nimh.nih.gov/about/director/2012/autismprogress.shtml

No Child Left Behind Act of 2001, Pub. L. No. 107-110 (2002).

Olley, J. G., Devellis, R. F., McEveoy Devellis, B., Wall, A. J., \& Long, C. E. (1981). The autism attitude scale for teachers. Exceptional Children, 47(5), 371-372.

Osborne, L. A., \& Reed, P. (2011). School factors associated with mainstream progress in secondary education for included pupils with Autism Spectrum Disorders. Research in Autism Spectrum Disorders, 5(3), 1253-1263.

Ozonoff, S., \& Jensen, J. (1999). Brief report: Specific executive function profiles in three neurodevelopmental disorders. Journal of Autism and Developmental Disorders, 29(2), 171-177. 
Park, M., \& Chitiyo, M. (2011). An examination of teacher attitudes towards children with autism. Journal of Research in Special Educational Needs, 11(1), 70-78.

Patton, M. Q. (2002). Qualitative research \& evaluation methods. Thousand Oaks, CA: Sage Publications.

Pennsylvania Association for Retarded Children (PARC) v. Commonwealth of Pennsylvania, 334 F. Supp. 1257 (E.D. PA 1971).

Pugach, M. C. (2001). The stories we choose to tell: Fulfilling the promise of qualitative research or special education. Exceptional Children, 67(4), 439-453.

Reindal, S. M. (2009). Disability, capability, and special education: Towards a capability-based theory. European Journal of Special Needs Education, 24(2), 155-168.

Reynolds, M. (1989). An historical perspective: The delivery of special education to mildly disabled and at-risk students. Remedial and Special Education, 10(7), 711.

Robertson, K., Chamberlain, B., \& Kasari, C., (2003). General education teachers' relationships with included students with autism. Journal of Autism and Developmental Disorders, 33(2), 123-130.

Robeyns, I. (2005). The capability approach: A theoretical survey. Journal of Human Development, 6 (1), 93-114.

Rothman, D. (1971). Discovery of the asylum: Social order and disorder in the new republic. Boston: Little Brown.

Rumrill, P. D., Cook, B. G., \& Wiley, A. L. (2011). Research in special education: Designs, methods, and applications. Springfield, IL: Charles C. Thomas Publisher LTD.

Safran, S. P. (2008). Why youngsters with autistic spectrum disorders remain underrepresented in special education. Remedial and Special Education, 29(2), 90-95.

Sansosti, F. J., Powell-Smith, K. A., \& Cowan, R. (2010). High-functioning autism/Asperger syndrome in schools: Assessment and intervention. New York: Guilford Press.

Sansosti, J. M. [Jenine], \& Sansosti, F. J. [Frank]. (2012). Inclusion for students 
with high-functioning autism spectrum disorders and decision making. Psychology in the Schools, 49(10) 917-931.

Scruggs, T. E., \& Mastropieri, M. A. (1996). Teacher perceptions of mainstreaming/inclusion, 1958-1995: A research synthesis. Exceptional Children, 63(1), 59-74.

Scruggs, T. E., Mastropieri, M. A., \& McDuffie, K. A. (2007). Co-teaching in inclusive classrooms: A metasynthesis of qualitative research. Exceptional Children, 73(4), 392-416.

Sen, A. K. (1993). Capability and well-being. In M. C. Nussbaum \& A. K. Sen (Eds.), The quality of life (pp. 30-53). Oxford [England]: Clarendon Press.

Sen, A. K., \& Nussbaum, M. (1993). The quality of life. Oxford [England]: Clarendon Press.

Shriner, J. G., \& Ganguly, R. (2007). Assessment and accommodation issues under the no child left behind act with the individuals with disabilities improvement act: Information for IEP teams. Assessment for Effective Intervention, 32, 231-243.

Simpson, R. L.; de Boer-Ott, S. R.; Smith-Myles, B. (2003). Inclusion of learners with autism spectrum disorders in general education settings. Topics in Language Disorders, 2, 116-133.

Simpson, R. L., \& Smith Myles, B. (1998). Educating children and youth with autism. Austin, TX: Pro-Ed.

Smith Myles, B., \& Simpson, R. L. (2002a). Asperger syndrome: An overview of characteristics. Focus on Autism and Other Developmental Disabilities, 17(3), 132-137.

Smith Myles, B., \& Simpson, R. L. (2002b). The complexities of Asperger syndrome: What we know and what we have yet to learn. Educational Horizons, 81(1), $38-44$.

Soto-Chodiman, R., Pooley, J. A., Cohen, L., \& Taylor, M. F. (2012). Students with ASD in mainstream primary education settings: Teachers' experience in Western Australian classrooms. Australian Journal of Special Education, 36(2), 97-111.

Strain, P. S., Wilson, K., \& Dunlap, G. (2011). Prevent-teach-reinforce: Addressing problem behaviors of students with autism in general education classrooms. Behavioral Disorders, 36(3), 160-171. 
Swisher, A. H. (2009). Practitioner views of Asperger's disorder: Clinical diagnosis and special education eligibility (Doctoral dissertation). Retrieved from Proquest Dissertations and Thesis databases. (UMI No. 3399048).

Symes, W., \& Humphrey, N. (2011). School factors that facilitate or hinder the ability of teaching assistants to effectively support pupils with autism spectrum disorders (ASDs) in mainstream secondary schools. Journal of Research in Special Education Needs, 11(3), 153-161.

Szatmari, P., Bremmer, R., \& Nagy, J. (1989). Asperger syndrome: A review of clinical features. Canadian Journal of Psychiatry, 34, 554-560.

Tantam, D. (1990). Asperger syndrome in adulthood. In U. Frith (Ed.), Autism and Asperger syndrome, (pp. 147-183). Cambridge, UK: Cambridge University Press.

Terzi, L. (2005). Beyond the dilemma of difference: The capability approach to disability and special educational needs. Journal of Philosophy of Education, 39(3), 443-459.

Thompson, S. J., Morse, A. B., Sharpe, M, \& Hall, S. (2005). Accommodations manual: How to select, administer, and evaluate use of accommodations for instruction and assessment of students with disabilities. Retrieved from http://www.ccsso.org/Documents/2005/Accommodations_Manual_How_2005.pd $\mathrm{f}$

Toson, A. L. M., Burrello, L. C., \& Knollman, G. (2013). Educational justice for all: The capability approach and inclusive education leadership. International Journal of Inclusive Education, 17(5), 490-506.

U.S. Department of Education, National Center for Education Statistics. (2013). Digest of Education Statistics, 2012 (NCES 2014-015), Table 48. Retrieved from http://nces.ed.gov/fastfacts/display.asp?id=64

U.S. Department of Education, National Center for Educational Evaluation and Regional Assistance. (2015). School practices and accountability for students with disabilities. (ED Publication No. ED553421). Retrieved from http://www.eric.ed.gov/contentdelivery/servlet/ERICServlet?accno=ED553421

van Hover, S. D., \& Yeager, E. A. (2003). Secondary History Teachers and Inclusion of Student with Disabilities: An Exploratory Study. Journal of Social Studies Research, 27(1), 36-45.

Van Krevelen, D. (1971). Early infantile autism and autistic psychopathy. Journal of Autism and Childhood Schizophrenia, 1(1), 82-86. 
Van Reusen, A. K., Shoho, A. R., \& Barker, K. S. (2001). High school teacher attitudes toward inclusion. High School Journal, 84(2), 7-20.

Vaughn, S., Schumm, J. S., Jallad, B., Slusher, J., \& Saumell, L. (1994, April). Teachers' views of inclusion: I'd rather pump gas. Paper presented at the Annual Meeting of the American Educational Research Association, New Orleans, LA.

Walters, B. J. (2012). Perspectives of general education teachers who work with students with autism. (Doctoral dissertation). Retrieved from Proquest Dissertations and Thesis databases. (UMI No. 3554017).

Ward, L., Abernathy, V., \& Cunningham, J. (1983). Background, enactment, and implementation of P.L. 94-142. Peabody Journal of Education, 1-30.

Whiteneck, G. (2006). Conceptual models of disability: Past, present, and future. In M.J. Field, A.M. Jette, \& L. Martin (Eds.), Workshop on disability in America: A new look-summary and background papers (pp. 50-66). Retrieved from http://www.nap.edu/catalog/11579.html

Wiggins, C. C. (2012). High school teachers' perceptions of inclusion (Doctoral dissertation). Retrieved from ProQuest Dissertations \& Theses Full Text. (1235578227).

Williams, K. (2001). Understanding the student with Asperger syndrome: Guidelines for teachers. Intervention in School and Clinic, 36(5), 287-292.

Willis, P. (1977). Learning to labor: How working class kids get working class jobs. New York, NY: Columbia University Press.

Wilkerson, S. E. (2012). Assessing teacher attitude toward the inclusion of students with autism (Doctoral dissertation). Retrieved from Proquest Dissertations and Thesis databases. (UMI No. 3531450).

Wing, L. (1981). Asperger's syndrome: A clinical account. Psychological Medicine, 11(1), 115-129.

Wing, L. (2005). Reflections on opening Pandora's box. Journal of Autism and Developmental Disorders, 35(2), 197-203.

Wolcott, H. (1973). The man in the principal's office. New York, NY: AltaMira Press.

Worrell, J. (2008). How secondary schools can avoid the seven deadly "sins" of inclusion. American Secondary Education, 36(2), 43-56. 
Yin, R. K. (2009). Case study research: Design and method $\left(4^{\text {th }}\right.$ ed.). Thousand Oaks, CA: Sage Publications.

Ysseldyke, J.; Algozzine, B.; \& Allen, D. (1982). Perception of regular education teachers in special education team decision making. Exceptional Children, 48, 365-366. doi:10.1177/001440298204800415

Ysseldyke, J., Thurlow, M., Bielinski, J., House, A., Moody, M., \& Haigh, J. (2001). The relationship between instructional and assessment accommodations in an inclusive state accountability system. Journal of Learning Disabilities, 34(3), 212-220. 


\section{APPENDIX A}

\section{ASPERGER SYNDROME DIAGNOSTIC}

\section{CRITERIA FROM DSM-IV TR}

A. Qualitative impairment in social interaction, as manifested by at least two of the following:

1. Marked impairment in the use of multiple nonverbal behaviors such as eye-to-eye gaze, facial expression, body postures, and gestures to regulate social interaction

2. Failure to develop peer relationships appropriate to developmental level

3. A lack of spontaneous seeking to share enjoyment, interests, or achievements with other people (e.g., by a lack of showing, bringing, or pointing out objects of interest to other people.

4. Lack of social or emotional reciprocity

B. Restricted repetitive and stereotyped patterns of behavior, interests and activities, as manifested by at least one of the following:

1. Encompassing preoccupation with one or more stereotyped and restricted patterns of interest that is abnormal either in intensity or focus

2. Apparently inflexible adherence to specific, nonfunctional routines or rituals

3. Stereotyped and repetitive motor mannerisms (e.g., hand or finger flapping or twisting, or complex whole-body movements)

4. Persistent preoccupation with parts or objects

C. The disturbance causes clinically significant impairment in social, occupational, or other important areas of functioning.

D. There is no clinically significant general delay in language (e.g. single words used by age 2 years, communicative phrases used by age 3 years).

E. There is no clinically significant delay in cognitive development or in the development of age-appropriate self-help skills, adaptive behavior (other than in social interaction), and curiosity about the environment in childhood.

F. Criteria are not met for another specific Pervasive Developmental Disorder or Schizophrenia. 
APPENDIX B

RECRUITMENT E-MAIL

Dear (Participant)

I am a doctoral student at Illinois State University as well as an employee of District XXX. I am currently completing my doctoral dissertation and am conducting a study, which explores high school general education English teacher's awareness and understanding of IEP accommodations that were developed through the IEP process for students with Asperger Syndrome and higher functioning autism. This study will also examine the acceptability and perceived effectiveness of the interventions from the lens of you, the general education teacher, as well as gain an understanding of your experiences of having students with Asperger Syndrome in your classroom.

For this study, I am soliciting high school English teachers with a minimum of three years experience over their teaching career of having students with Asperger Syndrome who have had IEP directed accommodations. If you believe you meet the criteria for the participants, I am requesting your participation, which will involve an initial audiotaped interview with myself that will take place in a location convenient to you. I expect the interview to last approximately $45-60$ minutes. The questions will relate to your thoughts and experiences with interventions and accommodations for students with Asperger Syndrome and high functioning autism in your general education classes. I will also ask you to identify a student with Asperger Syndrome in one of your current classes that I would be able to observe following the interview. Depending on the need for any clarification or further questions, I may ask to meet with you a second time for a brief interview. Finally, I will ask you to complete a short open-ended written (electronic) journal following an experience of supporting a student with Asperger Syndrome in your classroom. The total time that would be asked of you to be involved in this study would be no more than 3 hours.

Your participation is voluntary and your identity and school will be confidential. If you would like to be a part of this research study, please respond to this e-mail. I will then send you link to a brief questionnaire that will ask basic background information. Upon the receipt of the questionnaire, I will contact you to schedule a time to complete the initial interview.

Thank you very much for your time and interest in this study. Your opinions will be invaluable to the success of this research study. As a token of my appreciation for your 
participation in this study, I will offer each participant a \$25 iTunes gift card upon completion of the data collection.

Sincerely,

Mary Pat Krones 


\section{APPENDIX C \\ DEMOGRAPHIC INFORMATION SURVEY}

The participants were sent a link to an electronic survey site (Google Form) and asked to provide the following information:

- Name

- Preferred e-mail address

- Preferred phone number

- School

- Number of years having students with Asperger Syndrome/High Functioning Autism in their classroom (if less than 3, please stop and submit survey)

- Do you currently have at least one student in one of your classes with Asperger Syndrome/High Functioning Autism? (if the answer is no, please stop and submit the survey)

- Current courses

- Please indicate any current courses which are in the co-teaching model

- Number of years teaching

- Number of years in current district

- Number of years in current department

- Other relevant experiences in education (other districts, other roles prior to current role)

- Education (undergraduate major/minor and year, any degrees or work beyond undergrad)

- Have you ever attended professional development sessions on Asperger Syndrome/High Functioning Autism?

○ If yes, please briefly explain

Thank you for your assistance. I will be contacting you soon to schedule your initial interview. 


\section{APPENDIX D \\ GUIDING QUESTIONS FOR INTERVIEWS}

1. Please describe your experiences with having students with Asperger Syndrome and high functioning autism in your classroom.

2. Please describe the challenges you have experienced on a more frequent basis when having students with Asperger Syndrome in your classroom?

3. What have been your greatest successes working with students with Asperger Syndrome in your classroom?

4. What is your general attitude in regard to the inclusion of students with Asperger Syndrome in general education classrooms?

5. What kind of instructional strategies do you prefer to utilize when working with students with Asperger Syndrome in your classroom?

6. When you are made aware you will have a student with Asperger Syndrome in one of your classes, what information do you want to know?

7. Thinking about these students, can you describe or list some of the accommodations that were to be implemented in your classroom as a part of these student's IEPs? Examples might include extended time on tests, providing visual notes, etc.

8. How are the needed accommodations communicated to you (if probing needed: email, meeting with case manager, no communication)?

a. How do you keep track of or manage the various accommodations to be implemented in your classroom?

9. Who is/was responsible for implementing the accommodations? (if probing needed: you, case manager, teacher assistant)

10. Are you given the opportunity to ask questions or get clarification in regards to accommodations?

11. When you think about various accommodations, were there ones that you found to be easier to implement as a general education teacher? 
12. What makes those easier to implement? As the general education teacher, were there any accommodations that you found difficult to implement?

a. If so, what makes them difficult to implement?

b. If TA (1:1) has not been brought up, as about that here**

13. Thinking about the students, in regards to the effectiveness of the accommodations, did you find these to be generally effective or generally ineffective?

a. Which ones were most effective? Why?

b. Which ones were least effective? Why?

14. As the general education teacher, were you ever asked for feedback in regards to whether or not the accommodations were working for your student?

a. If so, how was this feedback solicited?

15. What impacts (positive, negative, no impact) have you seen the implementation of the 1:1 iPad program for all students in the district has had on students with Asperger Syndrome?

a. If impacts noted, ask for description

16. Have you had the experience of having the same student more than one time?

a. How did that impacted how you supported that student?

17. As a general education teacher, were you asked to attend IEP meetings and speak to these accommodations?

a. If so, what kind of feedback to you provide?

b. If not, would you like to have been asked to attend IEP meetings and/or provide feedback prior to an IEP meeting?

18. Have you ever had a time in your experience as a general education teacher in which you felt that perhaps the accommodations were so extreme that your classroom might not be the right educational setting for that particular student?

a. If so, please describe that experience.

b. Did you communicate that to the case manager?

c. What was the response from the staff? (Were they able to problem-solve with you, change the level of the class, etc.)

19. What resources do you feel you have access to that helps you teach students with Asperger Syndrome in your classroom?

20. What resources do you feel are lacking to help you teach students with Asperger Syndrome in your classroom?

21. What suggestions do you have to make it easier as the classroom teacher to implement accommodations? 
22. How has teaching students with Asperger Syndrome in your classroom affected you as a person?

23. What else would you like to share about your experiences of working with students with Asperger Syndrome?

24. Earlier you provided the name of a student, (PSUEDONYM) in your (NAME OF CLASS) who I will be observing when I come into your classroom for an observation.

a. Please tell me a little about this student and his or her strengths and needs.

b. What accommodations are a part of his or her IEP?

c. How frequently do you need to implement these accommodations?

d. Are there accommodations you implement that are not a part of the IEP? If so, please describe?

e. Is there anything in particular you would like me to focus on when observing this student and his or her interaction in your classroom, related to his needs?

f. When I come in for the observation, I will ask you to provide me with any documents you provide the student as a part of his or her accommodations (notes, etc.).

g. Is there anything else you would like me to know about this student before I come in for the observation? 
APPENDIX E

\section{CLASSROOM OBSERVATION FORM}

\begin{tabular}{|l|l|}
\hline Date: & Time: \\
\hline Participant: & Course: \\
\hline
\end{tabular}

Description of physical elements (Number of students, number of adults, configuration):

Description of Lesson/Activities during observation:

Goals:

Teaching Strategies:

Transitions:

Types of Communication: 


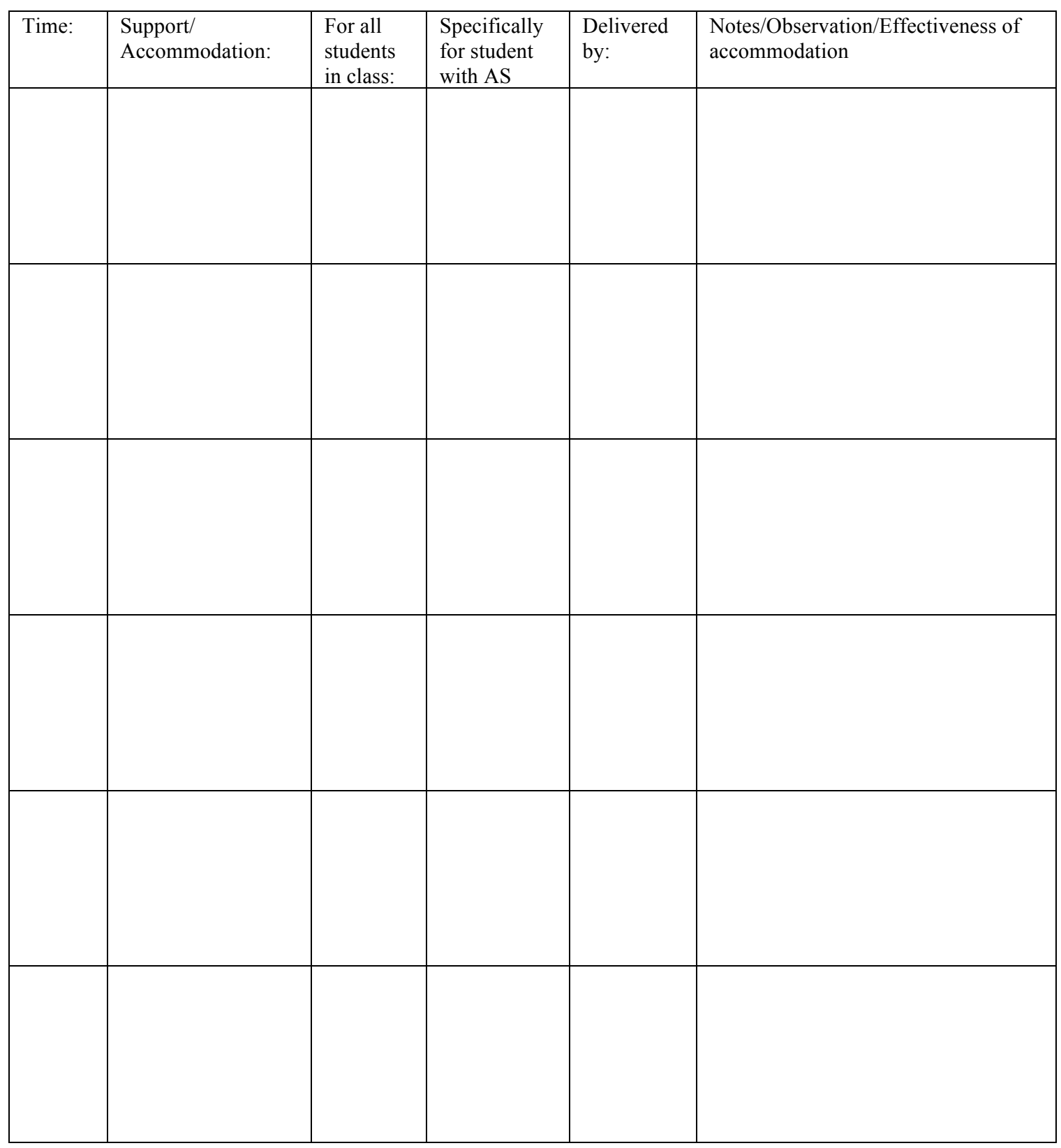




\section{APPENDIX F}

\section{JOURNAL ENTRY}

Following the initial interview and the classroom observation, each participant was asked to complete a reflective journal, which were be returned electronically. The journal requested the following information:

Name

Class/Period

Date of journal entry

Date of event of the reflection

Please attach any materials provided to all students on the day of the class in which you are reflecting, as well as any materials provided which were specific to the student with Asperger Syndrome.

Thinking of the student we spoke about (PSUEDONYM) during our initial interview, please reflect on your experience with that student during the class session you have chosen for this journal entry.

1. Briefly describe the lesson and any activities associated with the lesson.

2. Please describe accommodations you provided to the student during this class.

3. Which accommodations specific to this student were determined ahead of time when you were planning the day?

4. Were there any accommodations you implemented that were not planned?

5. How frequently do you implement these accommodations?

6. What prompted you to implement these accommodations during this lesson?

7. What was the purpose of implementing these accommodations?

8. Were these accommodations part of the student's IEP?

9. What impact (if any) did the accommodations have on the student during this lesson?

10. What were the barriers to using the accommodation? 
11. Will you use or would you recommend using this accommodation again?

12. Please share any other information you believe would be relevant regarding the accommodations for this student. 


\section{APPENDIX G \\ INFORMED CONSENT}

Dear

I am a doctoral student under the direction of Dr. Gary Weilbacher in the School of Teaching and Learning at Illinois State University. I am conducting a study for the completion of my dissertation, which examines the general education teacher's awareness, and understanding of IEP accommodations that were developed through the IEP process, to be implemented in their classrooms, for students with Asperger Syndrome and higher functioning autism. This study will also examine the acceptability and perceived effectiveness of the interventions from the lens of you, the general education teacher.

I am requesting your participation, which will involve:

- An initial interview that will take place at a location convenient to you and last about 60 minutes. The interview will be audio taped, with your permission.

- One classroom observation in one of your current courses.

- A guided journal entry to be completed by you.

- A potential brief follow-up interview for clarification.

Your participation in this study is voluntary. If you choose not to participate or to withdraw from the study at any time, there will be no penalty of any kind. Your decision to participate or not to participate will not affect your employment in any way. The results of the study will be used in a published dissertation and oral defense, but your name will never be used. I will take all precautions to maintain your confidentiality. Pseudonyms will be used during the interview and in the final report.

There are minimal physical, psychological or social risks to this research study. Please be assured that no information that you reveal in the interview regarding the challenges and barriers to providing accommodations for students will be given to teachers or administrators. To minimize risk, interviews will be conducted in settings that provide the maximum amount of privacy and confidentiality to you. And of course, you have the right to refuse to answer any questions during the interview.

The possible benefit of your participation would be to reflect upon your own experiences and to assist in identifying ways to improve the process for future students and educators. 
As a small gesture of appreciation for participating in this study, you will be given a $\$ 25$ iTunes gift card.

If you have any questions concerning the research study, please call me at (XXX) XXXXXX, or Dr. Gary Weilbacher at (XXX) XXX-XXXX.

Sincerely,

Mary Pat Krones

I give consent to participate in the above study.

Signature

Date

If you have any questions about your rights as a subject/participant in this research, or if you feel you have been placed at risk, you can contact the Research Ethics \& Compliance Office at Illinois State University at (309) 438-2529. 
APPENDIX H

\section{THEMES AS THEY RELATE TO THE RESEARCH QUESTIONS}

What are the experiences of Secondary English teachers who have students with Asperger Syndrome in their classroom?

- Building relationships with students with Asperger Syndrome

- Not asked to offer input for IEPs

- Have not had a student who didn't belong in general education

- Student growth

- Getting students with AS to interact with others is a success

- Working with students with AS has made me a better teacher

- Students with AS are not alike/uniqueness

- Stress importance of teaching self-advocacy

- Teacher as an advocate

What obstacles do Secondary English teachers experience in working with students with Asperger Syndrome in the general education classroom?

- Bullying

- Social skills-lack of friends/perceptions

- Writing

- Lack of information shared with them/specific

- Lack of access to special education teacher

- Difficulty in building relationships

- Self-control

- Ability to work in a group

- Organization skills

- Limited information in IEP document

- Some accommodations are distracting to others

- Some accommodations are limiting to the student's ability

- Technology interference

- Need for more structure

What are the perceptions of Secondary English teachers of the accommodations for students with Asperger Syndrome in the general education classroom?

- Some accommodations part of every IEP

- Some accommodations are distracting

- Classroom teacher responsible for implementing accommodations

- Only a few accommodations difficult 
- Experience with Teacher Assistants

What accommodations are teachers using in the general education classroom (a),

- Teacher Assistant

- Preferential seating

- Visual supports

- iPad/Technology

- Extended time

- More structure

- Sensory supports

and from where do they derive these (b)?

- On own

- Internet

- Special Education Teacher

- Other Teachers

- IEP

How effective do the Secondary English teachers perceive the accommodations are for their students with Asperger Syndrome?

- Experience with Teacher Assistants is mixed

- Some students would not be in their class if they didn't have the Teacher Assistant

- What works is often not in the IEP

What resources do Secondary English teachers require to understand and support the needs of students with Asperger Syndrome in the general education classroom?

- Better understanding of the unique characteristics of autism

- Specific information about individual students and his/her needs

- Classroom teacher provide tips that work for individual student to be passed along

- Better training for Teacher Assistants

- Face time with Teacher Assistants

- Face time with special education teacher

- Quicker/easier access to information

- Training

- Involvement in IEP meeting

- Prior experience 
APPENDIX I

EXAMPLE CODING MATRIX

\begin{tabular}{|c|c|c|c|c|c|c|}
\hline \multirow[b]{2}{*}{ Experience } & \multicolumn{6}{|c|}{$\begin{array}{l}\text { PARTICIPANT \& PAGE NUMBERS FROM TRANSCRIPTS AND } \\
\text { ARTIFACTS: }\end{array}$} \\
\hline & 1 & 2 & 3 & 4 & 5 & 6 \\
\hline $\begin{array}{l}\text { Building } \\
\text { relationship } \\
\text { with student } \\
\text { with AS } \\
\end{array}$ & $\begin{array}{l}4,5,6,19 \\
25,35,39\end{array}$ & 6,9 & $2,3,7,9$, & 7,28 & $\begin{array}{c}3,5,6,9, \\
27,31,32\end{array}$ & $5,7,20$ \\
\hline $\begin{array}{l}\text { Not asked to } \\
\text { offer input for } \\
\text { IEPS }\end{array}$ & 24 & 11,18 & $7,8,23$ & $\begin{array}{l}24,31,32 \\
33\end{array}$ & 20,23 & 13 \\
\hline $\begin{array}{l}\text { Have not had } \\
\text { student who } \\
\text { didn't belong } \\
\text { in gen ed }\end{array}$ & 28 & 4,12 & 3 & 5 & & 5,16 \\
\hline Growth & & & 11,23 & 3,23 & 5 & 4,15 \\
\hline $\begin{array}{l}\text { Getting student } \\
\text { with AS to } \\
\text { interact with } \\
\text { others is a } \\
\text { success }\end{array}$ & & 4 & 23 & 3,4, & & \\
\hline $\begin{array}{l}\text { Working with } \\
\text { students with } \\
\text { AS has made } \\
\text { me a better } \\
\text { teacher }\end{array}$ & 2 & & & 21,36 & & \\
\hline $\begin{array}{l}\text { Students with } \\
\text { AS are not } \\
\text { alike, } \\
\text { uniqueness }\end{array}$ & 8,31, & & 4 & $21,23,40$ & $\begin{array}{l}6,8,17 \\
24,\end{array}$ & $2,3,5,14$ \\
\hline $\begin{array}{l}\text { Parent contact } \\
\text { important with } \\
\text { this group }\end{array}$ & 4,26 & $2,5,15$ & & $\begin{array}{c}3,9,30 \\
31,32\end{array}$ & & 6,16 \\
\hline $\begin{array}{l}\text { Stress } \\
\text { importance of } \\
\text { self-advocacy }\end{array}$ & & $19,2,22$ & 3 & $\begin{array}{l}13,14,15 \\
23,36\end{array}$ & 20,21 & 8 \\
\hline
\end{tabular}

